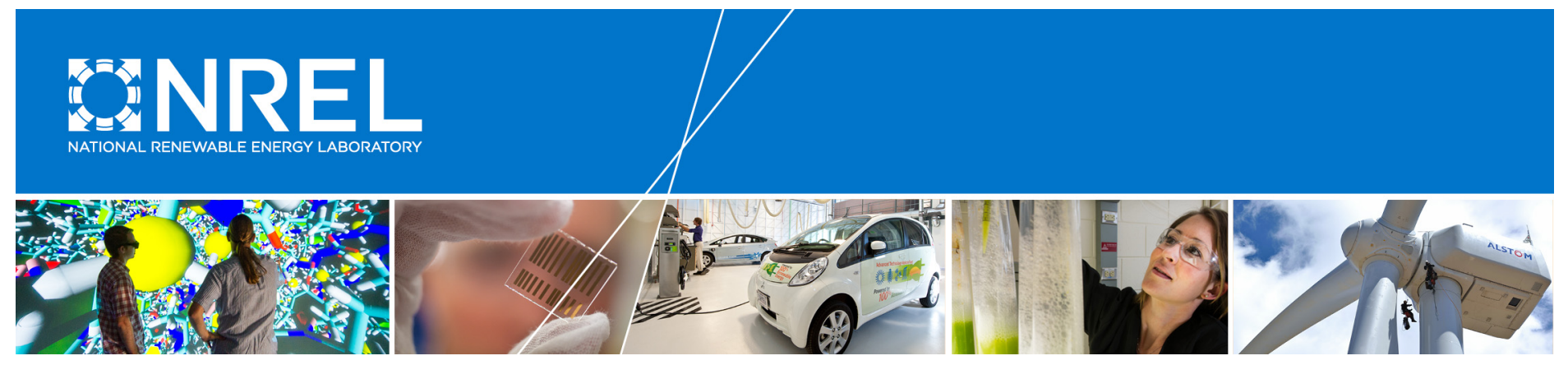

\title{
Validation of a FAST Model of the SWAY Prototype Floating Wind Turbine
}

J.H. Koh and E.Y.K. Ng Nanyang Technological University

Amy Robertson, Jason Jonkman, and Frederick Driscoll National Renewable Energy Laboratory

NREL is a national laboratory of the U.S. Department of Energy Office of Energy Efficiency \& Renewable Energy Operated by the Alliance for Sustainable Energy, LLC

This report is available at no cost from the National Renewable Energy Laboratory (NREL) at www.nrel.gov/publications.

Technical Report

NREL/TP-5000-61744

June 2016 


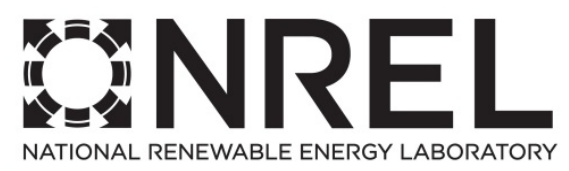

\title{
Validation of a FAST Model of the SWAY Prototype Floating Wind Turbine
}

\author{
J.H. Koh and E.Y.K. Ng
}

Nanyang Technological University

Amy Robertson, Jason Jonkman, and Frederick Driscoll

National Renewable Energy Laboratory

Prepared under Task No. WE15.5A02

NREL is a national laboratory of the U.S. Department of Energy Office of Energy Efficiency \& Renewable Energy Operated by the Alliance for Sustainable Energy, LLC

This report is available at no cost from the National Renewable Energy Laboratory (NREL) at www.nrel.gov/publications.

National Renewable Energy Laboratory 15013 Denver West Parkway Golden, CO 80401 303-275-3000 • www.nrel.gov

\section{Technical Report}

NREL/TP-5100-61744

June 2016

Contract No. DE-AC36-08G028308 


\section{NOTICE}

This report was prepared as an account of work sponsored by an agency of the United States government. Neither the United States government nor any agency thereof, nor any of their employees, makes any warranty, express or implied, or assumes any legal liability or responsibility for the accuracy, completeness, or usefulness of any information, apparatus, product, or process disclosed, or represents that its use would not infringe privately owned rights. Reference herein to any specific commercial product, process, or service by trade name, trademark, manufacturer, or otherwise does not necessarily constitute or imply its endorsement, recommendation, or favoring by the United States government or any agency thereof. The views and opinions of authors expressed herein do not necessarily state or reflect those of the United States government or any agency thereof.

This report is available at no cost from the National Renewable Energy Laboratory (NREL) at www.nrel.gov/publications.

Available electronically at SciTech Connect http:/www.osti.gov/scitech

Available for a processing fee to U.S. Department of Energy and its contractors, in paper, from:

U.S. Department of Energy

Office of Scientific and Technical Information

P.O. Box 62

Oak Ridge, TN 37831-0062

OSTI http://www.osti.gov

Phone: 865.576.8401

Fax: 865.576.5728

Email: reports@osti.gov

Available for sale to the public, in paper, from:

U.S. Department of Commerce

National Technical Information Service

5301 Shawnee Road

Alexandria, VA 22312

NTIS http://www.ntis.gov

Phone: 800.553 .6847 or 703.605 .6000

Fax: 703.605.6900

Email: orders@ntis.gov 


\section{Acknowledgments}

This work was supported by the U.S. Department of Energy under Contract No. DE-AC3608GO28308 with the National Renewable Energy Laboratory. Funding for the work was provided by the DOE Office of Energy Efficiency and Renewable Energy, Wind and Water Power Technologies Office. The authors gratefully acknowledge the support provided by the Energy Research Institute at Nanyang Technological University. In addition, the expertise and support of SWAY AS in conducting the model test and providing valuable test data is greatly appreciated. 


\section{Executive Summary}

In an offshore floating wind turbine design process, use of accurate numerical simulation tools is essential in predicting the complex aero-hydro-servo-elastic response of the system. While validation of the tools has been hampered by the scarcity of experimental results for floating offshore wind turbines with which to compare simulated results, it is an important process to ensure their accuracy for a variety of offshore wind systems.

As part of a collaboration of the National Renewable Energy Laboratory (NREL) and SWAY AS, NREL installed scientific wind, wave, and motion measurement equipment on the spar-type $1 / 6.5^{\text {th }}$-scale prototype SWAY floating offshore wind system. The equipment enhanced SWAY's data collection and allowed SWAY to verify the concept and NREL to validate a FAST model of the SWAY design in an open-water condition. Nanyang Technological University (NTU), in collaboration with NREL, assisted with the validation.

This final report gives an overview of the SWAY prototype and NREL and NTU's efforts to validate a model of the system. The report provides a summary of the different software tools used in the study, the modeling strategies, and the development of a FAST model of the SWAY prototype wind turbine, including justification of the modeling assumptions. Because of uncertainty in system parameters and modeling assumptions due to the complexity of the design, several system properties were tuned to better represent the system and improve the accuracy of the simulations. Calibration was performed using data from a static equilibrium test and freedecay tests.

After calibration, the model was validated using two nonoperating test cases at significant wave height of 0.31 meters $(\mathrm{m}$ ) and $0.78 \mathrm{~m}$ (with corresponding mean wind speeds of $5.05 \mathrm{~m} / \mathrm{s}$ and $13.97 \mathrm{~m} / \mathrm{s}$ ) and two operating test cases with the turbine rotating at mean rotational speeds of 22.27 RPM and 33.67 RPM. The simulation results were compared with experimental results for similar wind, wave, and current conditions. While the validation study did not yield great comparisons, key learning points, limitations of the FAST model and experimental test data, and other potential problematic areas were identified. 


\section{Table of Contents}

Executive Summary ...................................................................................................................... ii

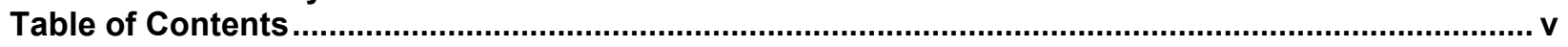

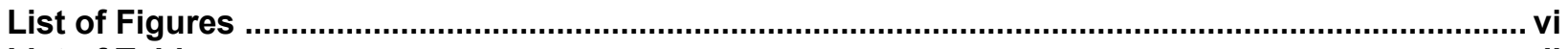

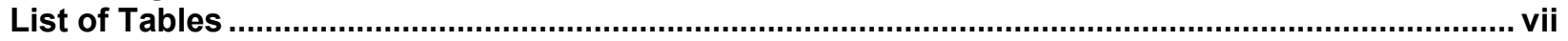

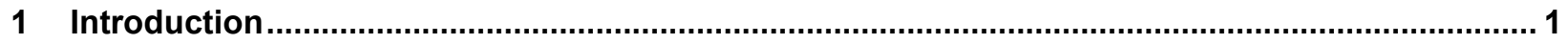

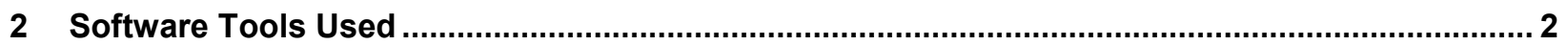

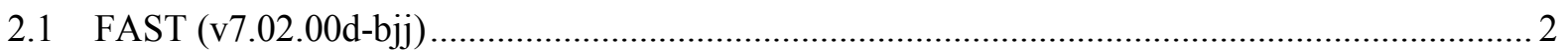

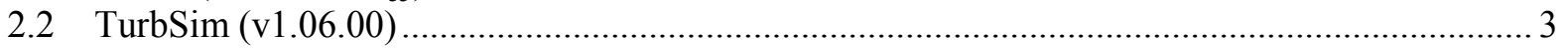

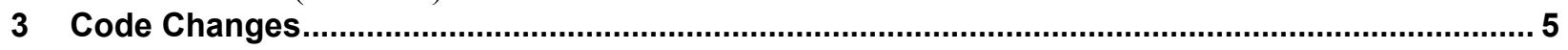

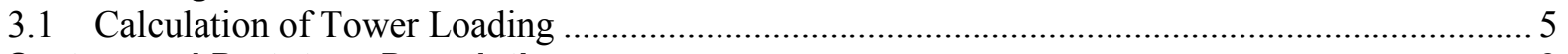

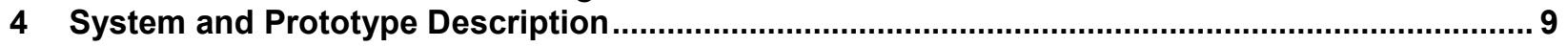

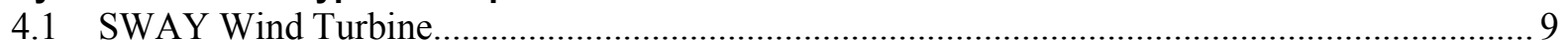

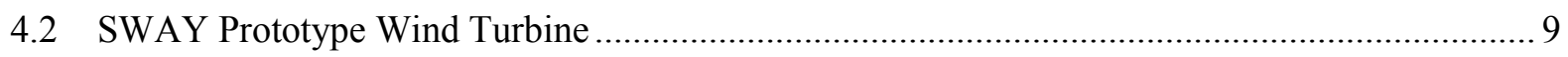

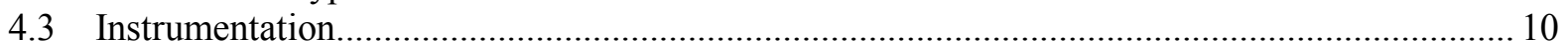

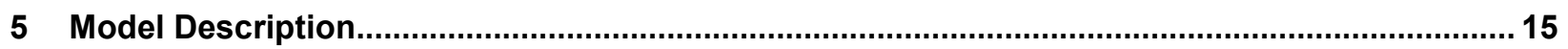

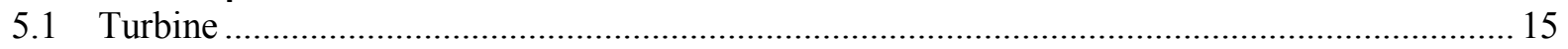

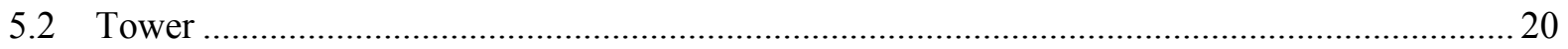

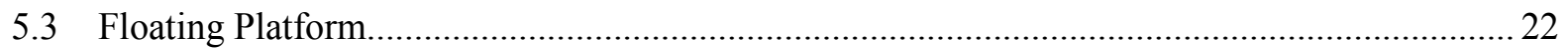

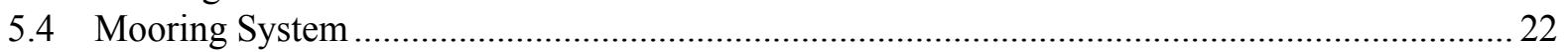

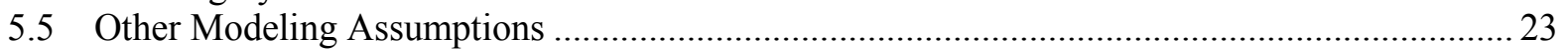

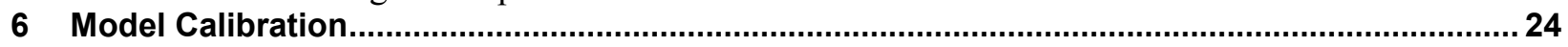

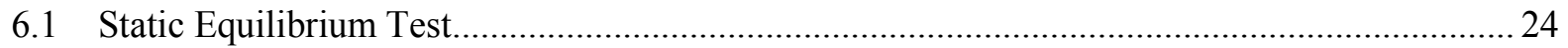

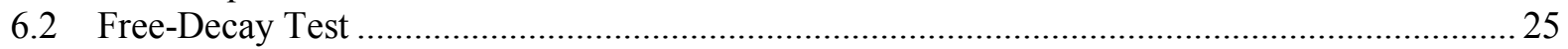

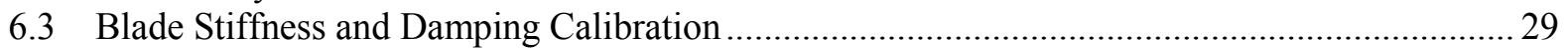

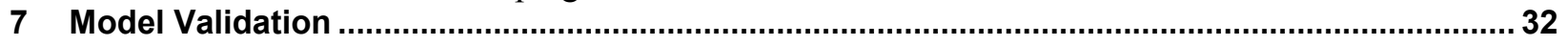

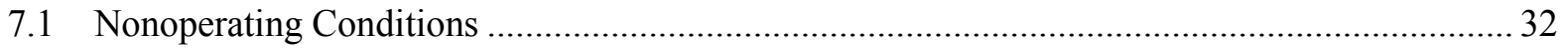

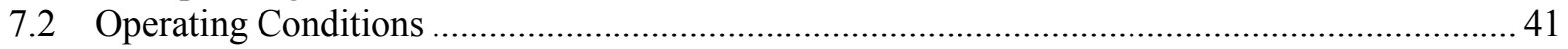

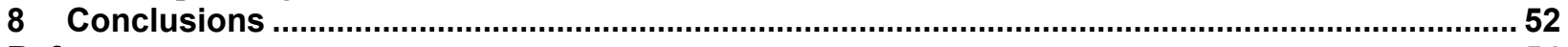

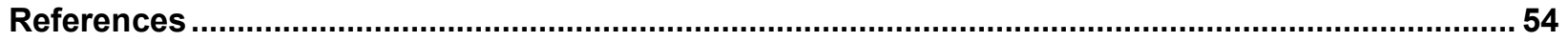




\section{List of Figures}

Figure 1. Coordinate systems and platform DOF. Image courtesy of SWAY AS ............................... 4

Figure 2. Simulation flowchart for calculation of tower loading ................................................... 7

Figure 3. Undisturbed wind inflow along the rotor and tower ..................................................... 8

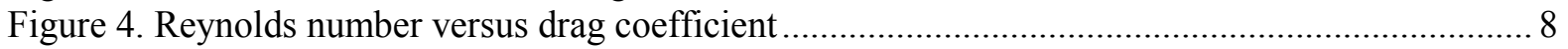

Figure 5. SWAY floating wind turbine. Image courtesy of SWAY AS .............................................. 9

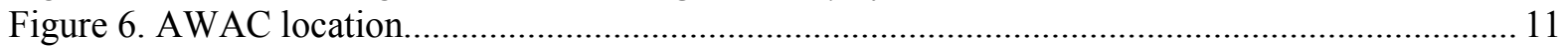

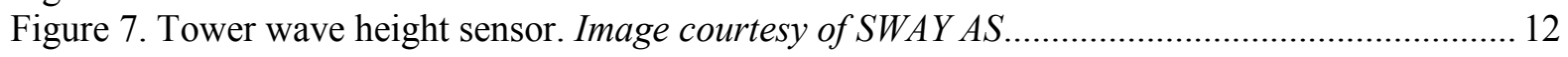

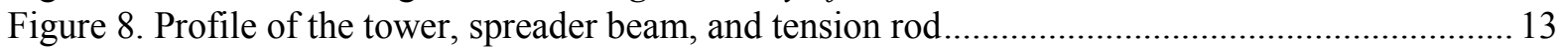

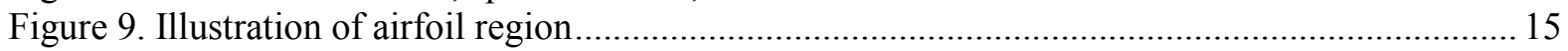

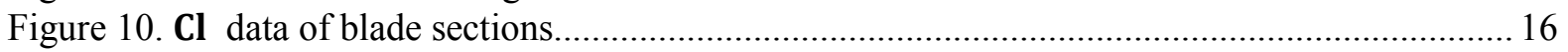

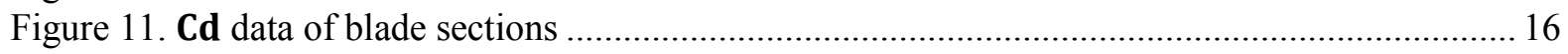

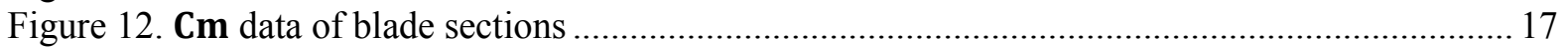

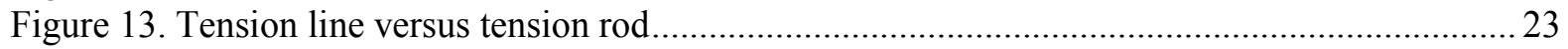

Figure 14. Free decay test. Image extracted from video recorded by NREL ................................. 25

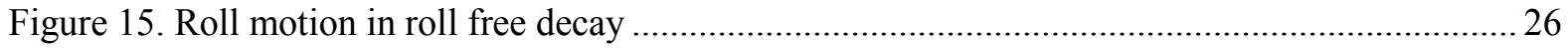

Figure 16. Power spectral density (PSD) versus frequency of roll DOF (enlarged on right).............. 27

Figure 17. Illustration of physical motion of first and second peak frequency ................................. 27

Figure 18. PSD versus frequency of tension rod motion (enlarged view on right) ............................. 28

Figure 19. Pitch motion in pitch free decay .................................................................................. 28

Figure 20. PSD versus frequency of pitch DOF (enlarged view on right) ........................................ 29

Figure 21. FFT analysis of flapwise blade loads at wind speed $=4.35 \mathrm{~m} / \mathrm{s}$ for the FAST and

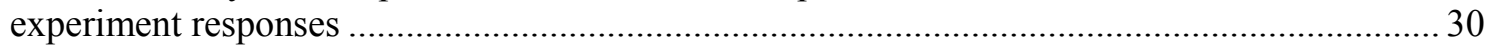

Figure 22. FFT analysis of edgewise blade loads at wind speed $=4.35 \mathrm{~m} / \mathrm{s}$ for the FAST and

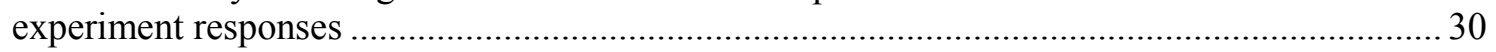

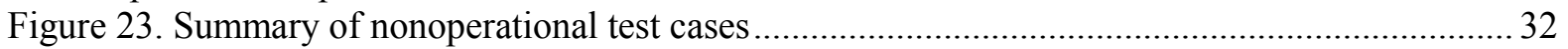

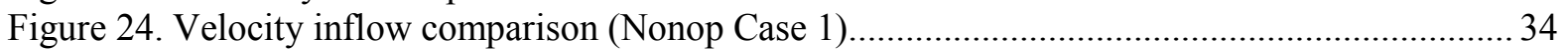

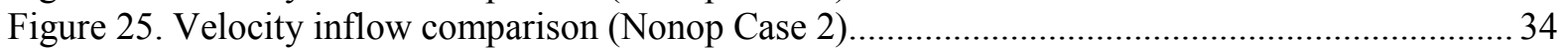

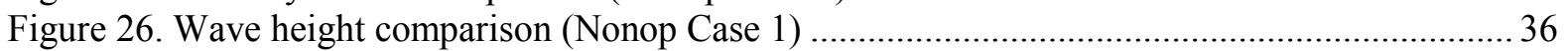

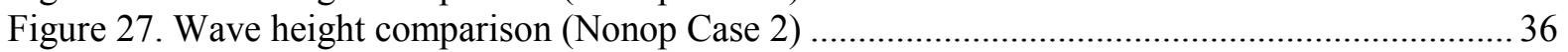

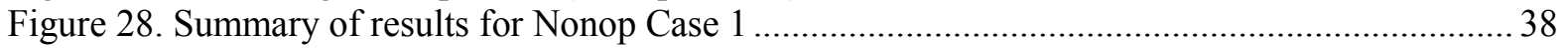

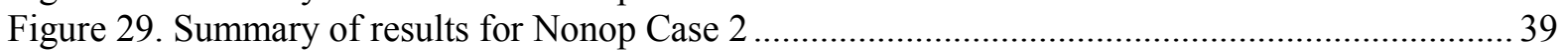

Figure 30. Rotor speed and blade pitch angle for operating cases ............................................... 42

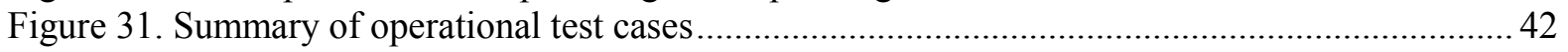

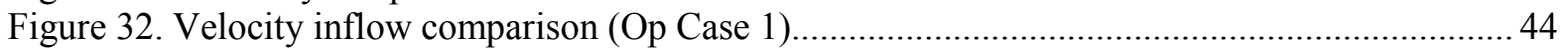

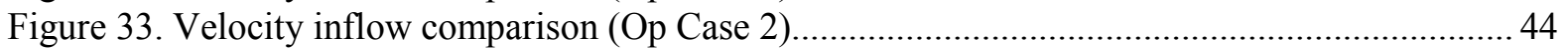

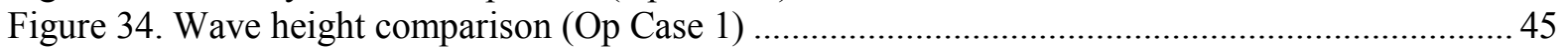

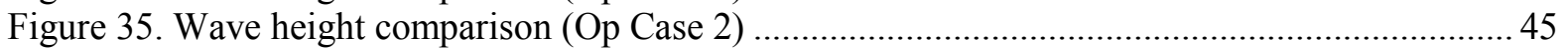

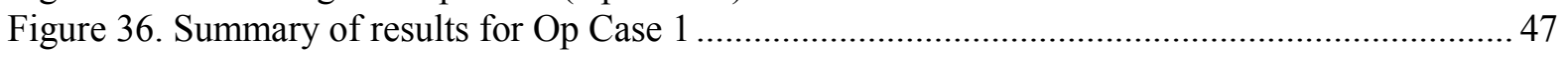

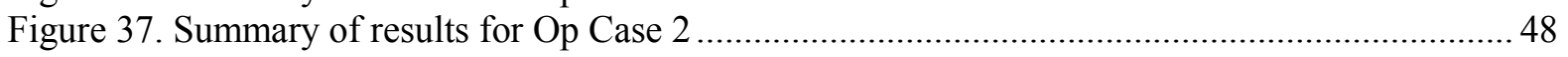

Figure 38. FFT analysis of the flapwise loading on Blade 2 for Op Case 1 ..................................... 50

Figure 39. FFT analysis of the edgewise loading on Blade 2 for Op Case 1 ................................... 50

Figure 40. FFT analysis of the flapwise loading on Blade 2 for Op Case 2 ................................... 51

Figure 41. FFT analysis of the edgewise loading on Blade 2 for Op Case 2 ................................... 51 


\section{List of Tables}

Table 1. SWAY 1:6.5th-Scale Wind Turbine Prototype Specifications …......................................... 10

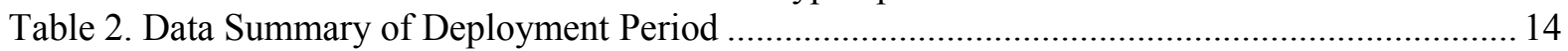

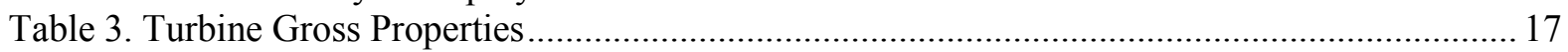

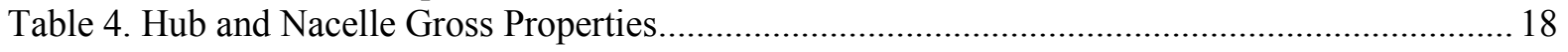

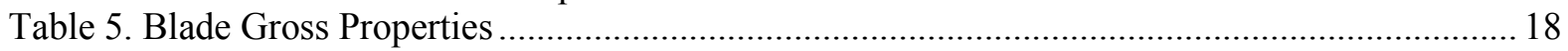

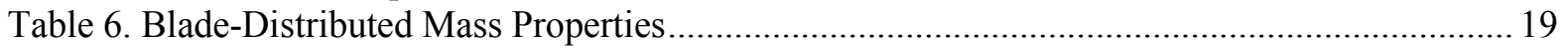

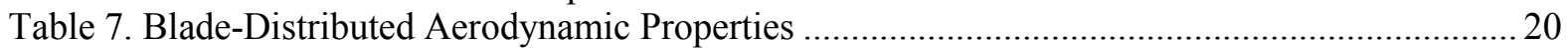

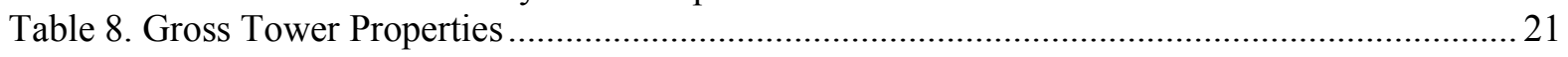

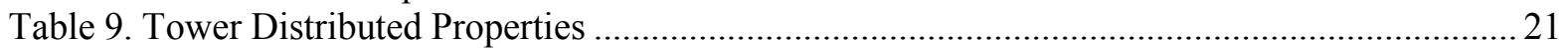

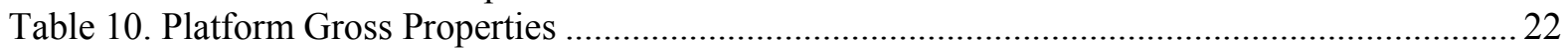

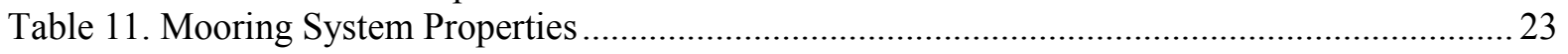

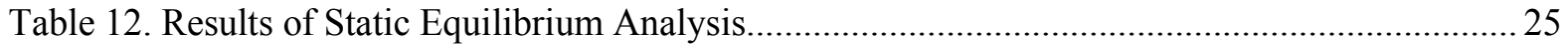

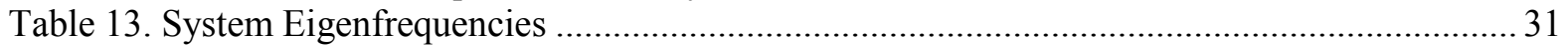

Table 14. TurbSim Wind Inflow Properties for Nonoperating Case.................................................. 33

Table 15. Comparison of Wind Properties for Nonop Case 1 .......................................................... 35

Table 16. Comparison of Wind Properties for Nonop Case 2 ........................................................... 35

Table 17. Mean and Standard Deviation for DOFs for the Nonop Case 1 ....................................... 37

Table 18. Mean and Standard Deviation for DOFs for the Nonop Case 2 ...................................... 37

Table 19. TurbSim Wind Inflow Properties for Operating Cases ....................................................... 43

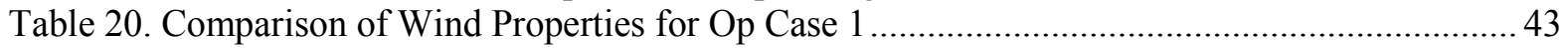

Table 21. Comparison of Wind Properties for Op Case 2 .............................................................. 44

Table 22. Mean and Standard Deviation for DOFs for the Op Case 1 ..............................................46

Table 23. Mean and Standard Deviation for DOFs for the Op Case 2 ............................................ 46

Table 24. Blade Frequencies (Hz) Observed in Experiment and Simulation for Op Case 1...............51

Table 25. Blade Frequencies (Hz) Observed in Experiment and Simulation for Op Case 2............... 51 


\section{Introduction}

In an offshore floating wind turbine design process, use of accurate numerical simulation tools is essential in predicting the complex aero-hydro-servo-elastic response of the system. FAST, developed by the National Renewable Energy Laboratory (NREL) [1], [2] is one of the numerical simulation tools that is capable of modeling floating wind turbines. Verification and validation of these tools is needed to ensure their accuracy for a variety of offshore wind systems.

Validation of the tools has been hampered by the scarcity of experimental data for floating offshore wind turbines with which to compare simulated results. Recently, Browning and Goupee [3], Stewart et al. [4], Prowell et al. [5], and Coulling et al. [6] worked on the calibration and validation of FAST models with wind-wave basin tests conducted at the Maritime Research Institute Netherlands (MARIN) led by the DeepCwind consortium. Most published studies on code-to-data validation work use data generated from a laboratory setting. Validation using response and performance data from real environmental conditions is beneficial to the development of aero-hydro-servo-elastic numerical tools as such tests are performed in realistic environmental conditions. In addition, larger-than-laboratory-scale testing will yield results with less scaling issues as it is able to show the overall system characteristic behavior more accurately.

As part of a collaboration of NREL and SWAY AS, NREL installed scientific wind, wave, and motion measurement equipment on the SWAY prototype system. The equipment enhanced SWAY's data collection and allowed SWAY to verify the concept and NREL to validate a model of the SWAY design in an open-water condition. Nanyang Technological University (NTU), in collaboration with NREL, assisted with the validation.

This work is focused on the effort to use the open-water test data of the SWAY prototype wind turbine to calibrate and validate a FAST floating offshore downwind turbine model. This is the first time that the FAST tool has been compared to a real floating wind turbine system deployed in open water, which has a number of challenges compared to tank testing.

The report is organized as follows. Section 2 describes the software tools used in this study while Section 3 shows the changes made to the software for this study. Section 4 describes the SWAY wind turbine and the instrumentations used on the prototype model. Section 5 presents the properties prescribed in FAST and modeling assumptions used in this study. Section 6 discusses the calibration work on the FAST model, including system mass/inertia calibration using static and free-decay tests and calibration of blade stiffness and damping. Section 7 covers the validation process of studying the system responses in nonoperating conditions and operating conditions. Section 8 summarizes the conclusions drawn from the project. 


\section{Software Tools Used}

\subsection{FAST (v7.02.00d-bjj)}

In this study, FAST version 7 (v7.02.00d-bjj) was used. It employs a combined modal and multibody system approach for modeling the structural dynamics of offshore wind systems. The blades and tower are modeled using a nonlinear beam model that retains only a few modes (assuming moderate deflections), with two flap-wise bending modes and one edge-wise bending mode per blade and two fore-aft and two side-to-side bending modes for the tower. A separate finite element method pre-processor BModes developed by Bir [7] is used to compute the coupled mode shapes.

The tower is cantilevered on the floating platform, which has six degrees-of-freedom (DOF) rigid-body motion, and the drivetrain is modeled using rigid-body rotation and a linear rotational spring and damper system. A detailed description of the theory, code and numerical solution techniques can be found in the FAST Theory Manual [8], in the FAST User Guide's [1], and on the National Wind Technology Center website (http://nwtc.nrel.gov).

A newer version of FAST (v8.09.00a-bjj) was made available in September 2014 that included new capabilities for modeling offshore wind systems, but the original work in this project was initiated before this release.

\subsubsection{Aerodynamics (AeroDyn v13.00.02a-bjj with AirfoilPrep v2)}

In this study, AeroDyn version 13 (v13.00.02a-bjj) was used. AeroDyn is element-level horizontal-axis wind turbine aerodynamics analysis code developed by Windward Engineering and improved and maintained by NREL. AeroDyn is strip-theory-based horizontal-axis wind turbine aerodynamics analysis code that has the option of using either blade element momentum (BEM) theory (used in this study) or generalized dynamic wake theory. AeroDyn includes a model of unsteady airfoil aerodynamics, including dynamic stall. In the analysis, Prandtl's tip and hub loss corrections were applied.

AirfoilPrep (v2) is a spreadsheet developed by NREL for users to generate airfoil data files required by AeroDyn. In this study, it was used to generate 360-degree data of the airfoil data input files using the Viterna and Janetzke [9] method. The spreadsheet was also used to interpolate the aerodynamic coefficients for other span locations and to apply three-dimensional delayed stall corrections caused by blade rotation using the method proposed by Du and Selig [10] and Eggers and Digumarthi [11].

In this work-where a downwind configuration is used-it is important to discuss the tower influence on blade aerodynamics. In AeroDyn, the upwind influence is based on the work of Bak et al. [12], which uses a potential flow solution around a cylinder as the base flow field together with a downwind wake model dependent on a tower drag coefficient $C_{d, t o w e r}$ (which in turn is dependent on diameter), and a tower dam model. For a downwind rotor, the work of Bak et al. [12] becomes unrealistic since it uses a defined width that does not increase with downwind distance. Therefore, the model was supplemented by a tower wake (velocity deficit) model from the work of Powles [13]. 
In the publicly available version of FAST v7 and AeroDyn 13, the drag forces from the wind on the tower are not calculated. Improvements to the code in this area are described in Section 3.1.

Details of the AeroDyn module are discussed in the AeroDyn User's Guide [14], and the AeroDyn Theory Manual [15].

\subsubsection{Hydrodynamics (HydroDyn with WAMIT v6.416)}

HydroDyn is a module coupled to FAST that computes the hydrodynamic equations as part of the hydro-elastic solution. The module was developed by Jonkman [16] and full details can be found in his dissertation [2]. The hydrodynamic loading accounts for (1) linear hydrostatic restoring, (2) nonlinear viscous drag from Morison's equation, (3) added mass and damping contributions from linear wave radiation (including free-surface memory effects), and (4) incident wave excitation from linear diffraction. Airy wave theory with free-surface corrections was used to calculate the wave kinematics for the module. Both regular and irregular waves can be introduced, with irregular waves defined using either a JONSWAP spectrum, PiersonMoskowitz (PM) spectrum, or a user-defined wave spectrum (used in this study).

To obtain the hydrodynamic parameters required by HydroDyn, radiation and diffraction problems are solved using the boundary integral equation method in the frequency domain for a platform of arbitrary shape using WAMIT (Wave Analysis at Massachusetts Institute of Technology), a program used for computing wave loads and dynamics of ships and offshore structures developed by researchers at Massachusetts Institute of Technology [17].

The translational DOFs of the platform in the X, Y, and Z directions are called surge, sway, and heave; and rotations about the $\mathrm{X}, \mathrm{Y}$, and $\mathrm{Z}$ axes are called roll, pitch, and yaw. Each DOF can be turned on or off individually. Figure 1 shows the coordinate systems and platform DOF terminology used in this report; the origin is located at mean sea level (MSL) and dimensions described in this report are referenced to this inertial frame coordinate system unless otherwise stated.

\subsubsection{Mooring Lines}

Within HydroDyn, a quasi-static mooring system module is implemented to solve the nonlinear mooring-line restoring forces. It is able to account for taut or catenary lines, the weight of the line in fluid, elastic stretching, and seabed friction; however, it does not account for line bending stiffness or hydrodynamic inertia and damping. Full details of the quasi-static mooring line module can be found in Jonkman's work [2], [16].

\subsection{TurbSim (v1.06.00)}

The TurbSim stochastic inflow turbulence code is able to generate a full-field flow with various wind spectral models, turbulence models, coherent turbulence structures and wind profiles. This includes models specified by the IEC standards as well as non-IEC models that simulate flow instabilities associated with nocturnal boundary layer flows. The key purpose of the code is to provide the wind turbine designer simulated inflow turbulence environment to drive wind turbine design codes. The details for the use of the TurbSim code is available in TurbSim User's

Guide [18]. 


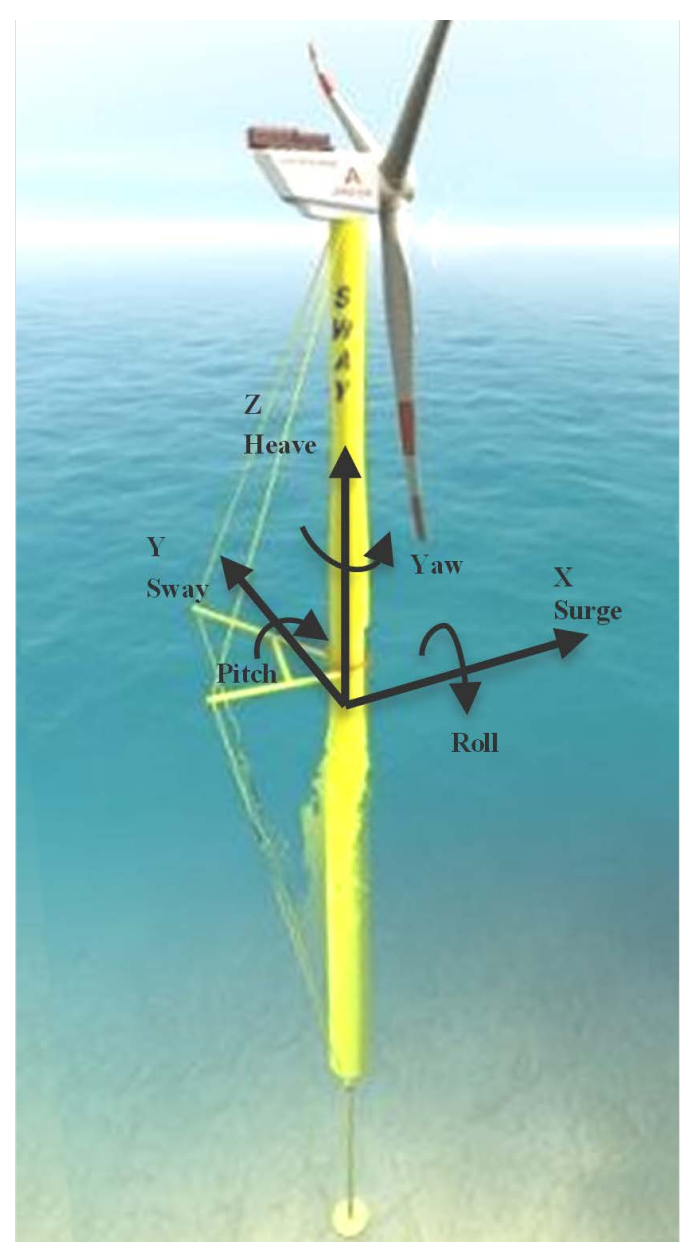

Figure 1. Coordinate systems and platform DOF. Image courtesy of SWAY AS 


\section{Code Changes}

\subsection{Calculation of Tower Loading}

During their initial analysis of the simulation cases, the authors speculated that including tower loading to the SWAY system in conditions where the turbine blades are not rotating is important. To account for the tower drag, changes were made to FAST to calculate the wind loading on each tower element for each simulation time-step. The approach used assumes that the tower is a cylinder, either tapered or un-tapered, and has limited application to multi-member or lattice-type towers.

Several strategies for accounting for wind loading on towers are available from industrial standards and other researchers. For example, according to the International Standards Organization (ISO) 4354 [19, p. 68] standard, the total wind load can be a combination of three components. The first is the mean component that is due to the mean wind force. The second is the fluctuating (background) component, which results from the unstable nature of flow around bluff bodies including in buffeting, flow separation, reattachments and vortex shedding. Other transient loads can also be induced by the motion of the structure caused by the wind such as galloping or flutter. The third is the "resonant" component, which results in a phenomenon called lock-in [20] or vortex-induced vibration, which occurs when the frequency of vortex shedding is similar to the frequency motion of the body.

For the majority of structures, the resonant component is small, and as suggested by Scruton [21] and ISO 4354 [19], the assumption of static loads due to wind is reasonably adequate unless the structure is large, lightweight and lightly damped. Although this assumption may fully apply to a wind turbine tower, because of difficulties and uncertainties in quantifying the fluctuating component in a time-domain simulation, only the mean component of the wind force with effects of natural free-stream turbulence is considered in this code improvement.

The code improvement is summarized in the simulation flow chart illustrated in Figure 2. First, FAST checks the platform input file for the platform load model (PtfmModel) value set by the user. If the value (4) is set to include tower loading, FAST reads the tower drag coefficient and tower diameter values from the tower input file. Next, FAST checks the type of wind inflow data used. If TurbSim-generated wind inflow data are used, FAST obtains the lowest Z-position of the wind data defined as GridBase. As a result, the wind inflow for the region below GridBase is undefined, as shown in Figure 3. It is common practice to only define wind inflow data for the expected region of turbine blade motion, as generation of a larger area of wind inflow is limited by computational cost and limited memory.

Next, for every simulation time-step and tower node, FAST checks the position of the tower node and retrieves the undisturbed wind velocity from the wind inflow data if the position is equal or more than the GridBase value. If the position is less than the GridBase value, the wind inflow data for the undefined region (which is needed for the tower drag calculations) are obtained by assuming that the wind profile from the GridBase to MSL follows the power law (Eq.1). The exponent $\alpha=0.140$ is recommended by the IEC 61400-3 [22] for offshore wind conditions. 


$$
U_{z}=U_{\text {Gridbase }}\left(\frac{Z}{\text { GridBase }}\right)^{0.140}
$$

With the wind inflow data obtained, the magnitude of the drag force per unit length is calculated using Eq. 2 and added vectorially along the relative wind direction to the overall platform and tower loads calculation for every time-step.

$$
D_{\text {tower }}=\frac{1}{2} \rho\left(\overline{\left(V-V_{\text {tower }}\right)}\right)^{2} C_{D, \text { tower }} d_{\text {tower }}
$$

$D_{\text {tower }}$ is the drag force per unit length of the tower element, $\rho$ is the density of air, $\overline{\left(V-V_{\text {tower }}\right)}$ is the magnitude of the difference between the undisturbed inflow velocity (with turbulence) and the velocity of the tower element at the tower element location $\left(V_{\text {tower }}\right), C_{D, t o w e r}$ is the drag coefficient of the tower element, and $d_{\text {tower }}$ is the diameter of the tower element.

It is also commonly known that factors such as aspect ratio, surface roughness, turbulence intensity, and Reynolds number may affect the $C_{D \text {,tower }}$ for circular cylinders. For example, Roshko [23] and Wieselsberger [24] described the various flow regimes, the occurrence of the critical Reynolds number, and drag coefficient values for a circular cylinder with smooth surface across different Reynolds number. Scruton et al. [25] showed that reduction in drag coefficient occurs for circular cylinder of finite aspect ratio with a single free end. The surface roughness effect on lowering the critical Reynolds number range is also shown in E.S.D.U. 80025 [26].

Because of the high variability and numerous factors, the drag coefficient of the tower was designed to be manually inputted by the user. This gives the user a certain degree of control, which can be useful in accounting for wind loads for non-tubular towers or utilizing drag coefficients prescribed specifically for individual tower designs or standards such as the ISO 4354 [19] and EN 1991-1-4 [27]. Otherwise, the user can use the default $\operatorname{Re}-C_{D, \text { tower }}$ table (plotted in Figure 4 and used in this study), which is applicable for a circular smooth cylinder of high aspect ratio. The data is obtained from the work of Roshko [23] and Wieselsberger [24]. The Reynolds number of the flow is calculated based on Eq. 3.

$$
R e_{\text {tower }}=\frac{\overline{\left(V-V_{\text {tower }}\right)} \times d_{\text {tower }}}{v}
$$

where $v$ is the kinematic viscosity of air. 


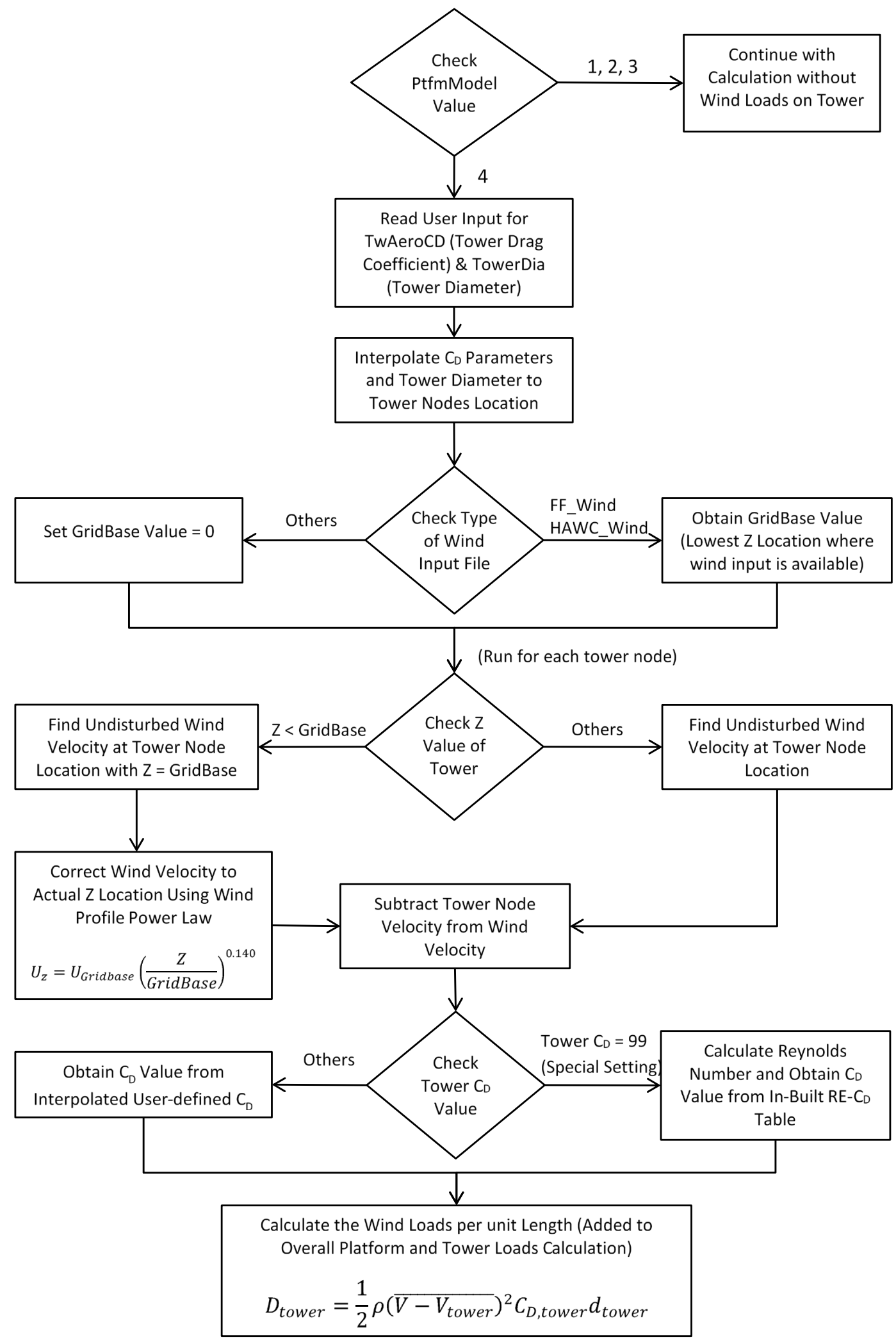

Figure 2. Simulation flowchart for calculation of tower loading 


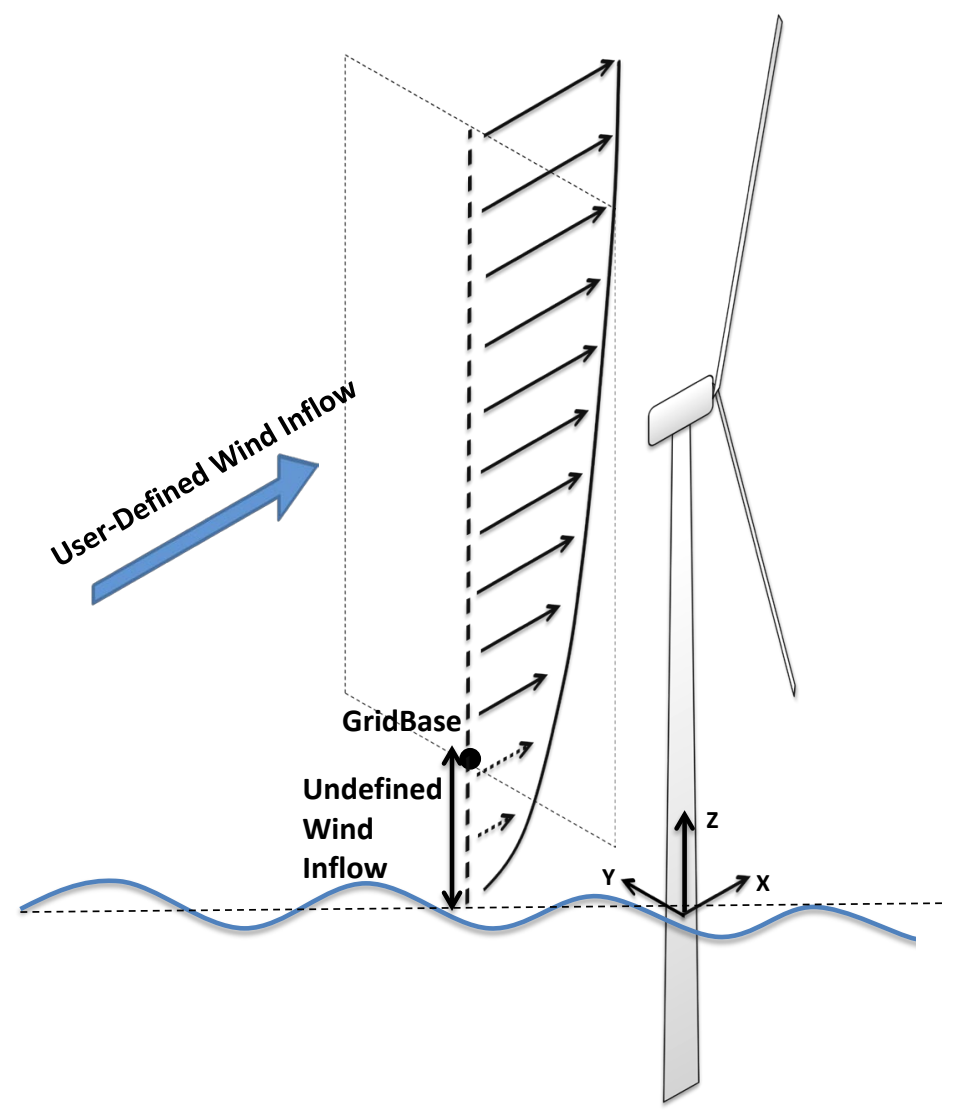

Figure 3. Undisturbed wind inflow along the rotor and tower

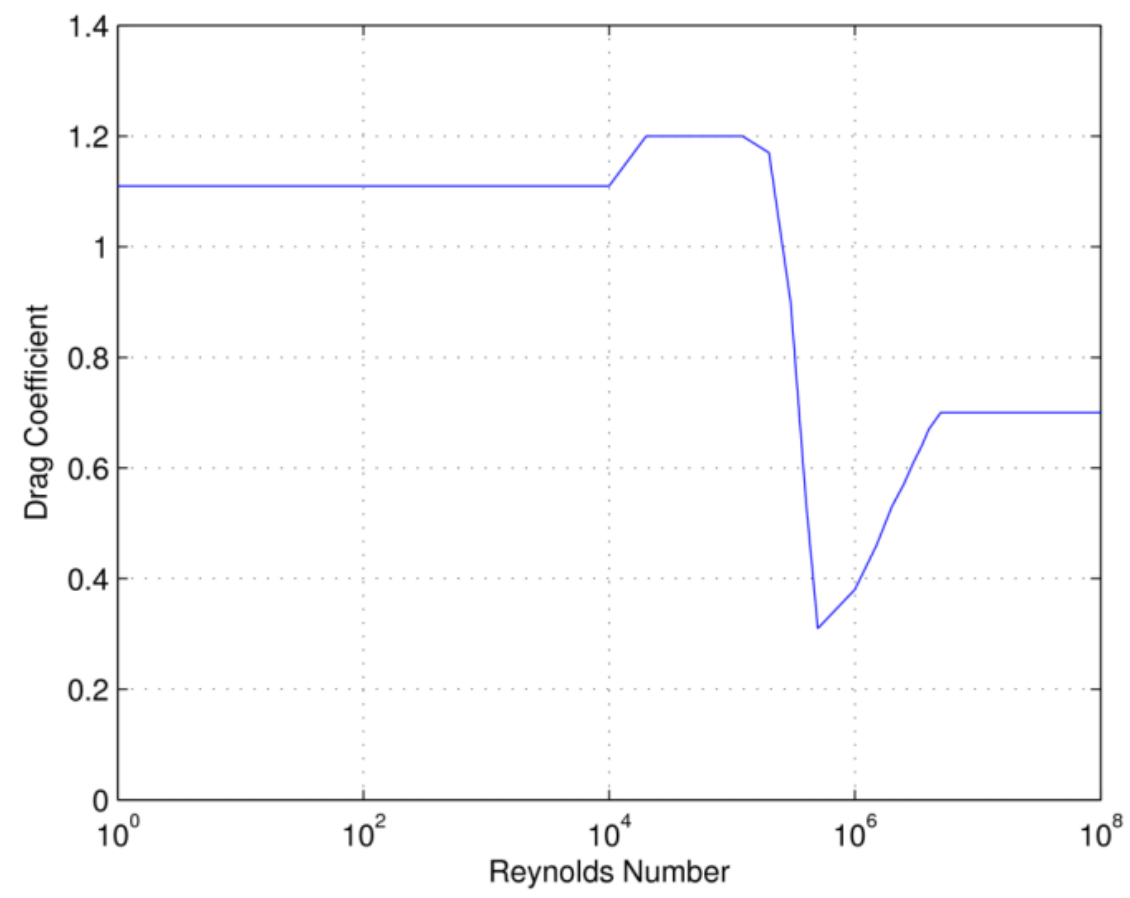

Figure 4. Reynolds number versus drag coefficient 


\section{System and Prototype Description}

\subsection{SWAY Wind Turbine}

The SWAY spar-type floating wind turbine (as shown in Figure 5) has a three-bladed downwind configuration that uses a tension rod system for station-keeping and maintaining the hydrostatic stability of the wind turbine. The bottom of the spar structure is fixed to the tension rod with a universal joint. The other end of the tension rod is attached to a large steel mass (gravity anchor) on the seafloor with a universal joint. A downwind configuration allows the possibility of using a passive yaw system that eliminates the cost that would be incurred by having an active yaw system in an upwind design. The wind turbine system, including the tower, yaws about the yaw mechanism located at the universal joint at the bottom of the tower. In addition, the blade clearance from the tower, which is a concern for larger turbines, is less of a concern for the downwind SWAY turbine.

The wind turbine has individual blade-pitch control, and the nacelle is fixed to the tower at an optimal angle so that the rotor axis is oriented horizontally (parallel to the wind) when the tower pitches during operation. Some of the key components in the system are unique spreader beams and tension cables, which help stiffen the tower, reduce fatigue loads, and allow the tower to carry a larger turbine.

The full-scale SWAY wind turbine is designed to have a rated power of 2.5-10 MW, a rotor diameter up to $190 \mathrm{~m}$, and a substructure up to $300 \mathrm{~m}$ in length.

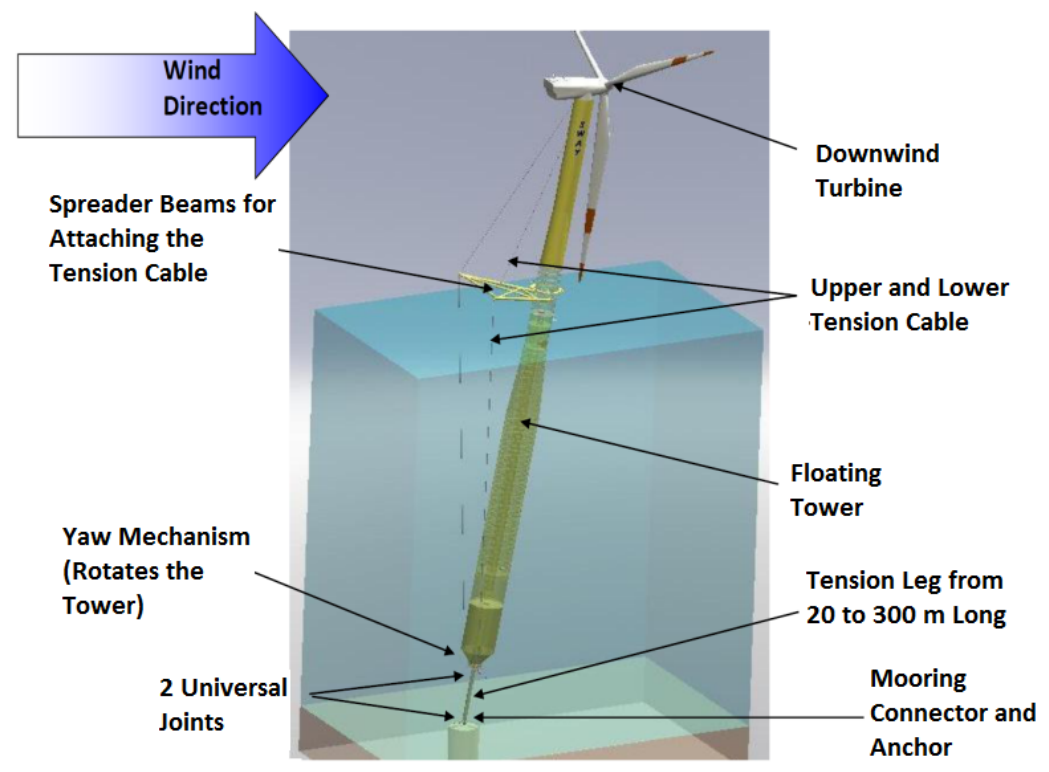

Figure 5. SWAY floating wind turbine. Image courtesy of SWAY AS

\subsection{SWAY Prototype Wind Turbine}

A 1/6.5th-scale prototype of the SWAY spar-type floating wind turbine was deployed in Hjeltefjorden, east of Øygarden in Hordaland, Norway, in May 2012. Table 1 provides the key specifications of the prototype wind turbine. 
Table 1. SWAY 1:6.5th-Scale Wind Turbine Prototype Specifications

\begin{tabular}{l|l}
\hline Support structure manufacturer & SWAY \\
Make, model of turbine & SWAY $1 / 6.5^{\text {th }}$-scale prototype \\
Production year of turbine & 2011 \\
Rotation axis & Horizontal \\
Orientation & Downwind \\
Number of blades & 3 \\
Rotor diameter & $14.9 \mathrm{~m}$ (after extension in 2012) \\
Hub height & $\sim 13 \mathrm{~m}$ \\
Control & Individual pitch control \\
Tower type & Tubular \\
Floater type & Spar buoy \\
Cut-in wind speed & $2 \mathrm{~m} / \mathrm{s}$ \\
Rated wind speed & $8 \mathrm{~m} / \mathrm{s}$ \\
Cut-out wind speed & $16 \mathrm{~m} / \mathrm{s}$ \\
\hline
\end{tabular}

\subsection{Instrumentation}

Turbine data were acquired through two independent data acquisition systems (DAS). A Bachman MPC240 controller and SCADA system were used to operate the turbine and gather information from a set of sensors. The other DAS was a National Instruments (NI) PXI system running LabVIEW. The PXI was chosen because of its ability to (1) rapidly interrogate sensors that are widely distributed and (2) use global positioning system (GPS) time to tightly coordinate and synchronize measurements.

The PXI was installed by NREL in the tower base. Select data sets from the Bachman controller were acquired through a real-time DeviceNet link between the PXI and controller operating at 100 hertz (Hz). Each controller variable was acquired by the Bachman hardware through a variety of analog and digital interfaces. Controller variables were scaled into engineering units by SWAY's Bachman control code according to calibrations derived by SWAY documentation. The Bachman controller was installed before NREL joined the project, and NREL was provided no information on calibration; therefore, data from the Bachman controller were used with caution.

NREL installed several instruments, each of which internally measured and processed its data. Those data were acquired by the PXI via R232/422 serial communication and synchronized to either a GPS time reference using onboard GPS receivers or an external GPS-synchronized trigger pulse. Data acquired by the PXI system were stored locally in the NI TDMS file format in files that are one-hour long. A personal computer (PC) housed in a nearby onshore data shed automatically synchronized new PXI data files with a local data archive every hour. The wave and current measurements were provided by an Acoustic Wave and Current (AWAC) unit where 
data were logged internally on the instrument and manually synchronized with the PC in the data shed through an underwater serial data cable.

Data consolidated by all instruments were able to be remotely accessed via a file transfer protocol (FTP) link, but poor bandwidth to the test site limited the amount of data that could be downloaded. This data acquisition system was monitored and administered remotely at the NWTC.

\subsubsection{Measurements}

The wind speed and direction were measured with two three-axis ATI SATI/3K ultrasonic anemometers. One was mounted on a horizontal boom that extended upwind and perpendicular to the tower. NREL installed this boom to try to obtain an undisturbed measurement of the wind inflow to the turbine. The other anemometer was mounted by SWAY near the base of the nacelle.

The platform motions were measured with two motion reference units. A Teledyne DMS-05 motion reference unit was located in the tower near the centerline just above the waterline, and an Xsens MTi-G motion tracker unit was located near the end of the anemometer boom at nacelle height. A dual antenna Hemisphere V101 GPS was used to provide position and heading.

Profiles of the water velocity and directional wave spectra were measured by a Nortek $600-\mathrm{kHz}$ AWAC mounted on the seafloor approximately $12.5 \mathrm{~m}$ north-northeast of the turbine at a depth of about $20 \mathrm{~m}$. Due to installation limitations, the AWAC was located in an area close to bedrock and contour regions shown in Figure 6. Data from the AWAC were internally recorded and averaged to 1-hour (hr) readings.

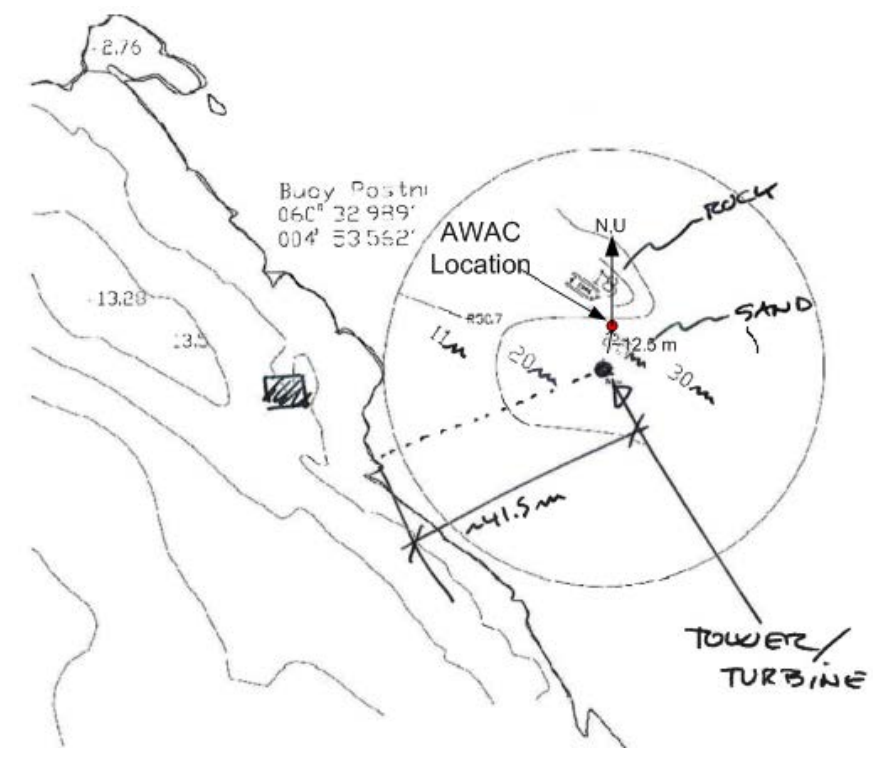

Figure 6. AWAC location

A tower wave height sensor measured the wave height at the tower base using an ultrasonic transducer. The measurement was manually adjusted to account for the heave motion of the system. Also, the measurement may have been influenced by reflected and radiated waves by the 
platform. The location and orientation of the transducer is shown in Figure 7. The advantage of using the tower wave height signal is its sample rate of $100 \mathrm{~Hz}$, which is useful to generate and analyze the wave spectra.

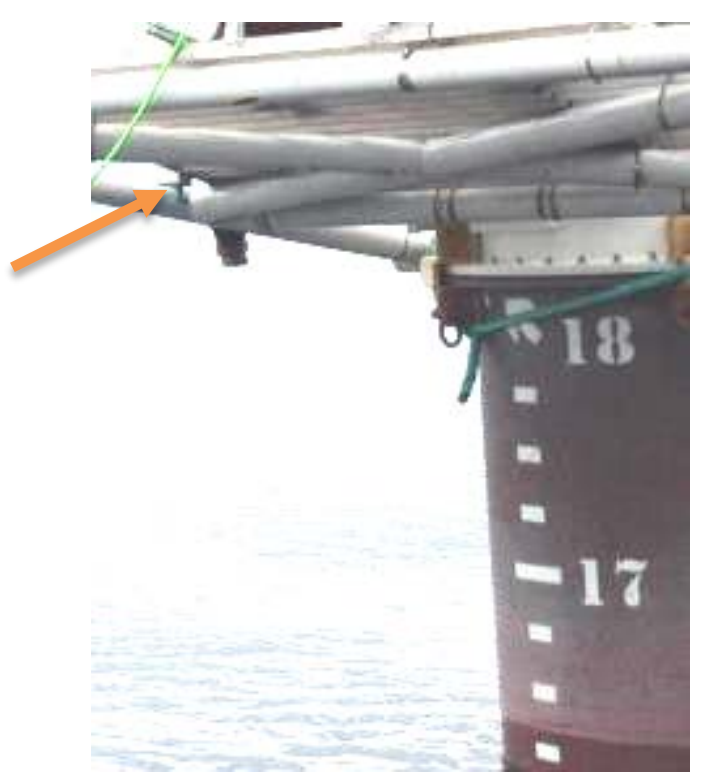

Figure 7. Tower wave height sensor. Image courtesy of SWAY AS 
Figure 8 shows the profile of the tower, spreader beam, and tension rod. In FAST, the blue region is modeled as the wind turbine tower whereas the red region is modeled as the platform. Yellow circles indicate the locations of the instruments.

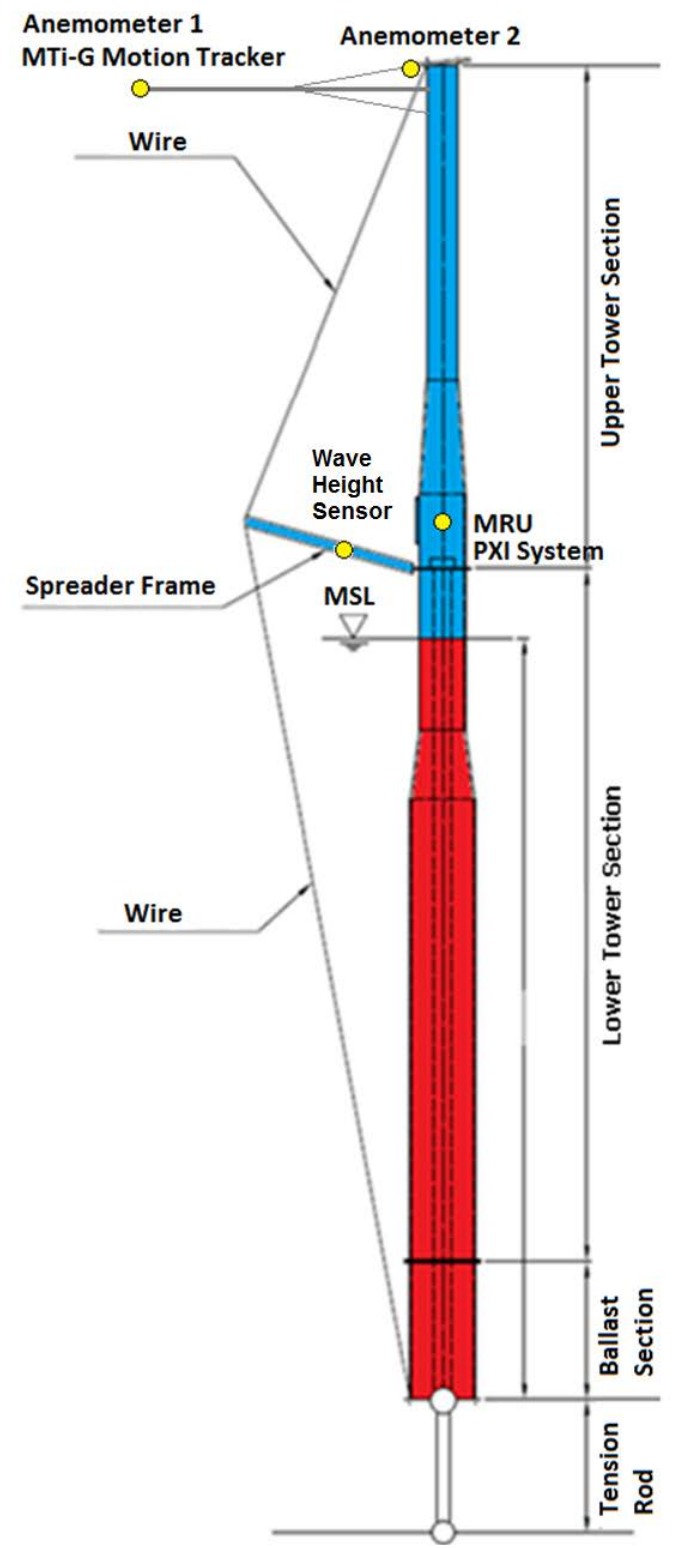

Figure 8. Profile of the tower, spreader beam, and tension rod 


\subsubsection{Data Collection}

The NREL DAS was deployed in late June 2012 and started to collect data on June 20, 2012. The turbine was decommissioned and removed in December 2013. The NREL DAS operated nearly continuously for 2012; however, the PC stopped functioning in September, resulting in a data loss from September 22 through October 20. In early 2013, the NREL DAS began to exhibit increasing instability, and it required periodic rebooting and eventual reinstallation of the software. As a result, the dataset has many gaps, many of them for durations exceeding one month. The last data were recorded on September 27, 2013.

During the deployment period, the SWAY turbine was infrequently operated, which resulted in very limited operational data. Table 2 summarizes the number of 1-hour data sets measured by wind speed and wave height.

Table 2. Data Summary of Deployment Period

Significant Wave Height $(\mathrm{m})$

\begin{tabular}{|l|l|l|l|l|l|}
\hline & 0.25 & 0.5 & 0.75 & 1 & 1.25 \\
\hline 1 & 209 & 2 & & & \\
\hline 2 & 587 & 5 & & & \\
\hline 3 & 596 & 7 & & & \\
\hline 4 & 431 & 7 & & & \\
\hline $\mathbf{5}$ & 298 & 30 & & & \\
\hline $\mathbf{6}$ & 163 & 58 & 1 & & \\
\hline $\mathbf{8}$ & 98 & 83 & 1 & & \\
\hline $\mathbf{8}$ & 39 & 84 & & & \\
\hline $\mathbf{5}$ & 17 & 86 & 2 & & \\
\hline 10 & 2 & 36 & 2 & & \\
\hline 11 & & 24 & 6 & & \\
\hline 12 & & 5 & 12 & & \\
\hline 13 & & 5 & 10 & & \\
\hline 14 & 1 & 1 & 10 & 3 & \\
\hline 15 & & & & 3 & \\
\hline
\end{tabular}




\section{Model Description}

This section details the methodology used to create a model of the SWAY demonstration system in FAST. Although the system has a pitch offset in its static equilibrium position, the tower of the FAST model was built in a vertical configuration with a shaft tilt. All heights and values listed in this section assume the tower is vertical.

\subsection{Turbine}

The turbine blades that were mounted on the rotor are OLW620_R1 profiles produced by Olsen Wings. The blade gross properties were obtained from estimates from a technical report developed by GL Garrad Hassan [28], which was engaged by SWAY AS for design calculations. The original blade length was designed at $6.2 \mathrm{~m}$ and used in the analysis in the GL Garrad Hassan report. However, during the final installation, a $1 \mathrm{~m}$ cylinder extension was added to the root of the blade to increase the rotor radius.

The blade, as shown in Figure 9, is made of three different blade profiles: a cylinder near the root of the blade, a transition airfoil, and a main airfoil; however, airfoil data were only available for the $2 \mathrm{D}$ main airfoil section (lift, drag, and moment coefficients $\mathrm{C}_{\mathrm{l}}, \mathrm{C}_{\mathrm{d}}$, and $\mathrm{C}_{\mathrm{m}}$ ). To obtain the drag coefficient of the cylinder, the Reynolds number near the root of the blade was calculated at the operating condition of the wind turbine. The $C_{d}$ value was then obtained by looking up the appropriate value on a $C_{d}$ versus Reynolds number curve for cylinders. Using the blending function in AirfoilPrep, the transition airfoil properties were produced by linear interpolation of the $C_{l}, C_{d}$, and $C_{m}$ of the cylinder and the main airfoil with equal weighting. Though the transition airfoil region might be subject to error due to the assumptions made, the majority of the load on the blade is generated by the outside half of the blade, where blade data was available.

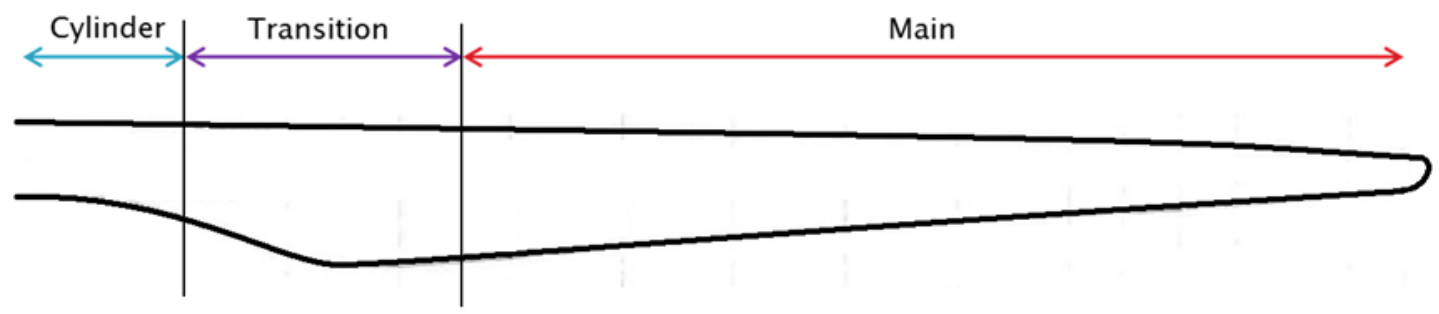

Figure 9. Illustration of airfoil region

To improve the accuracy of the main airfoil, it was further divided into three sections: Main 1, Main 2, and Main 3. Three-dimensional-delayed stall corrections as a result of blade rotation were applied in AirfoilPrep. The $\mathrm{C}_{\mathrm{l}}, \mathrm{C}_{\mathrm{d}}$, and $\mathrm{C}_{\mathrm{m}}$ properties for the cylinder, transition, and sections Main 1, Main 2, and Main 3 are plotted in Figure 10, Figure 11, and Figure 12, respectively.

The blade mode shapes were derived separately using BModes. 


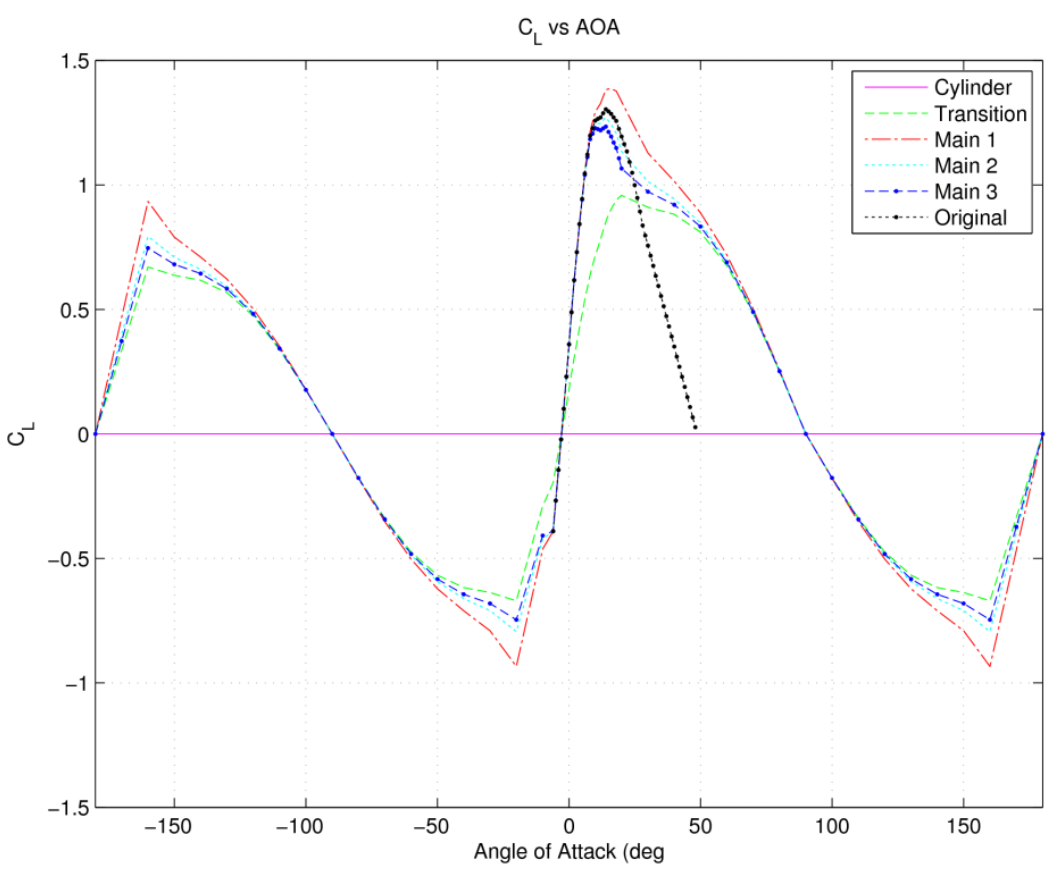

Figure 10. $\mathrm{C}_{1}$ data of blade sections

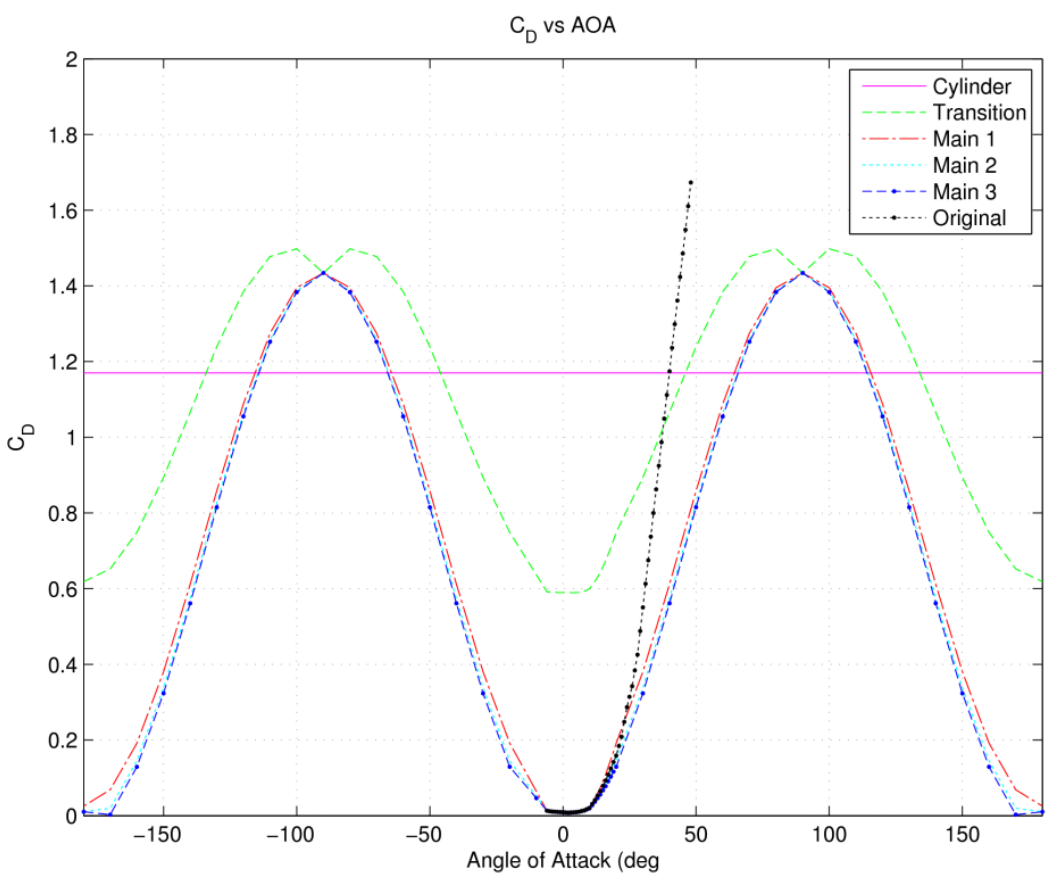

Figure 11. $C_{d}$ data of blade sections 


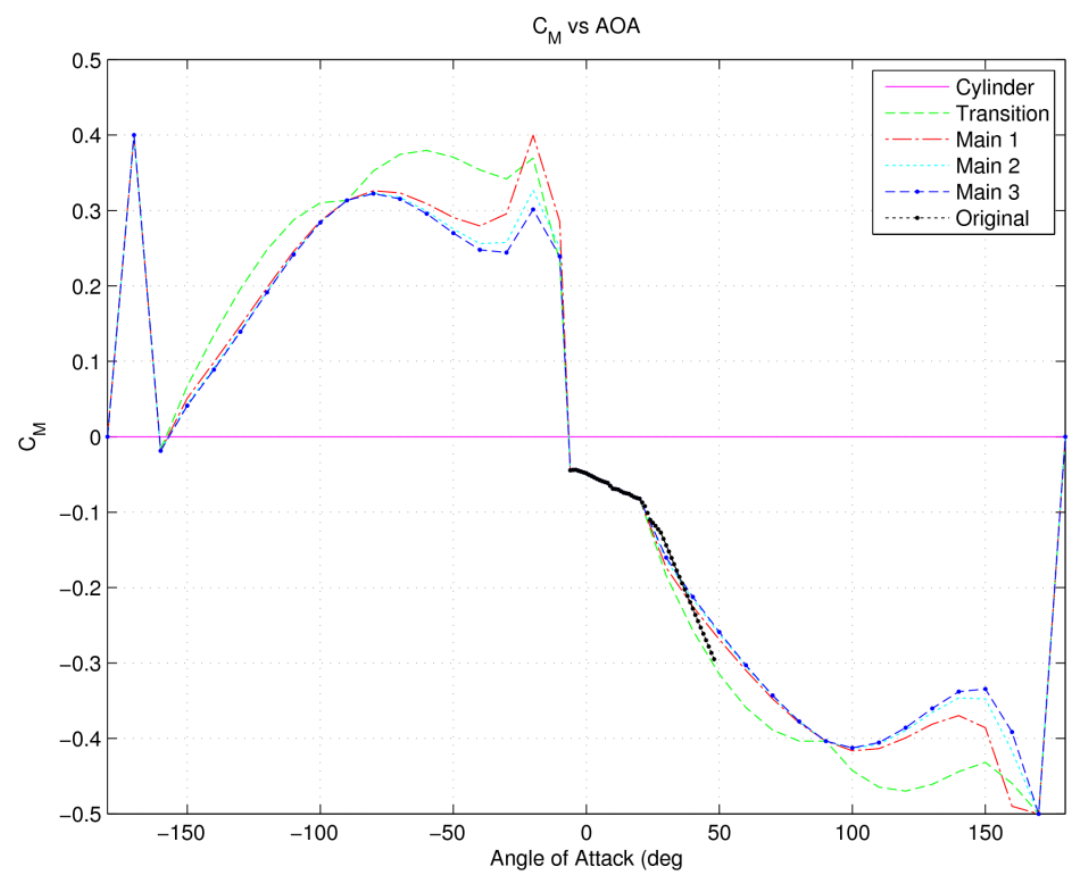

Figure 12. $\mathrm{C}_{\mathrm{m}}$ data of blade sections

The turbine gross properties, hub and nacelle gross properties, blade gross properties, bladedistributed mass properties and blade-distributed aerodynamic properties are shown in Table 3, Table 4, Table 5, Table 6 , and Table 7 . The values are the original properties provided by SWAY design documents ([28], [29], [30]) .

Table 3. Turbine Gross Properties

Rotor orientation, configuration

Rotor, hub diameter

Hub height above MSL

Height of tower-top flange above MSL

Overhang, shaft tilt, precone

Vertical distance along tower centerline between tower top and shaft

Total tower-top mass
Downwind, three-bladed

$14.9 \mathrm{~m}, 0.5 \mathrm{~m}$

$13.133 \mathrm{~m}$

$12.500 \mathrm{~m}$

$0.72275 \mathrm{~m}, 5^{\circ}, 4^{\circ}$

$0.587 \mathrm{~m}$

$1,294.60$ kilograms $(\mathrm{kg})$ 
Table 4. Hub and Nacelle Gross Properties

\begin{tabular}{l|l}
\hline Nacelle mass & $910 \mathrm{~kg}$ \\
Nacelle center of mass (above tower) & $0.45 \mathrm{~m}$ \\
Nacelle center of mass (downwind) & $0.2815 \mathrm{~m}$ \\
Nacelle center of mass (lateral) & $-0.0392 \mathrm{~m}$ \\
Hub mass & $134 \mathrm{~kg}$ \\
Hub inertia about rotor axis & $75 \mathrm{~kg} \mathrm{~m}^{2}$ \\
Generator inertia about high speed shaft & $0.00777 \mathrm{~kg} \mathrm{~m}^{2}$ \\
Gearbox ratio & 74.77 \\
\hline
\end{tabular}

Table 5. Blade Gross Properties

\begin{tabular}{l|l}
\hline Blade length & $6.2 \mathrm{~m}+1 \mathrm{~m}$ (extension) \\
Blade mass & $83.534 \mathrm{~kg}$ \\
Location of blade center of mass (measured from blade root) & $2.762 \mathrm{~m}$ \\
Blade first mass moment of inertia (w.r.t. Root) & $230.690 \mathrm{~kg} \mathrm{~m}$ \\
Blade second mass moment of inertia (w.r.t. Root) & $912.556 \mathrm{~kg} \mathrm{~m}^{2}$ \\
\hline
\end{tabular}


Table 6. Blade-Distributed Mass Properties

\begin{tabular}{|c|c|c|c|c|c|}
\hline $\begin{array}{l}\text { Radius } \\
\text { (m) }\end{array}$ & AeroCent $^{\mathrm{a}}$ & $\begin{array}{l}\text { Structural Twist } \\
\text { (deg) }\end{array}$ & $\begin{array}{l}\text { Mass } \\
(\mathrm{kg} / \mathrm{m})\end{array}$ & $\begin{array}{l}\text { Flapwise Stiffness } \\
\left(\mathrm{Nm}^{2}\right)\end{array}$ & $\begin{array}{l}\text { Edgewise Stiffness } \\
\left(\mathrm{Nm}^{2}\right)\end{array}$ \\
\hline 0.00 & 0.25000 & 38.88 & 11.667 & $3.74 \mathrm{E}+06$ & $3.74 \mathrm{E}+06$ \\
\hline 1.00 & 0.25000 & 38.88 & 16.917 & $3.74 \mathrm{E}+06$ & $3.74 \mathrm{E}+06$ \\
\hline 1.10 & 0.25000 & 35.49 & 16.68 & $4.60 \mathrm{E}+06$ & $4.60 \mathrm{E}+06$ \\
\hline 1.45 & 0.25000 & 28.30 & 15.849 & $2.39 \mathrm{E}+06$ & $2.39 \mathrm{E}+06$ \\
\hline 1.70 & 0.24153 & 22.81 & 15.255 & $1.06 \mathrm{E}+06$ & $1.33 \mathrm{E}+06$ \\
\hline 1.95 & 0.23307 & 18.66 & 14.661 & $8.83 E+05$ & $1.47 \mathrm{E}+06$ \\
\hline 2.20 & 0.22460 & 15.49 & 14.068 & $6.53 \mathrm{E}+05$ & $1.52 \mathrm{E}+06$ \\
\hline 2.45 & 0.24600 & 13.02 & 13.474 & $4.37 \mathrm{E}+05$ & $1.32 \mathrm{E}+06$ \\
\hline 2.70 & 0.25100 & 11.06 & 12.88 & $3.29 \mathrm{E}+05$ & $1.15 \mathrm{E}+06$ \\
\hline 3.20 & 0.24100 & 8.17 & 11.693 & $2.09 \mathrm{E}+05$ & $8.45 E+05$ \\
\hline 3.70 & 0.22300 & 6.16 & 10.506 & $1.30 \mathrm{E}+05$ & $5.93 \mathrm{E}+05$ \\
\hline 4.20 & 0.20500 & 4.68 & 9.319 & $8.31 \mathrm{E}+04$ & $4.20 \mathrm{E}+05$ \\
\hline 4.70 & 0.19000 & 3.56 & 8.131 & $3.89 \mathrm{E}+04$ & $2.11 \mathrm{E}+05$ \\
\hline 5.20 & 0.18000 & 2.67 & 6.944 & $2.81 \mathrm{E}+04$ & $1.61 \mathrm{E}+05$ \\
\hline 5.70 & 0.17300 & 1.96 & 5.757 & $2.13 \mathrm{E}+04$ & $2.55 \mathrm{E}+05$ \\
\hline 5.95 & 0.16900 & 1.65 & 5.163 & $9.54 \mathrm{E}+03$ & $1.14 \mathrm{E}+05$ \\
\hline 6.20 & 0.16500 & 1.37 & 4.57 & $8.11 \mathrm{E}+03$ & $9.73 E+04$ \\
\hline 6.45 & 0.16000 & 1.12 & 3.976 & $6.63 \mathrm{E}+03$ & $7.95 \mathrm{E}+04$ \\
\hline 6.70 & 0.15000 & 0.88 & 3.382 & $4.87 \mathrm{E}+03$ & $5.84 \mathrm{E}+04$ \\
\hline 6.95 & 0.15000 & 1.17 & 2.789 & $2.58 \mathrm{E}+03$ & $3.10 \mathrm{E}+04$ \\
\hline 7.00 & 0.15000 & 1.44 & 2.67 & $1.01 \mathrm{E}+03$ & $1.21 \mathrm{E}+04$ \\
\hline 7.05 & 0.15000 & 1.94 & 2.551 & $1.01 \mathrm{E}+03$ & $1.21 \mathrm{E}+04$ \\
\hline 7.10 & 0.15000 & 2.44 & 2.433 & $1.01 \mathrm{E}+03$ & $1.21 \mathrm{E}+04$ \\
\hline 7.15 & 0.15000 & 3.14 & 2.314 & $1.01 \mathrm{E}+03$ & $1.21 \mathrm{E}+04$ \\
\hline 7.20 & 0.15000 & 4.00 & 2.195 & $3.26 \mathrm{E}+00$ & $3.91 \mathrm{E}+01$ \\
\hline
\end{tabular}

${ }^{\text {a }}$ AeroCent input is used in FAST to locate the aerodynamic centre of the corresponding airfoil section, defined as:

AeroCent $=0.25-[$ (Fraction of chord from leading edge to actual pitch axis $)$

-(Fraction of chord from leading edge to actual aerodynamic centre)] 
Table 7. Blade-Distributed Aerodynamic Properties

\begin{tabular}{|c|c|c|c|}
\hline Node Radius (m) & Aerodynamic Twist (deg) & Chord Length (m) & Airfoil Designation \\
\hline 0.75 & 38.88 & 0.33 & Cylinder \\
\hline 1.3 & 37.185 & 0.33 & Cylinder \\
\hline 1.525 & 31.895 & 0.33 & Cylinder \\
\hline 1.825 & 25.555 & 0.365 & Transition \\
\hline 2.075 & 20.735 & 0.445 & Transition \\
\hline 2.325 & 17.075 & 0.535 & Transition \\
\hline 2.575 & 14.255 & 0.6 & Transition \\
\hline 2.825 & 12.04 & 0.625 & Main 1 \\
\hline 3.2 & 9.615 & 0.605 & Main 1 \\
\hline 3.7 & 7.165 & 0.55 & Main 1 \\
\hline 4.2 & 5.42 & 0.49 & Main 1 \\
\hline 4.7 & 4.12 & 0.435 & Main 1 \\
\hline 5.2 & 3.115 & 0.39 & Main 2 \\
\hline 5.7 & 2.315 & 0.35 & Main 2 \\
\hline 6.075 & 1.805 & 0.325 & Main 2 \\
\hline 6.325 & 1.51 & 0.31 & Main 2 \\
\hline 6.575 & 1.245 & 0.285 & Main 2 \\
\hline 6.825 & 1 & 0.255 & Main 3 \\
\hline 7.075 & 1.025 & 0.22 & Main 3 \\
\hline 7.225 & 1.305 & 0.195 & Main 3 \\
\hline 7.275 & 1.69 & 0.185 & Main 3 \\
\hline 7.325 & 2.19 & 0.175 & Main 3 \\
\hline 7.375 & 2.79 & 0.165 & Main 3 \\
\hline 7.425 & 3.57 & 0.155 & Main 3 \\
\hline
\end{tabular}

\subsection{Tower}

One limitation of FAST is that for a floating structure, all parts below the waterline are considered rigid. Therefore, the platform and any portion of the tower that is under water cannot have flexibility. A key issue was therefore to locate where the tower transitions to the platform. Another issue is that the tension wires and spreader-beam system generates an asymmetric stiffening of the tower in the fore and aft directions, whereas the current version of FAST is only able to model symmetric properties for the tower. For this work, the tower-bending flexibility was considered negligible because the wind turbine was freely floating and no significant bending moments were applied at the bottom of the structure. For this reason, the tower was modeled as a rigid structure, and the transition point from tower to platform was set at MSL as a first step in getting a working model. 
Many components in the design files ([28], [29], [30])—such as instrumentation equipment, service pipes, and a work platform - increase the complexity of building the tower parameters. Because it is impossible to place point masses for these components, calculations were done to account for all the components and obtain the tower properties in Table 8 and Table 9.

Table 8. Gross Tower Properties

\begin{tabular}{l|l}
\hline Tower height (from MSL) & $12.5 \mathrm{~m}$ \\
Tower base elevation above MSL & $0 \mathrm{~m}$ \\
Total mass & $2449.817 \mathrm{~kg}$ \\
\hline
\end{tabular}

Table 9. Tower Distributed Properties

\begin{tabular}{ll}
\hline Height $(\mathrm{m})$ & Mass $(\mathrm{kg} / \mathrm{m})$ \\
\hline 0.00000 & 156.1300 \\
1.10000 & 156.1300 \\
1.10001 & 456.1300 \\
1.60000 & 456.1300 \\
1.61251 & 824.6413 \\
2.10000 & 824.6413 \\
2.10001 & 524.6413 \\
2.80000 & 524.6413 \\
2.80001 & 224.6413 \\
3.20000 & 224.6413 \\
3.20001 & 161.4219 \\
5.70000 & 161.4219 \\
5.70001 & 105.7788 \\
10.90000 & 105.7788 \\
10.90001 & 181.7788 \\
11.90000 & 181.7788 \\
11.90001 & 105.7788 \\
12.50000 & 105.7788 \\
\hline
\end{tabular}




\subsection{Floating Platform}

The floating platform is modeled as a tapered cylinder in FAST. The floating platform model starts from MSL with a constant diameter of $1.0 \mathrm{~m}$ to the depth of $1.9 \mathrm{~m}$, and it tapers to a diameter of $1.4 \mathrm{~m}$ to the depth of $3.4 \mathrm{~m}$. It extends further with a constant diameter of $1.4 \mathrm{~m}$ to the platform base. Table 10 summarizes the overall properties of the structure.

Table 10. Platform Gross Properties

\begin{tabular}{l|l}
\hline Depth to platform base below MSL (total draft) & $16.4 \mathrm{~m}$ \\
Elevation to platform top (tower base) above MSL & $0 \mathrm{~m}$ \\
Effective platform diameter & $1.4 \mathrm{~m}$ \\
Effective platform normalized hydrodynamic viscous $\mathrm{C}_{\mathrm{D}}$ & 0.6 \\
Platform mass, including ballast & $18,608.36 \mathrm{~kg}$ \\
Displacement & $23.216 \mathrm{~m}^{3}$ \\
Center of mass (CM) below MSL along platform centerline & $12.614 \mathrm{~m}$ \\
Platform roll inertia about CM & $3973.057 \mathrm{E}+03 \mathrm{~kg} \mathrm{~m}^{2}$ \\
Platform pitch inertia about CM & $4373.057 \mathrm{E}+03 \mathrm{~kg} \mathrm{~m}^{2}$ \\
\hline
\end{tabular}

a The taper in the platform below MSL (which can be observed in Figure 3) was ignored for this parameter.

${ }^{b}$ Platform roll and pitch inertia were adjusted during the calibration of the free-decay test.

A WAMIT model was built to generate the hydrostatic and hydrodynamic matrices required by HydroDyn to account for the radiation and diffraction loads on the body. This model was discretized with 640 panels over one quarter of the body with two planes of symmetry, and it was built using exact design dimensions of the platform. In addition, the HydroDyn model includes the viscous drag term of Morison's equation with a normalized drag coefficient of 0.6. This drag coefficient was determined by estimating the Reynolds number of the flow over a cylindrical spar, and the flow was found to fall within the postcritical region.

\subsection{Mooring System}

As shown in Figure 13, the SWAY turbine uses a tension rod with universal joints instead of typical slack or taut mooring lines, which are commonly used for floating offshore platforms. Doing so provides restoring forces for the motion in surge, sway, roll, pitch, and heave.

As described in Section 2.1.3, FAST has a quasi-static mooring line model. To represent the tension rod in the FAST model, the tension rod is modeled as a taut mooring line. This assumption is valid, as the SWAY wind turbine should only generate tension forces in the design conditions. To ensure the robustness of the simulation, the fairlead and anchor tension for compressive forces ( $<0$ conditions) were monitored. Mass and thickness properties of the tension rod were used for the mooring-line model. While the specification for the tension rod stiffness was not available from turbine design data, an initial stiffness value was determined from the tension rod geometry and materials. This resulted in an overly stiff mooring line and caused divergence issues in the code. The stiffness was then readjusted to allow for a solution to be computed. The properties of the mooring system are described in Table 11. 


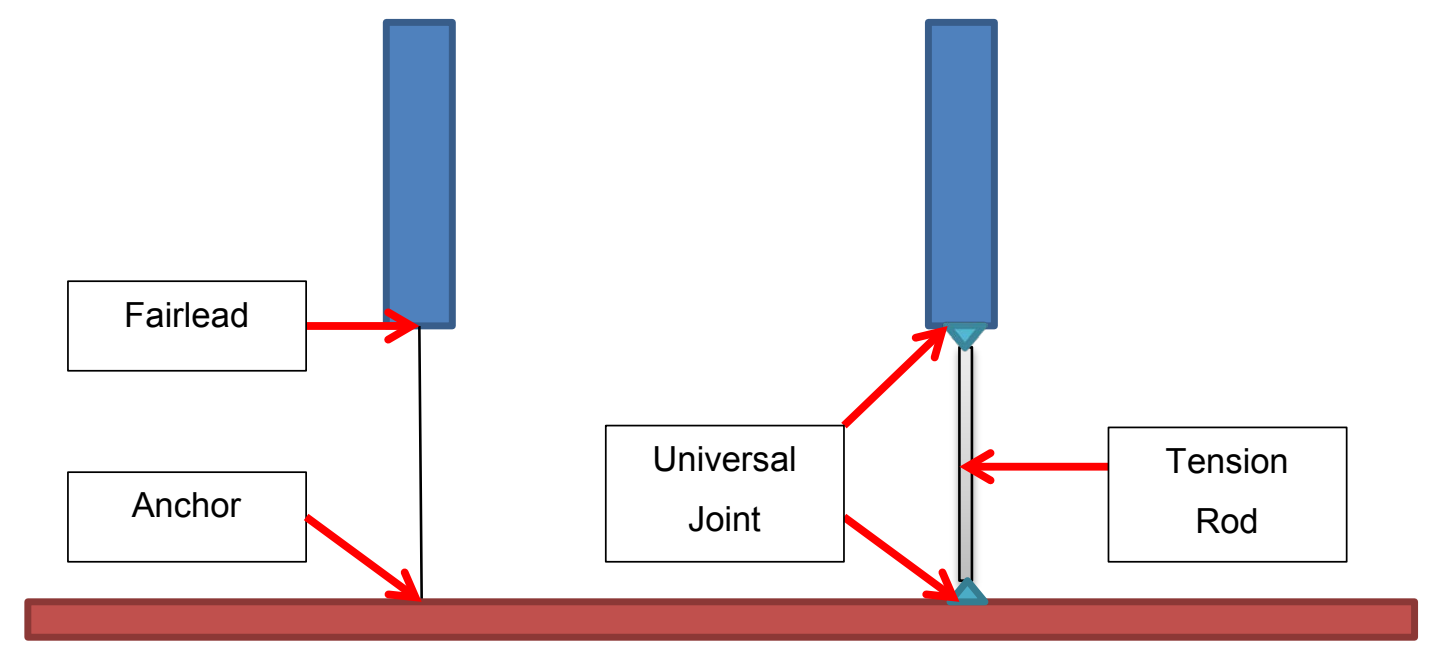

Figure 13. Tension line versus tension rod

Table 11. Mooring System Properties

\begin{tabular}{l|l}
\hline Number of mooring lines & 1 \\
Depth to anchors below MSL (water depth) & $18.686 \mathrm{~m}$ \\
Depth to fairleads below SW & $16.4 \mathrm{~m}$ \\
Radius to anchors from platform centerline & $0 \mathrm{~m}$ \\
Radius to fairleads from platform centerline & $0 \mathrm{~m}$ \\
Unstretched mooring line length & $2.278 \mathrm{~m}$ \\
Mooring line diameter & $0.245 \mathrm{~m}$ \\
Equivalent mooring line mass density & $48.125 \mathrm{~kg} / \mathrm{m}$ \\
Equivalent mooring line extensional stiffness & $\mathrm{b}$ \\
\hline
\end{tabular}

a According to design specifications stated by SWAY, mass density of mooring line is similar to mass density of water. The equivalent mooring line mass density was derived accordingly.

${ }^{b}$ As the actual tension rod is very stiff, it was not possible to input a large stiffness value, as the mooring line calculations would be unstable. This value was obtained by reducing the order of magnitude of the estimated tension rod stiffness.

\subsection{Other Modeling Assumptions}

The yawing of the wind turbine occurs at the yaw mechanism, which is located at the bottom of the spar, as opposed to a conventional yaw bearing located at the nacelle. A reasonable amount of yaw damping arises from aerodynamic drag, hydrodynamic drag, and friction forces of the yaw bearing at the two universal joints. From the experimental data, minimal yaw movements were observed, and thus, the nacelle and platform yaw DOF were switched off. This restricts the yaw motion of the wind turbine and allows the model to work without extensive code changes to FAST. 


\section{Model Calibration}

For this study, most of the wind turbine dimensions and blade properties were provided by SWAY AS; however, a few areas of uncertainties created the need for some calibration of the FAST model to match the recorded response behavior. One issue was the lack of complete information on the weight and location of components added to the tower and turbine. Such appurtenances include instrumentation added for measurements and other equipment. To address these uncertainties, the mass distribution of the tower and platform were adjusted as were their mass moments of inertia. Calibration was performed first using data obtained from a center of gravity test that was performed for the whole system before deployment. This information was used to tune the center of gravity of the FAST model, which is detailed in Section 5.1. A static equilibrium test was conducted to check for abnormalities in the model. Next, free-decay tests performed with the structure in the water were used to tune the mass moments of inertia of the platform, as detailed in Section 5.2.

From previous work on the DeepCWind validation [4], it was seen that the hydrodynamic damping of FAST can be underestimated. Therefore, an additional quadratic global platform damping matrix was used to better represent the damping of the system. This calibration was also performed using the free-decay tests.

Finally, since modifications were done to the original blade design, a complete set of the as-built blade properties were not available. Therefore, the blade stiffness and damping properties needed to be calibrated to the as-built properties. This calibration process is discussed in Section 6.3.

\subsection{Static Equilibrium Test}

A series of static equilibrium tests were conducted after deployment of the prototype in the ocean. Testing was conducted during calm conditions with a mean wind speed of $1.7 \mathrm{~m} / \mathrm{s}$ and minimum and maximum values of $0.25 \mathrm{~m} / \mathrm{s}$ and $5 \mathrm{~m} / \mathrm{s}$, respectively. The ocean was predominately flat with very small wind-generated capillary waves. The current velocity ranged from 6 to $8 \mathrm{~cm} / \mathrm{s}$ based on hourly averages. The turbine did not operate during the tests and it was initially expected that the calm conditions had minimal impact on the experimental data. Therefore, a static-equilibrium simulation was initially carried out with no wind-wave-current conditions on the FAST model to obtain the natural equilibrium position of the turbine.

In earlier work on the SWAY turbine (Koh et al. [31]), minor adjustments were made to the nacelle CG and the turbine overhang values in FAST to calibrate the mean pitch offset to $1^{\circ}$ (compared to an experimental value of $0.98^{\circ}$ ) and the mean surge offset to $0.287 \mathrm{~m}$ (compared to an experimental value of $0.34 \mathrm{~m}$ ). The sway, heave, and roll offsets were negligible. In a further analysis, these minor adjustments were found to be unnecessary. Two other cases with very low wind conditions at $1 \mathrm{~m} / \mathrm{s}$ mean wind speed (upwind and downwind direction) at hub height were simulated. The results are shown in Table 12. 
Table 12. Results of Static Equilibrium Analysis

\begin{tabular}{l|llll}
\hline Mean Offset & Experiment & $\begin{array}{l}\text { FAST } \\
\text { (no_wind) }\end{array}$ & $\begin{array}{l}\text { FAST (1m/s } \\
\text { downwind) }\end{array}$ & $\begin{array}{l}\text { FAST (1m/s } \\
\text { upwind) }\end{array}$ \\
\hline Pitch (degree) & 0.98 & 1.79 & 1.95 & -1.64 \\
Surge $(\mathrm{m})$ & 0.34 & 0.51 & 0.56 & -0.031 \\
\hline
\end{tabular}

The system's equilibrium position is fairly sensitive to the environmental conditions, as can be seen by the change in surge and pitch offset for a $1 \mathrm{~m} / \mathrm{s}$ upwind versus downwind condition. Because the static equilibrium of the prototype was calculated in varying wind conditions, it would be difficult to know what the static offsets would be without wind, and therefore the previous calibration work to achieve the correct static offsets were removed and the model was reverted to the original properties provided by the manufacturer.

\subsection{Free-Decay Test}

Further calibration of the model was performed using free-decay test data. After turbine deployment and installation of the NREL instrumentation, five free-decay tests were conducted on the SWAY prototype by displacing the system and allowing it to return to equilibrium: two in the roll direction, and one each for the pitch, surge, and sway directions. Ropes were attached to the nacelle and the base of the tower to perform the displacement. The ropes were held with a quick release system and pulled onshore (nearby to the prototype installation) to set the system to the desired initial displacement of the system.
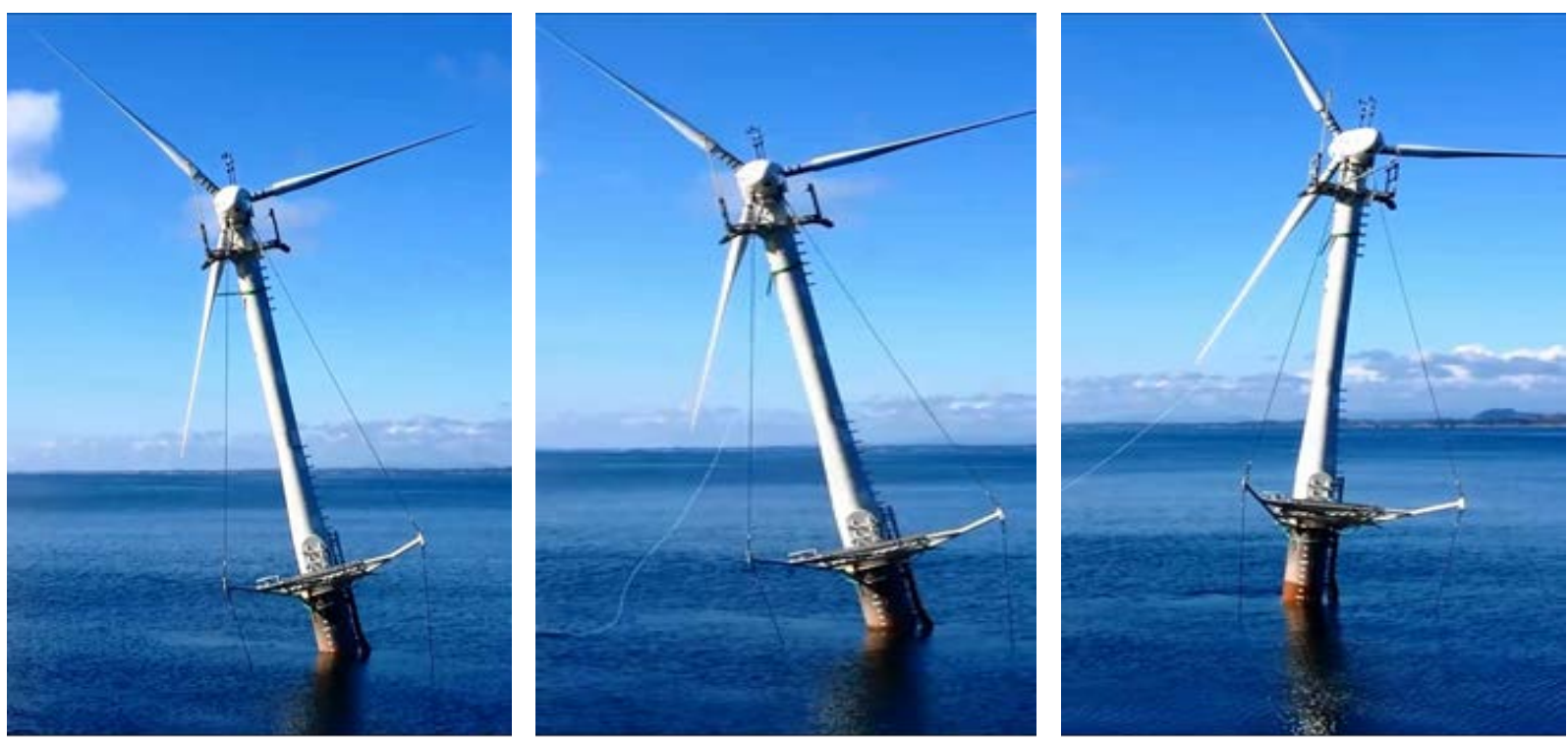

Figure 14. Free decay test. Image extracted from video recorded by NREL

Testing was conducted in the same conditions as the static equilibrium test were conducted, and the calm conditions were expected to have minimal impact on the experimental data, as the predominant motion of the system will be due to the free-decay conditions. Therefore, the freedecay simulations were conducted in no wind, wave, or current conditions. 
In an ideal condition, only one DOF would be excited at a time in a free-decay test to identify the frequency and damping of that DOF. However, during the actual test, the primary DOF of interest in each test was strongly coupled with other DOFs. For example, during a roll free-decay test, the sway DOF was heavily coupled while the pitch and surge of the system experienced small motions. Nonetheless, the results collected were sufficient to allow for manual tuning of the mass moment of inertia and hydrodynamic viscous damping of the platform to calibrate the natural frequency and response of the system. Of five free-decay tests, only one roll free-decay test and one pitch free-decay test were used for calibration.

\subsubsection{Roll Free-Decay}

The initial displacements (surge, sway, and heave) and rotations (roll and pitch) from the roll free-decay test were used as initial conditions in the FAST model. A free-decay simulation was then run, and the platform inertia and roll term (diagonal-only) in the damping matrix was tuned so that the roll period and magnitude matched the experimental data.

The experiments exhibited an average platform roll period of 45.6 seconds (s) whereas the FAST simulations had an average period of $44.0 \mathrm{~s}$ after calibration of the mass moment inertia of the platform and platform damping matrix. It is noted that both the experimental and simulated roll periods varied slightly throughout the entire free-decay test (the first experimental oscillation period was $42.9 \mathrm{~s}$ ). The roll motion of the system after tuning is shown in Figure 15. The simulated motion follows the experimental motion quite closely. Significant deviations of the period and amplitude occur after the fourth oscillation when the magnitude of oscillation decreases.

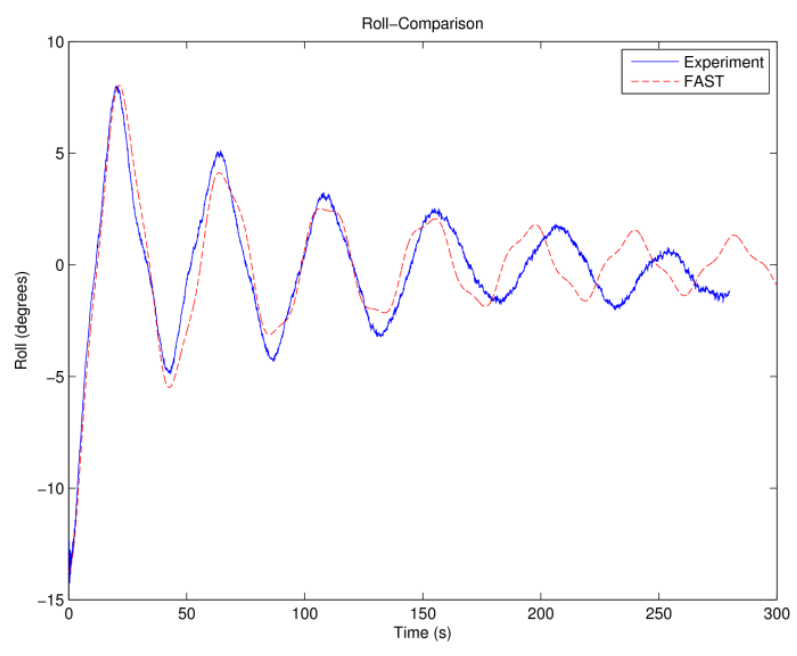

Figure 15. Roll motion in roll free decay

A fast Fourier transform (FFT) was carried out for the first $280 \mathrm{~s}$ of experimental time and simulation time to analyze the data in the frequency domain. Figure 16 shows the FFT results and enlarged views around the main peaks. The peak frequency of the experimental and simulated results occurs at values of about $0.02143 \mathrm{~Hz}$ and $0.02333 \mathrm{~Hz}$, which correspond to periods of $46.86 \mathrm{~s}$ and $43.48 \mathrm{~s}$, respectively. This is the roll frequency of the whole system and the calibration was deemed sufficient due to the low resolution in the experiment data. 

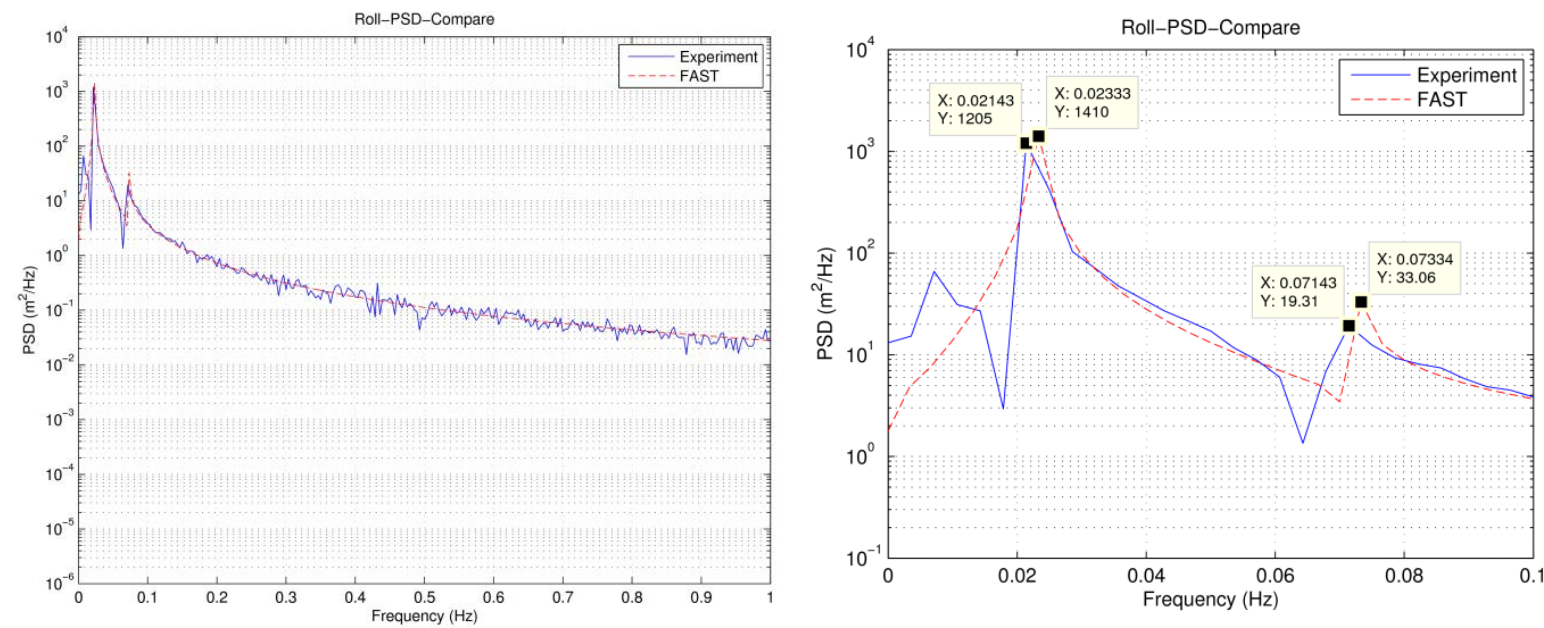

Figure 16. Power spectral density (PSD) versus frequency of roll DOF (enlarged on right)

A second peak frequency was also observed for experimental and simulated results occurring at values of about $0.07143 \mathrm{~Hz}$ and $0.07334 \mathrm{~Hz}$, respectively. The second peak frequency is caused by the flexibility of the universal joint between the spar structure and tension rod, which allows both to rotate about this joint. An illustration of the physical motion of the first and second peak frequency is depicted in Figure 17. This is verified by analyzing the measured angle of the tension rod with a motion plot and FFT analysis.

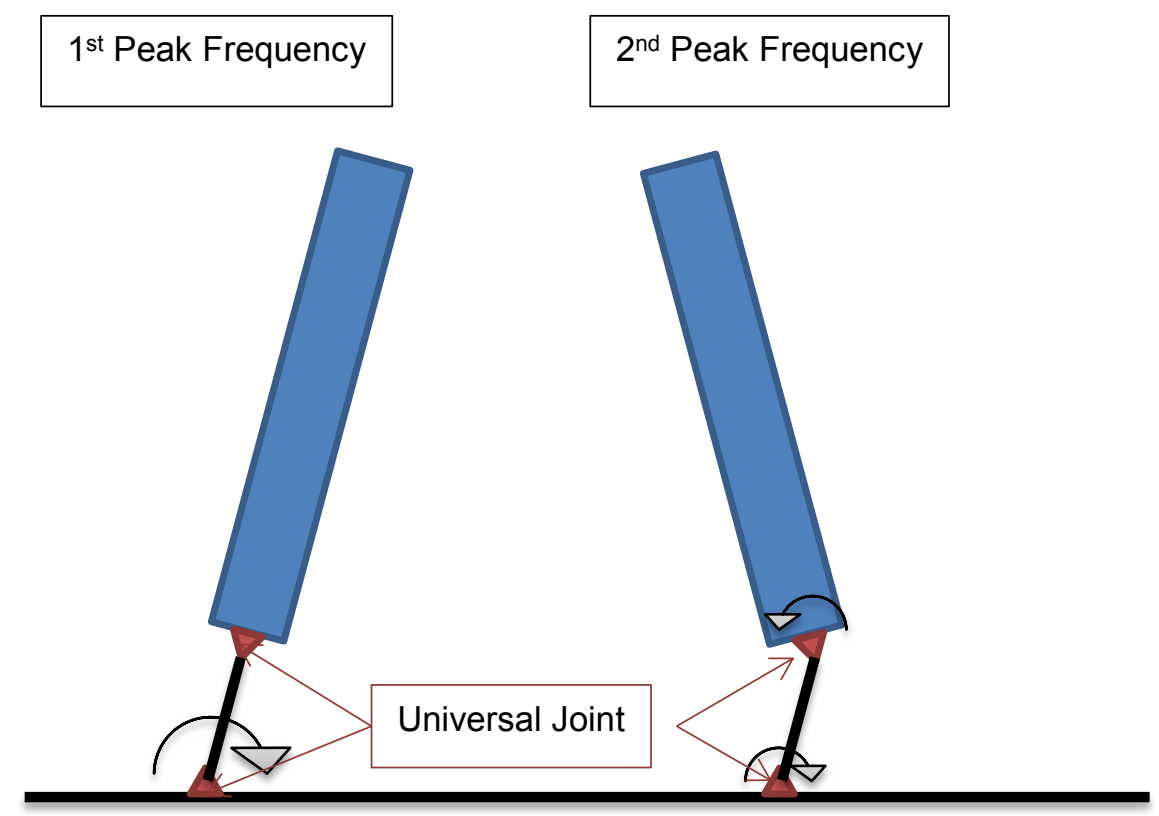

Figure 17. Illustration of physical motion of first and second peak frequency

Figure 18 shows the FFT results, indicating the primary frequency is $0.0681 \mathrm{~Hz}$ and $0.07168 \mathrm{~Hz}$ from the experimental data and FAST analysis, respectively, which corresponds closely to the second peak shown in the FFT results in Figure 16. 

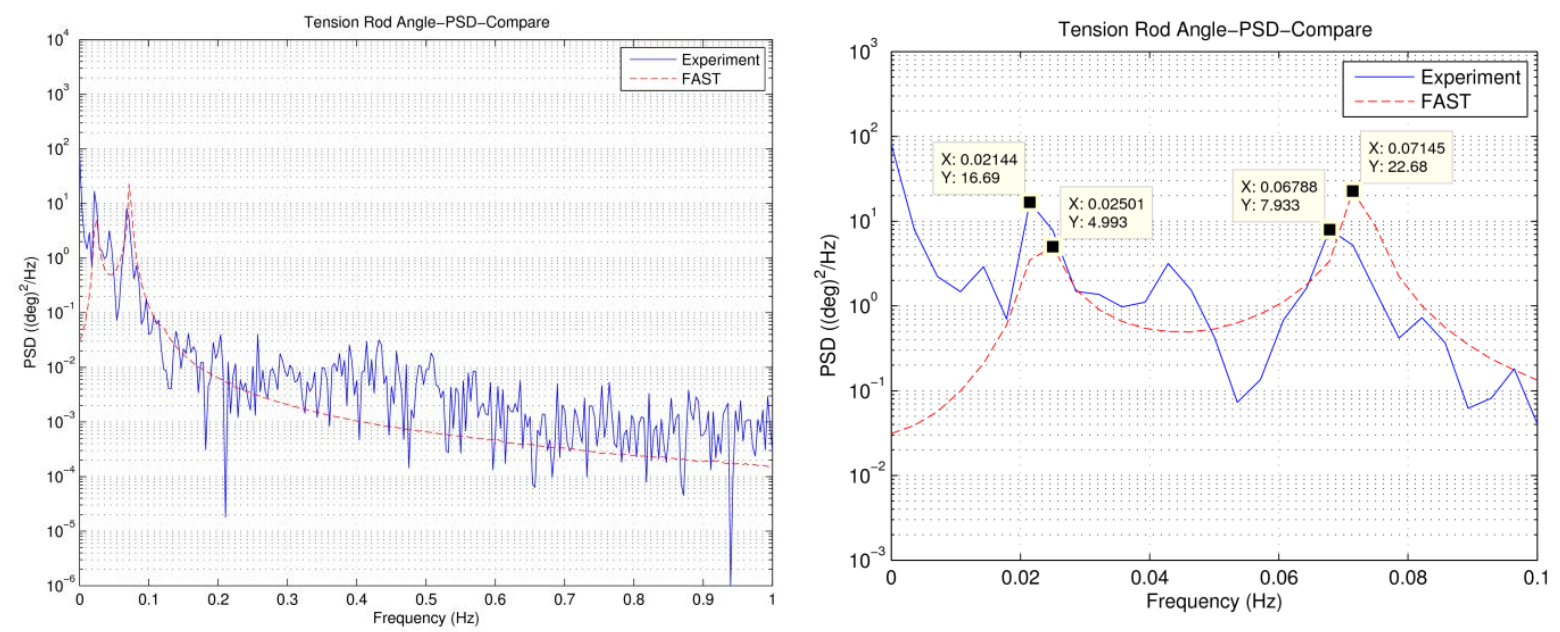

Figure 18. PSD versus frequency of tension rod motion (enlarged view on right)

\subsubsection{Pitch Free Decay}

Next, initial displacements and rotations were set in the FAST model to match the starting conditions for the pitch free-decay test. The simulated response in FAST was used to tune the platform inertia and damping matrix in the pitch direction (diagonal-term) so that the pitch period matched that of the experimental data.

The experiment had an average platform pitch period of $44.6 \mathrm{~s}$. After calibration, the FAST simulation had an average period of $42.9 \mathrm{~s}$. Similarly, both the experimental and simulated period varied slightly throughout the entire free- decay test. For the first oscillation, the experimental period of the pitch motion was $42.5 \mathrm{~s}$ while the simulation period was $43.7 \mathrm{~s}$. The pitch offset was similar (at about $1^{\circ}$ ) for the experimental and simulation results. The motion plots are shown in Figure 19. The simulated motion follows the experimental motion quite closely. Noticeable deviations for period and amplitude occur after the fifth oscillation when the magnitude of oscillation has decreased over time.

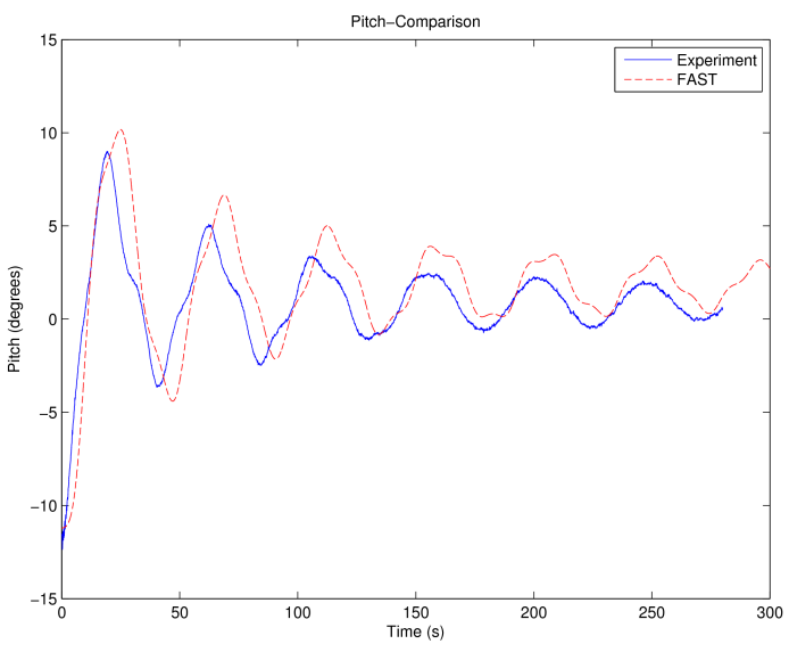

Figure 19. Pitch motion in pitch free decay 
An FFT was carried out for the first $300 \mathrm{~s}$ of experimental and simulation time. Figure 20 shows the FFT results and enlarged views around the main peaks. The peak frequency of the measured and simulated pitch occurs at values of about $0.02143 \mathrm{~Hz}$ and $0.02333 \mathrm{~Hz}$, which corresponds to periods of $46.66 \mathrm{~s}$ and $42.86 \mathrm{~s}$. This frequency is the pitch frequency of the whole system. A second peak frequency is also observed for measured and simulated pitch occurring at values of about $0.07143 \mathrm{~Hz}$ and $0.07 \mathrm{~Hz}$. As with the roll free-decay analysis, the second peak frequency is caused by the flexibility of the universal joint between the spar structure and tension rod.

Because of the small time length and sampling rate $(10 \mathrm{~Hz})$ of the test results, the range and resolution of the frequency data is limited. This error is significant at lower frequencies. For example, for the pitch free-decay test, the next frequency higher than $0.02333 \mathrm{~Hz}$ is $0.02667 \mathrm{~Hz}$, whereby the period would have decreased to $37.5 \mathrm{~s}$. Nonetheless, the FFT analysis shows matching frequency trends between experimental and simulation results.
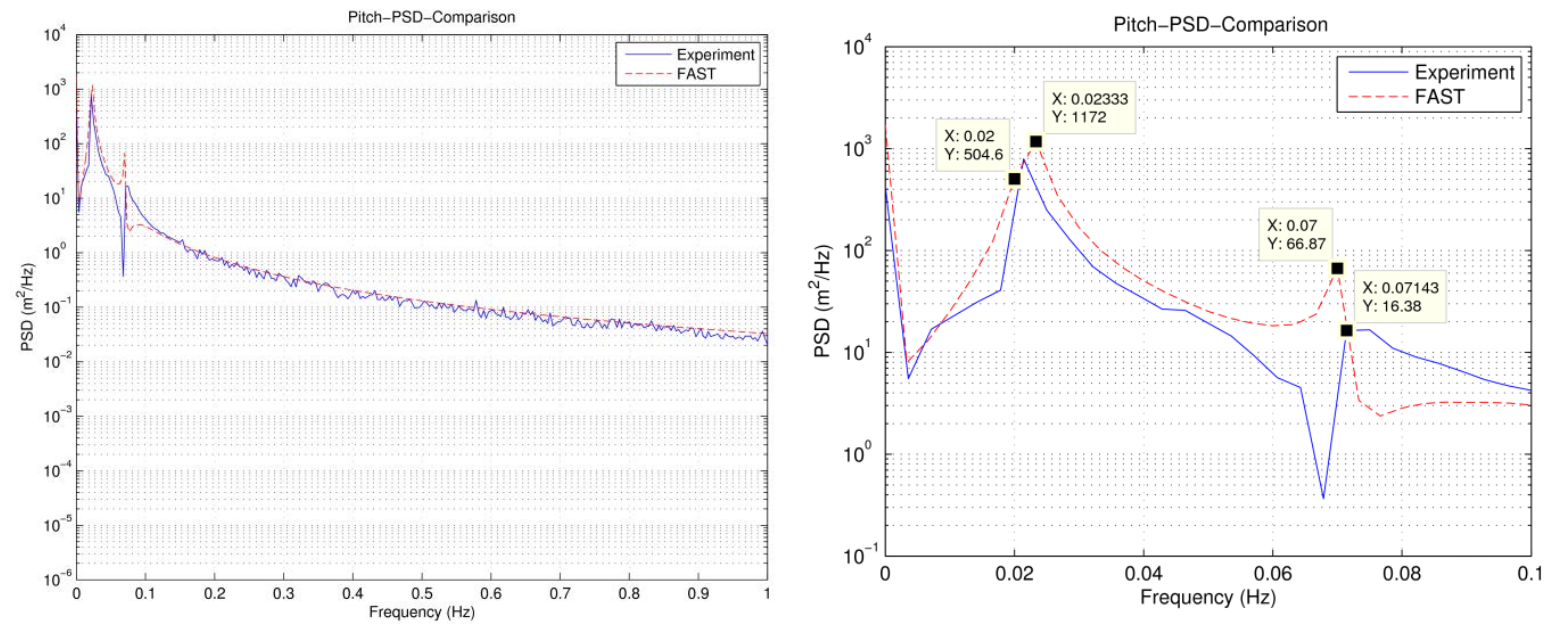

Figure 20. PSD versus frequency of pitch DOF (enlarged view on right)

\subsection{Blade Stiffness and Damping Calibration}

As discussed in Section 5.1, the blade properties were obtained from a GL Garrad Hassan technical report [28], which did not consider a blade extension that was added later. The blade properties therefore needed to be calibrated to match those of the installed system.

The blade flapwise and edgewise blending loads were analyzed using one 10-minute (min) test case with unsteady wind conditions at a mean wind speed of $4.35 \mathrm{~m} / \mathrm{s}$ at anemometer height. ${ }^{1}$ Inconsistent results were seen for the magnitude of the edgewise loads for Blade 2 as compared to Blades 1 and 3. Figure 21 shows the FFT analysis of the flapwise blade loads whereas Figure 22 shows the FFT analysis of the edgewise blade loads for Blade 1 from the experimental data. In the flapwise direction, the FFT analysis shows that the first flapwise modal frequency is about $4.156 \mathrm{~Hz}$ and the second flapwise modal frequency is about $10.18 \mathrm{~Hz}$. In the edgewise direction, the FFT analysis shows that the first edgewise modal frequency was about $6.072 \mathrm{~Hz}$, with

\footnotetext{
${ }^{1}$ Rotational speed of blades for wind speed at $4.35 \mathrm{~m} / \mathrm{s}$ was at 0.03181 radians per second or $0.3038 \mathrm{RPM}$.
} 
another peak detected at about $4.113 \mathrm{~Hz}$ which is associated with the first flapwise modal frequency.

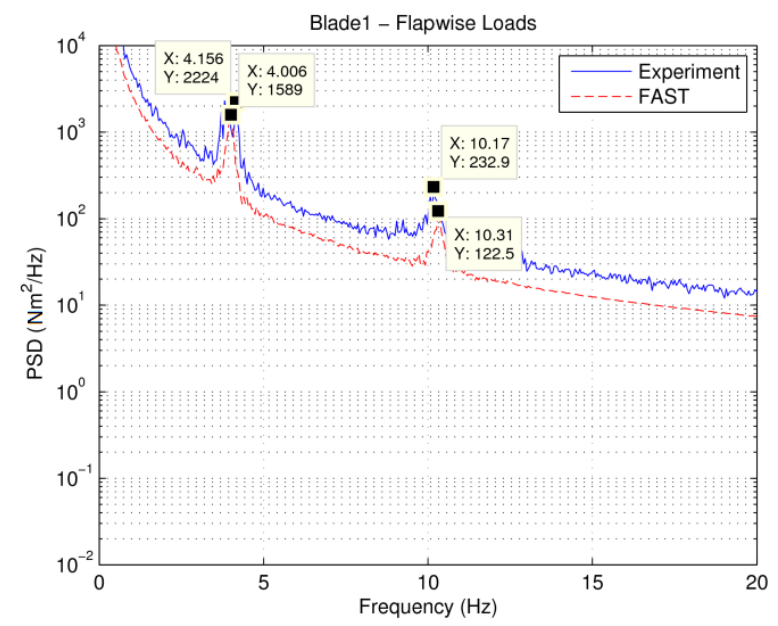

Figure 21. FFT analysis of flapwise blade loads at wind speed $=4.35 \mathrm{~m} / \mathrm{s}$ for the FAST and experiment responses

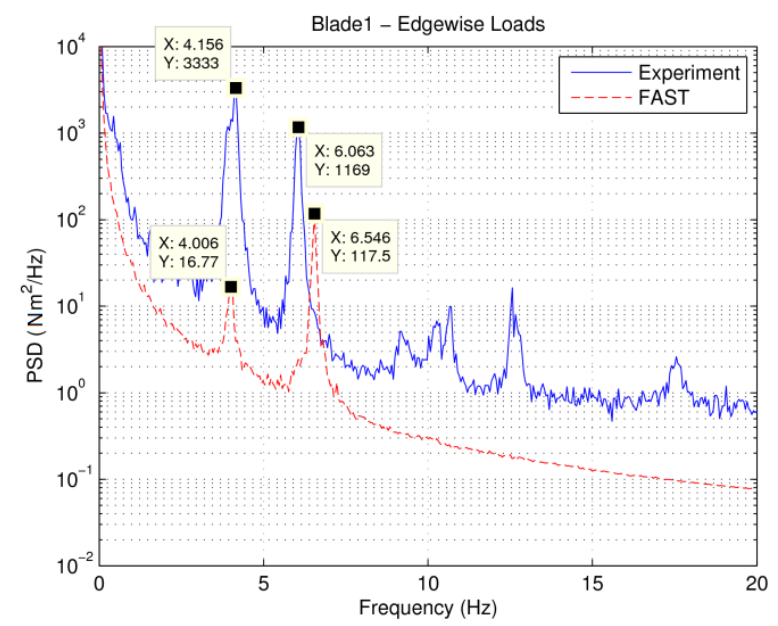

Figure 22. FFT analysis of edgewise blade loads at wind speed $=4.35 \mathrm{~m} / \mathrm{s}$ for the FAST and experiment responses

To calibrate the blade modal parameters, the test case was simulated in FAST, and the blade flapwise modal stiffness tuner for the first and second modes was adjusted with factors of 1.15 and 0.6 , respectively. The second factor is too large to be considered practical, and ideally the properties of the blade should be re-examined; however, for this analysis, our focus is on the global motions, and so this activity was not undertaken. FAST does not provide an edgewise modal stiffness tuner, but results are nonetheless compared.

After tuning, the first flapwise modal frequency was about $4.006 \mathrm{~Hz}$ whereas the second flapwise modal frequency was about $10.31 \mathrm{~Hz}$. Even without tuning (edgewise modal stiffness tuner is not available in FAST), the FFT analysis shows a good comparison for the edgewise modal 
frequency with experimental data. The first edgewise modal frequency was about $6.546 \mathrm{~Hz}$ and the first peak at $4.006 \mathrm{~Hz}$ is influenced by the first flapwise model frequency and was ignored.

Higher magnitude in the experiment data of the FFT analysis was observed for the flapwise blade loads in Figure 21, and more significantly for edgewise blade loads shown in Figure 22. The reasons for these observation are not yet understood.

Table 13. System Eigenfrequencies

\begin{tabular}{l|c|c}
\hline Degree of Freedom & $\begin{array}{l}\text { Experimental } \\
\text { Frequency }(\mathbf{H z})\end{array}$ & $\begin{array}{l}\text { Calibrated Model } \\
\text { Frequency }(\mathbf{H z})\end{array}$ \\
\hline Roll (1 ${ }^{\text {st }}$ peak $)$ & 0.02143 & 0.02333 \\
Roll $\left(2^{\text {nd }}\right.$ peak $)$ & 0.07143 & 0.07334 \\
Pitch (1 ${ }^{\text {st }}$ peak $)$ & 0.02143 & 0.0233 \\
Pitch (2 ${ }^{\text {nd }}$ peak) & 0.07143 & 0.07 \\
Blade $-1^{\text {st }}$ flapwise & 4.156 & 4.006 \\
Blade $-2^{\text {nd }}$ flapwise & 10.18 & 10.31 \\
Blade $-1^{\text {st }}$ edgewise & 6.072 & 6.546 \\
\hline
\end{tabular}




\section{Model Validation}

Once the FAST model had been calibrated, the accuracy of the model could be validated against the remaining available test data. This validation procedure is reviewed in this section. First, two nonoperational data sets are used (Section 7.1), and validation was then performed for two operational cases (Section 7.2).

\subsection{Nonoperating Conditions}

\subsubsection{Selection of Test Cases}

Given the large number of data sets recorded, it is important to start the validation work with simple test cases that have stable conditions over an extended period of time. Therefore, two 10-min data sets (Nonop Case 1 and 2) were selected with the following criteria for the ease of modeling in FAST:

1. Instruments operating without abnormalities

2. Zero or very low rotor speed values

3. Mean wind speed of the preceding 10 -min window has less than $5 \%$ in variation from the selected test case

4. Mean wind direction of the preceding 10-min window has less than $5^{\circ}$ in variation from the selected test case.

The criteria are focused on (1) reducing any transient motion generated by the conditions before the actual test case and (2) maintaining consistency of the wind throughout the test period. The wave height measurements were recorded as an average over either 20 minutes or 1 hour, and we therefore wanted to choose a 10-min data window that would not differ considerably from the 1hour average.

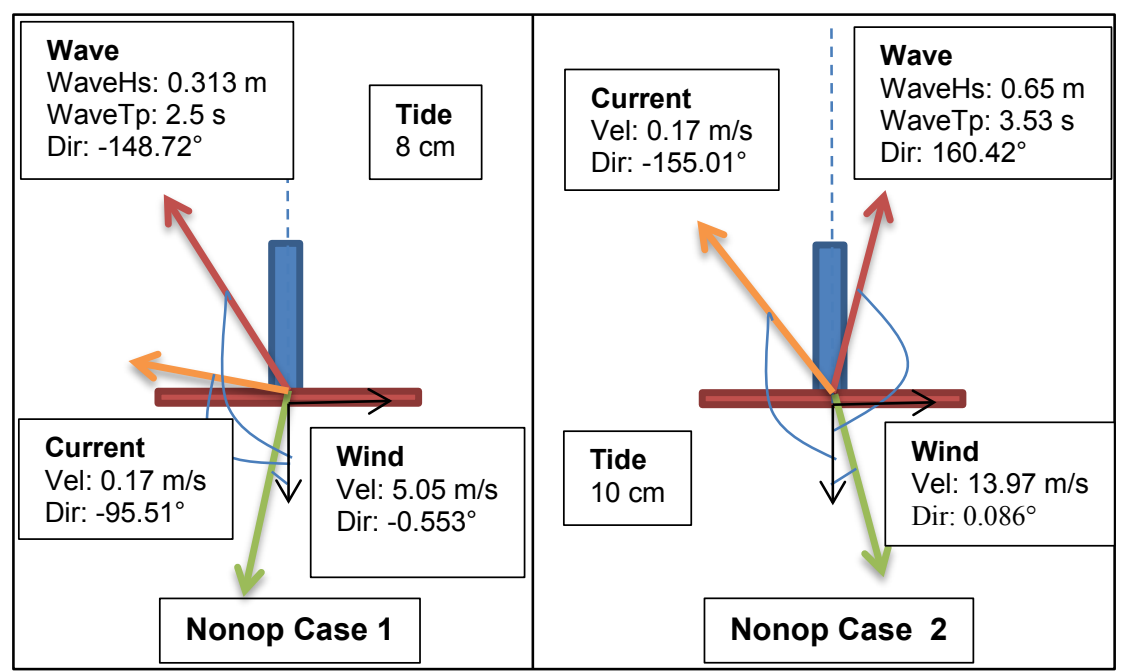

Figure 23. Summary of nonoperational test cases

Tide levels were obtained from observed data available at http://sehavniva.no/sted/Hordaland/Øygarden/Liøsøyna 105892/tidevann.html. 
The two 10-min test cases that were selected have mean wind speeds of $5 \mathrm{~m} / \mathrm{s}$ and $14 \mathrm{~m} / \mathrm{s}$ with corresponding significant wave heights of $0.31 \mathrm{~m}$ and $0.65 \mathrm{~m}$. The wind, wave, and current conditions are summarized in Figure 23. The accuracy of these data recordings was checked by comparing it to other data sets of similar conditions to ensure the recorded data was consistent.

\subsubsection{Simulation Procedure}

The system was first set at an equilibrium position calculated from a simulation of the static equilibrium. The FAST simulation was conducted for a simulation time of 1,200 s (20 minutes), and the first 10 minutes of the simulation were discarded to remove any initial transient behavior.

\subsubsection{Wind}

The wind inflow files used by AeroDyn were generated using TurbSim with the settings shown in Table 14. The mean wind speed and turbulence intensity were obtained from the sonic anemometer readings at the boom. Note that the minor yaw error (shown as wind direction in Figure 23) is a result of the system being a free-yaw system. This error was represented as a yaw offset in FAST. The analysis time was set at 1,200 s, to allow for 10 minutes of data after any initial transient behavior had died out. The vertical and horizontal grid-point sizes were set so that they were approximately the mean chord length of the blade.

Table 14. TurbSim Wind Inflow Properties for Nonoperating Case

\begin{tabular}{l|l|l}
\hline & Nonop Case 1 & Nonop Case 2 \\
\hline Vertical grid-point matrix dimension & 51 & \\
Horizontal grid-point matrix dimension & 63 & \\
Hub height [m] & 13.133 & \\
Grid height [m] & 20.000 & $13.715 \%$ \\
Grid width [m] & 25.000 & 13.970 \\
Turbulence model & IEC Kaimal spectral normal turbulence model \\
\cline { 2 - 2 } Turbulence intensity & $25.856 \%$ & \\
Reference wind speed [m/s] & 5.0460 & \\
\cline { 2 - 2 } Reference height of anemometer [m] & 12.500 & \\
Wind profile type & IEC, Power law on rotor disk, logarithmic elsewhere \\
Power law exponent & 0.140 & \\
Surface roughness length [m] & $0.030^{\mathrm{a}}$ & \\
\hline
\end{tabular}

a The surface roughness length of 0.030 is recommended by the IEC-61400-3 for offshore conditions.

The turbulence model was assumed to follow the IEC Kaimal spectral normal turbulence model [18], and the turbulence intensity and reference wind speed were derived from sonic anemometer readings of wind speeds from the four test cases. The power law exponent and surface roughness length are recommended values from the IEC 61400-3 [22]. 
Because the wind input file was generated in TurbSim with no mean crosswind component as explained previously, it is important to verify the statistical properties of the wind inflow, particularly the crosswind component of the system.

Figure 24 and Figure 25 show the time domain comparison of the wind inflow velocity for downwind and crosswind directions for both FAST and the experimental data. The spikes observed in the experimental data in these figures are assumed to be due to errors in the sensor or data logger. The horizontal lines in the graph represent the mean value of the wind inflow velocity. In both cases, the mean and standard deviation of the wind inflow velocity for the experiment show good comparison with the wind inflow generated by TurbSim. As the FAST data are obtained at the hub height while the experimental data were obtained at the boom height, this height difference led to a slightly larger mean for the experiment data. Summaries of the measured and simulated wind properties for both test cases are shown in Table 15 and Table 16.
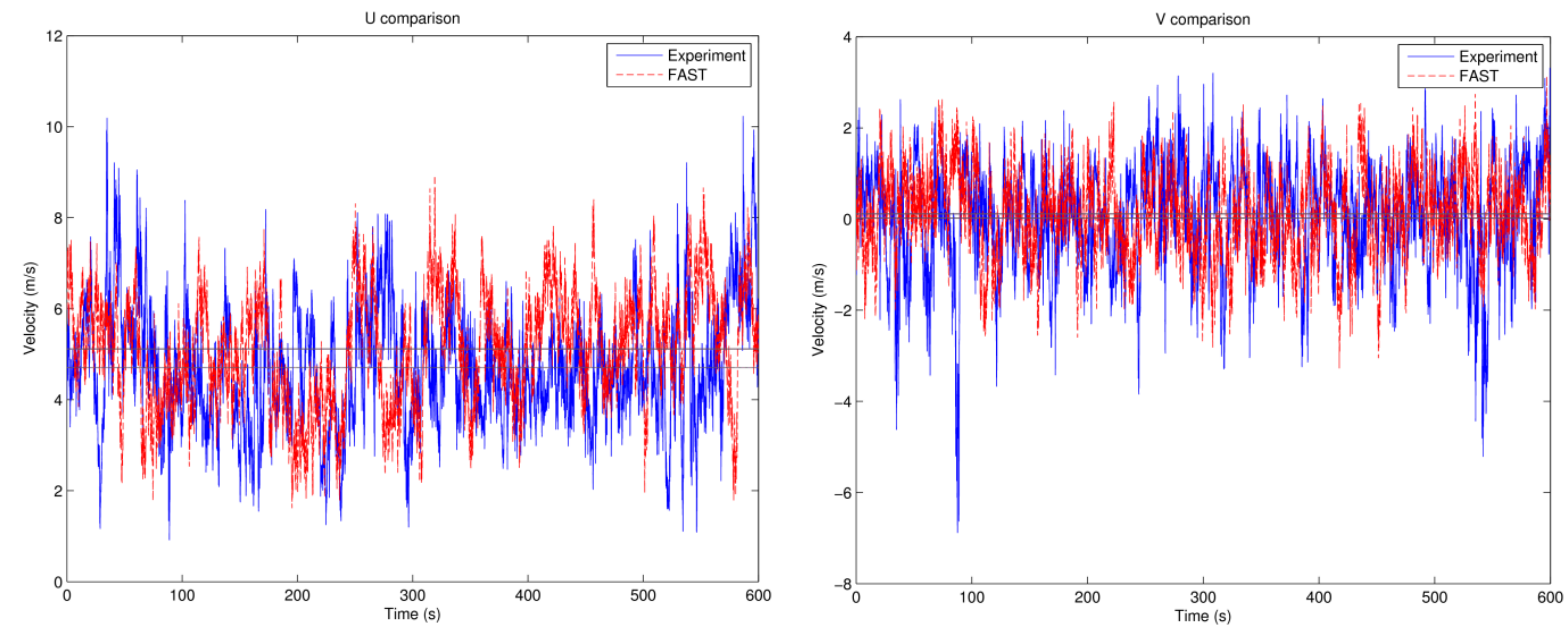

Figure 24. Velocity inflow comparison (Nonop Case 1)
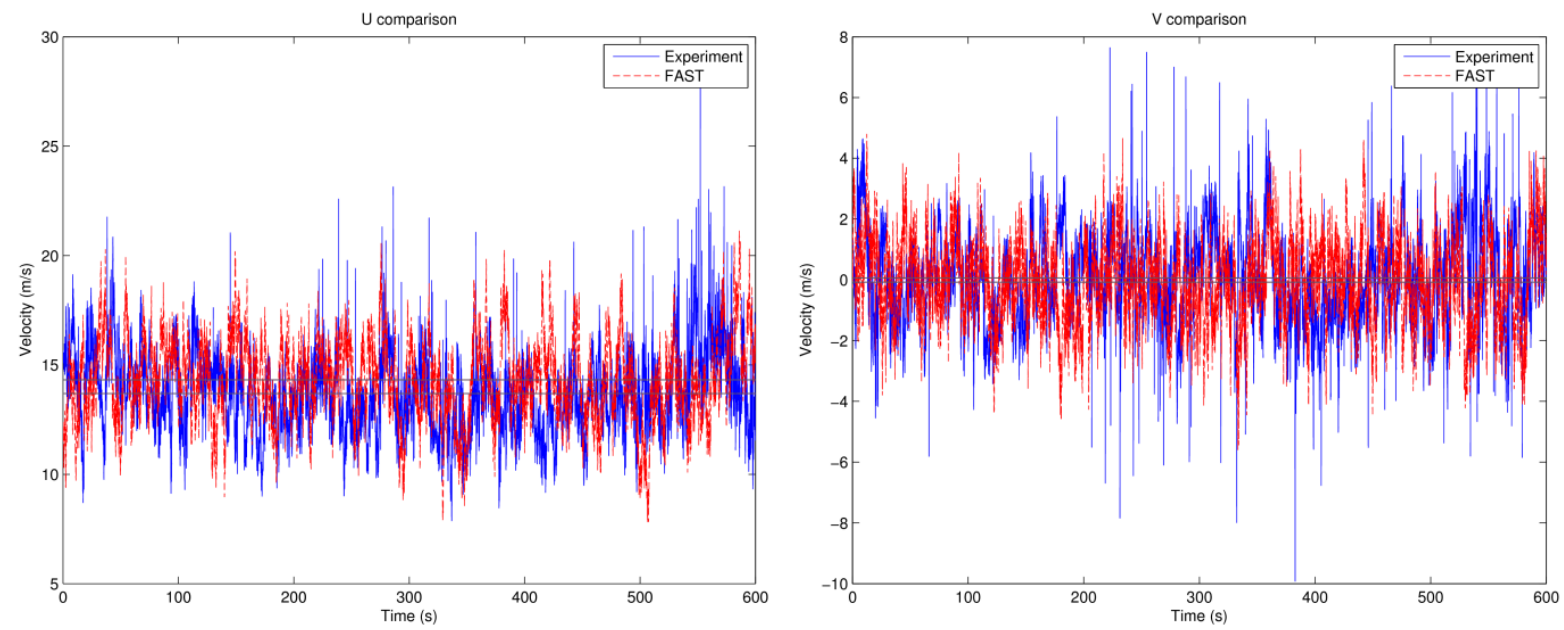

Figure 25. Velocity inflow comparison (Nonop Case 2) 
Table 15. Comparison of Wind Properties for Nonop Case 1

\begin{tabular}{l|llll}
\hline & Mean (Exp) & Mean (FAST) & Std. Dev. (Exp) & Std. Dev. (FAST) \\
\hline$U(\mathrm{~m} / \mathrm{s})$ & 4.7014 & 5.1131 & 1.2985 & 1.2453 \\
$\mathrm{~V}(\mathrm{~m} / \mathrm{s})$ & 0.0218 & 0.1170 & 1.1573 & 0.9159 \\
\hline
\end{tabular}

Table 16. Comparison of Wind Properties for Nonop Case 2

\begin{tabular}{l|llll}
\hline & Mean (Exp) & Mean (FAST) & Std. Dev.(Exp) & Std. Dev. (FAST) \\
\hline$U(\mathrm{~m} / \mathrm{s})$ & 13.6939 & 14.3237 & 1.8012 & 1.9356 \\
$\mathrm{~V}(\mathrm{~m} / \mathrm{s})$ & 0.0642 & -0.0761 & 1.5433 & 1.4118 \\
\hline
\end{tabular}

\subsubsection{Waves}

In the initial FAST simulation runs, the irregular waves were simulated in FAST by assuming that the energy distribution follows the PM spectrum (the JONSWAP spectrum was not used because of the less pronounced peak shown in Figure 26 and Figure 27). The wave parameters used in the FAST simulation were obtained from the 1-hr averaged data observed by the AWAC; however, the wave spectrum was not represented well, particularly in the lower frequency region. The wave and current data available from the AWAC were averaged to 1-hr readings, so there will be inaccuracy in the simulation results, as wave and current properties may differ significantly within the 1-hr sampling period. Also the wave conditions at the system location may be bimodal/multimodal in nature, which means they cannot be represented from the 1-hr averaged data from the AWAC, because it only returns the peak frequency and period.

Therefore, a user-defined wave spectrum was entered into FAST from the wave spectrum obtained from the adjusted 10-min wave height data from the tower wave height sensor. The mean wave direction was obtained from the 1-hr averaged data observed by the AWAC. This process was performed for both cases and the time- and frequency-domain comparisons of the waves generated in FAST and the experimental data are shown in Figure 26 and Figure 27. The wave spectrums in these figures do not match perfectly because only the latter 10 minutes of the waves generated from 20 minutes in FAST were processed. The time histories are also not expected to match because phases of the simulated wave time history are random. 

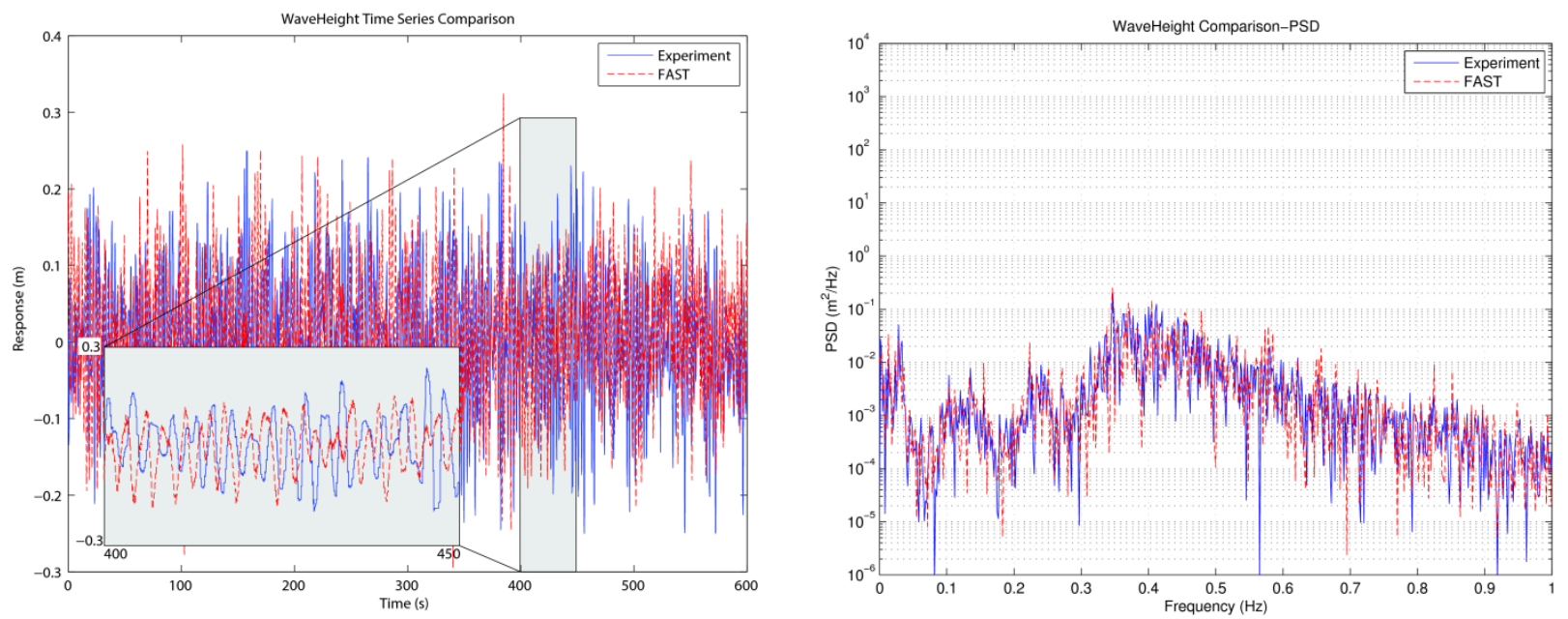

Figure 26. Wave height comparison (Nonop Case 1)
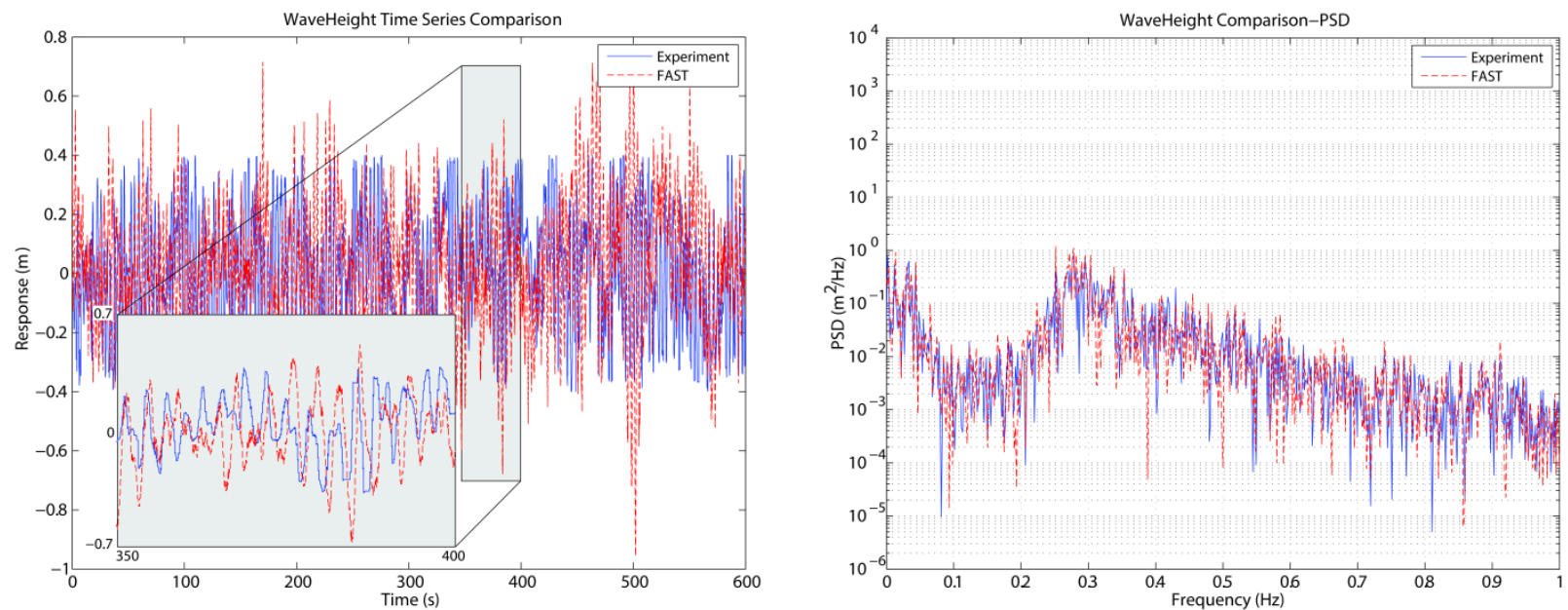

Figure 27. Wave height comparison (Nonop Case 2)

This report is available at no cost from the National Renewable Energy Laboratory (NREL) at www.nrel.gov/publications. 


\subsubsection{Results}

Table 17 and 18 show the mean and standard deviation values for the pitch, surge, roll, and sway motions of the wind turbine over the 10-min period for Nonop Case 1 and Nonop Case 2, respectively. The corresponding power spectral density (PSD) plots are shown in Figure 28 and Figure 29.

Table 17. Mean and Standard Deviation for DOFs for the Nonop Case 1

\begin{tabular}{l|lll}
\hline DOFs & Experiment & $\begin{array}{l}\text { FAST (with } \\
\text { Tower Load) }\end{array}$ & $\begin{array}{l}\text { FAST (w/o } \\
\text { Tower Load) }\end{array}$ \\
\hline Pitch (Mean) & $2.38470^{\circ}$ & $3.12673^{\circ}$ & $2.23870^{\circ}$ \\
Pitch (Std) & $0.81103^{\circ}$ & $0.86218^{\circ}$ & $0.60963^{\circ}$ \\
Surge (Mean) & $1.81859 \mathrm{~m}$ & $0.92096 \mathrm{~m}$ & $0.64828 \mathrm{~m}$ \\
Surge (Std) & $0.22220 \mathrm{~m}$ & $0.26364 \mathrm{~m}$ & $0.18665 \mathrm{~m}$ \\
Roll (Mean) & $-0.19097^{\circ}$ & $-0.01335^{\circ}$ & $-0.00286^{\circ}$ \\
Roll (Std) & $0.822535^{\circ}$ & $0.30514^{\circ}$ & $0.270413^{\circ}$ \\
Sway (Mean) & $1.54107 \mathrm{~m}$ & $-0.01370 \mathrm{~m}$ & $-0.01166 \mathrm{~m}$ \\
Sway (Std) & $0.25466 \mathrm{~m}$ & $0.08878 \mathrm{~m}$ & $0.07700 \mathrm{~m}$ \\
\hline
\end{tabular}

Table 18. Mean and Standard Deviation for DOFs for the Nonop Case 2

\begin{tabular}{l|lll}
\hline DOFs & Experiment & $\begin{array}{l}\text { FAST (with } \\
\text { Tower Load) }\end{array}$ & $\begin{array}{l}\text { FAST (w/o Tower } \\
\text { Load) }\end{array}$ \\
\hline Pitch (Mean) & $10.73092^{\circ}$ & $7.35102^{\circ}$ & $5.13869^{\circ}$ \\
Pitch (Std) & $2.02462^{\circ}$ & $2.20998^{\circ}$ & $1.87538^{\circ}$ \\
Surge (Mean) & $2.84368 \mathrm{~m}$ & $2.18756 \mathrm{~m}$ & $1.52206 \mathrm{~m}$ \\
Surge (Std) & $0.52778 \mathrm{~m}$ & $0.61528 \mathrm{~m}$ & $0.52537 \mathrm{~m}$ \\
Roll (Mean) & $-1.86967^{\circ}$ & $-0.12633^{\circ}$ & $-0.10568^{\circ}$ \\
Roll (Std) & $2.04729^{\circ}$ & $0.65069^{\circ}$ & $0.63543^{\circ}$ \\
Sway (Mean) & $1.02630 \mathrm{~m}$ & $0.04125 \mathrm{~m}$ & $0.03307 \mathrm{~m}$ \\
Sway (Std) & $0.56352 \mathrm{~m}$ & $0.18503 \mathrm{~m}$ & $0.17650 \mathrm{~m}$ \\
\hline
\end{tabular}



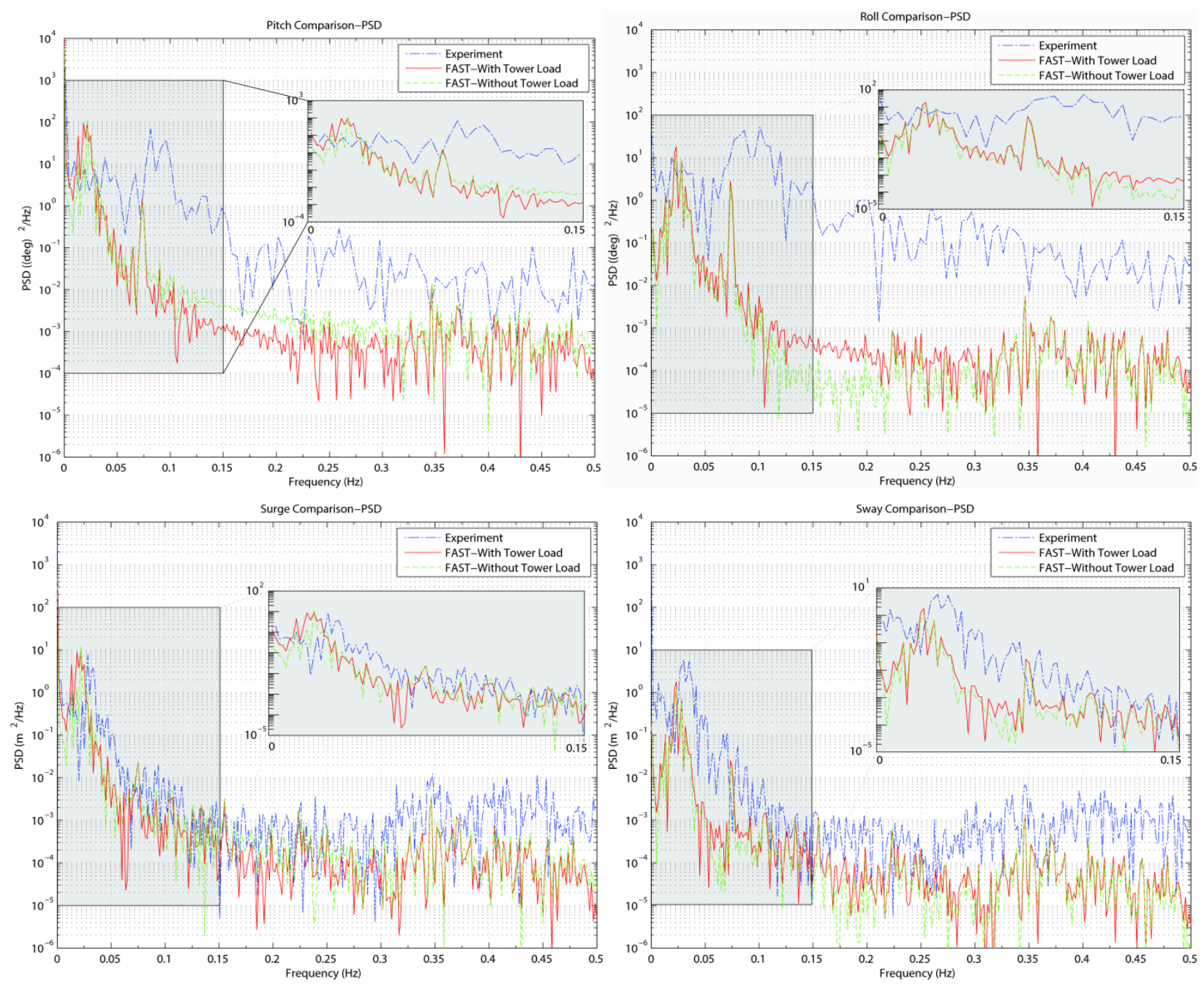

Figure 28. Summary of results for Nonop Case 1

This report is available at no cost from the National Renewable Energy Laboratory (NREL) at www.nrel.gov/publications. 

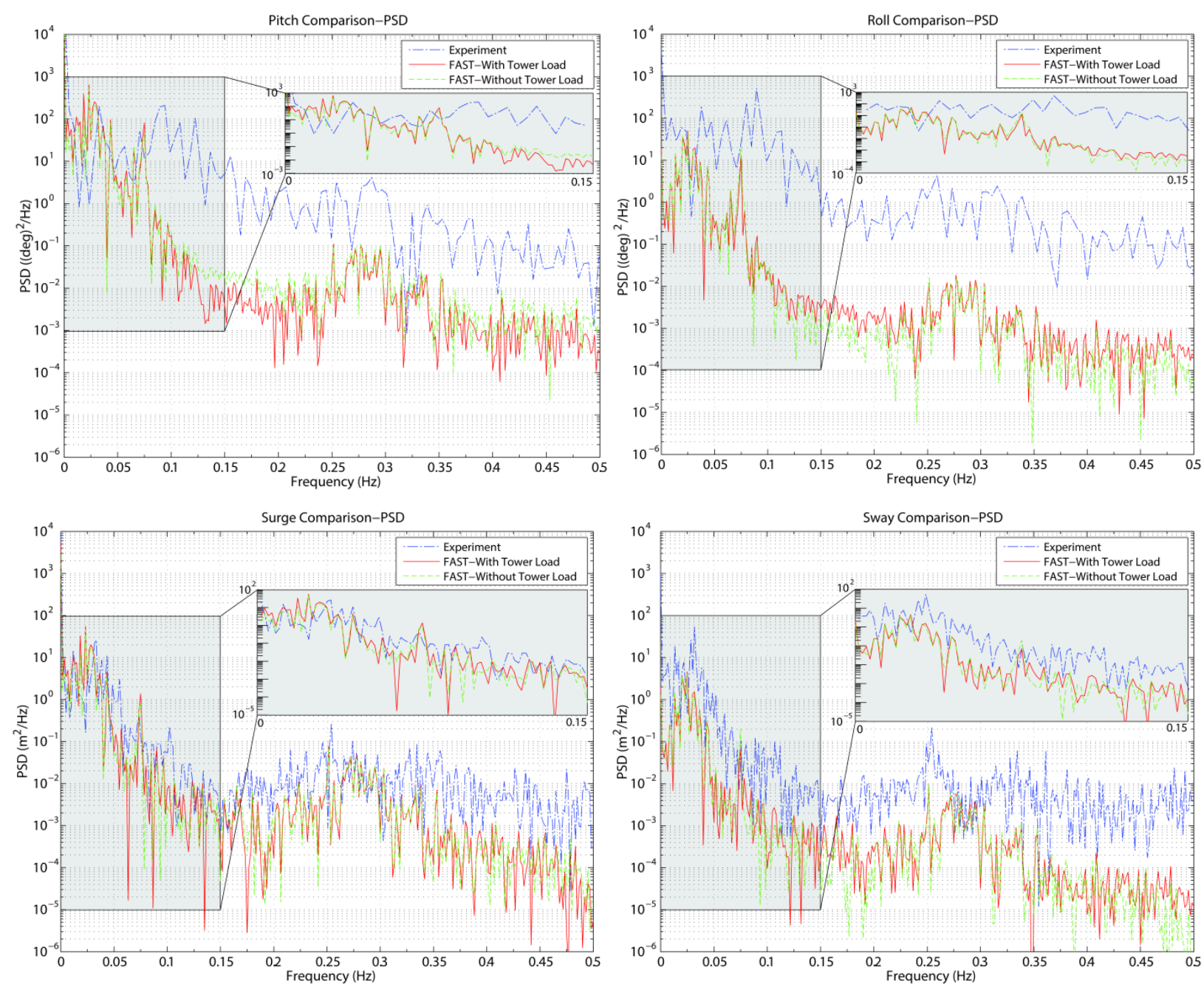

Figure 29. Summary of results for Nonop Case 2

\subsubsection{Tower Loading versus No Tower Loading}

For the Nonop Case 1, one can observe from Table 17 that the mean pitch increased from $2.24^{\circ}$ without tower loading to $3.13^{\circ}$ with tower loading, and the mean surge also increased from 0.65 $\mathrm{m}$ to $0.92 \mathrm{~m}$. The standard deviation of pitch and surge increased from $0.61^{\circ}$ to $0.86^{\circ}$ and $0.19 \mathrm{~m}$ to $0.26 \mathrm{~m}$, respectively. For the Nonop Case 2, one can observe from Table 18 that the mean pitch increased from $5.14^{\circ}$ without tower loading to $7.35^{\circ}$ with tower loading and the mean surge also increased from $1.52 \mathrm{~m}$ to $2.19 \mathrm{~m}$. The standard deviations of pitch and surge increased from $1.88^{\circ}$ to $2.21^{\circ}$ and $0.53 \mathrm{~m}$ to $0.62 \mathrm{~m}$, respectively. These data show wind loading does have a significant effect on the dynamics of the SWAY turbine.

The wind is more dominant in the surge/pitch direction of the system and there are minor crosswind effects on the system. The minor crosswind effects are reflected in the small increases in the mean and standard deviation values of the roll and sway values shown in Table 17 and 18.

From Figure 28 and Figure 29, one can observe that the inclusion of the wind loading on the tower does not affect the PSD plots significantly. Only minor increases throughout the entire 
range of frequency for all DOFs are seen, because the wind inflow generated from TurbSim is random and generally decays with increasing frequency.

\subsubsection{Experiment versus Simulation}

When comparing the simulated data with experimental data, it can be observed from Table 17 and 18 that simulating the wind loading on the tower increased the accuracy of the results for the surge and pitch component for the nonoperating cases.

For both cases, it can be observed from Table 17 and 18 that the roll and sway simulation data significantly deviated from the experimental observations. This could be caused by either

(1) unmodeled current or wave components coming from the non-dominant direction or

(2) unmodeled cross-wind components.

The difference in magnitude between simulation and experiment for the PSD plots in the Nonop Case 1 and 2 is quite significant, and it may be a result of experimental noise in the measurements. In particular, the pitch and roll PSD plots are similar in the lower frequencies, but the magnitude is much larger for the experiment in the higher frequencies. This lack of damping in the higher frequencies is unusual and the reason for it is not understood at this point, but it could be a consequence of compliance in the universal joint, flexibility of the system (whereas the simulations assume the body to be rigid), or complexity of the wind and wave conditions (such as reflected wave patterns or currents).

In the frequency domain for the Nonop Case 1, the simulated data shows significant frequency peaks at $0.023 \mathrm{~Hz}, 0.073 \mathrm{~Hz}$, and $0.347 \mathrm{~Hz}$ (see Figure 28). The $0.023-\mathrm{Hz}$ and $0.347-\mathrm{Hz}$ frequency peaks are aligned with the wave conditions, where the wave spectrum shows corresponding peaks at $0.028 \mathrm{~Hz}$ and $0.347 \mathrm{~Hz}$. The first pitch/roll natural frequency of the system is also near $0.02 \mathrm{~Hz}$. The $0.073-\mathrm{Hz}$ frequency peak is then the second roll/pitch natural frequency, which was discussed in Section 6.2. For the experimental data, the peaks occur at about $0.03 \mathrm{~Hz}, 0.082$, and $0.34 \mathrm{~Hz}$, and they are less defined but are observable in the PSD plots. The natural frequencies of the system have shifted a bit, and this is likely due to a change in tidal conditions.

For the Nonop Case 2, the simulated data show significant frequency peaks at $0.025 \mathrm{~Hz}, 0.075$ $\mathrm{Hz}$, and $0.278 \mathrm{~Hz}$ (see Figure 29). The $0.025-\mathrm{Hz}$ and $0.278-\mathrm{Hz}$ frequency peaks are influenced by the wave conditions as observed in the wave spectrum, showing corresponding peaks at 0.030 $\mathrm{Hz}$ and $0.278 \mathrm{~Hz}$. The $0.025 \mathrm{~Hz}$ peak is also near the first pitch natural frequency of the system, whereas the $0.075-\mathrm{Hz}$ frequency peak is close to the second pitch natural frequency. For the experimental data, the peaks at about $0.03 \mathrm{~Hz}$ and $0.25 \mathrm{~Hz}$ are influenced by the wave conditions, while the natural frequencies of the system have shifted to about 0.03 and $0.089 \mathrm{~Hz}$.

\subsubsection{Simulation Issues and Assumptions}

Some further reasons for the differences between the experimental and simulated results are reviewed here.

For an offshore floating wind turbine, the wind loads on the tower are expected to contribute significantly to the response of the system. The first round of simulations were run using the original version of FAST v7 and AeroDyn 13 that does not account for these tower loads. After 
making the code changes described in Section 3.1, wind loads are accounted for and the difference in the results is shown in the results simulation.

During the model building stage, the transition from tower to platform was set at MSL, as discussed previously. The simulations were conducted at MSL even though the tide level changes for different data sets. It is not possible to directly represent this tidal variation within FAST without making large changes to the input files, and tidal variation was therefore ignored in the analysis. The tide level, however, could have a strong influence on the system behavior, as it will change the displacement of the structure and therefore the stiffness in the mooring line, which will in turn affect the pitch/roll motion of the structure.

After the de-commissioning of the turbine in December 2013, some water was detected in one of the built-in ballast tanks positioned just below MSL (assumed to be emptied in the FAST model). As a result, the water in the ballast tank may have raised the center of gravity above what has been assumed, which in turn causes an increase of the pitch and roll periods.

The tower was modeled as a rigid body, which could result in unmodeled dynamics of the system. Additionally, the stiffness of the flexible body is larger in the fore-aft direction than sideside due to the positioning of the tension wires and spreader beams, which is not accounted for in the rigid model.

The mean wave and current direction data provided from the AWAC were averaged to 1-hr readings, which may cause inaccuracy in the simulation results as wave and current properties may differ significantly within the 1-hr sampling period. Also, the AWAC was located about $12.5 \mathrm{~m}$ from the wind turbine system in areas close to rock and varying seabed conditions. These circumstances reduced the confidence in the wave and current data obtained. The FAST simulation was therefore conducted in no current conditions.

From the wave verification results, it is also observed that the wave spectrum at the SWAY location may be bi-modal and multi-directional, which is likely due to the close proximity of the system to the shore. From both the AWAC and the tower wave height sensor, it was only possible to define the dominant peak period, significant wave height and wave direction but not these values for all the different wave modes. Even if the full wave definitions were available, FAST v7 does not allow users to represent multi-directional waves.

\subsection{Operating Conditions}

\subsubsection{Selection of Test Case}

After validation of nonoperational conditions, validation was performed for two operating conditions: one 5-min test condition in control region II (Op Case 1) and one 10-min operational test case in control region III (Op Case 2). Op Case 1 was used instead of a usual 10-min test case due to the short duration of consistent rotor speed with no blade pitch angle changes. Op Case 2 was selected due to the stable wind velocity and rotor speed over an extended period of time. As the control algorithm from the real system was not available in the numerical model, this test case was also selected due to its limited variations in blade pitch angle to minimize the effects of the lack of control system. For Op Case 1, the system operated at an average rotor speed of 22.27 RPM with an average wind speed of $3.53 \mathrm{~m} / \mathrm{s}$ measured at the anemometer height. For Op Case 2, the system had an average rotor speed of 33.67 RPM with a mean wind 
speed of $7.32 \mathrm{~m} / \mathrm{s}$. The measured time series data of the rotor speed and blade pitch angle is shown in Figure 30, whereas the wind, wave, and current conditions are shown in Figure 31.
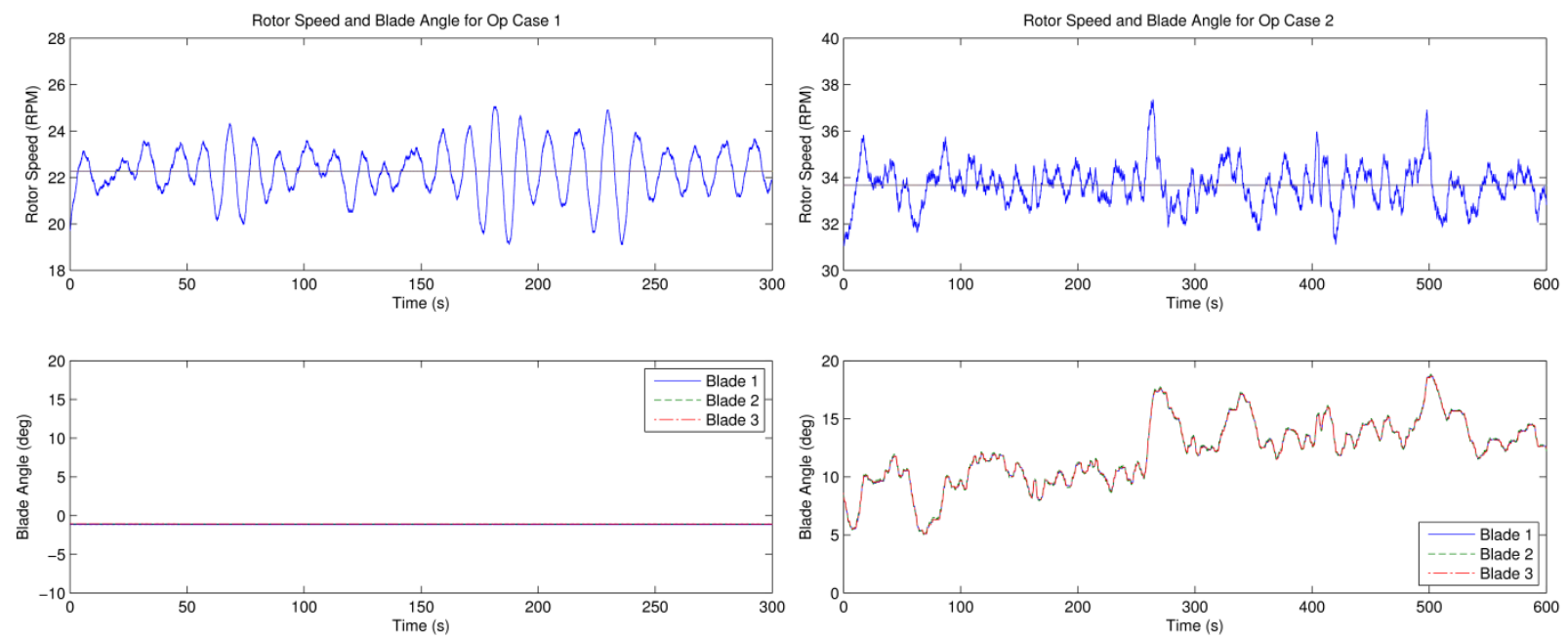

Figure 30. Rotor speed and blade pitch angle for operating cases

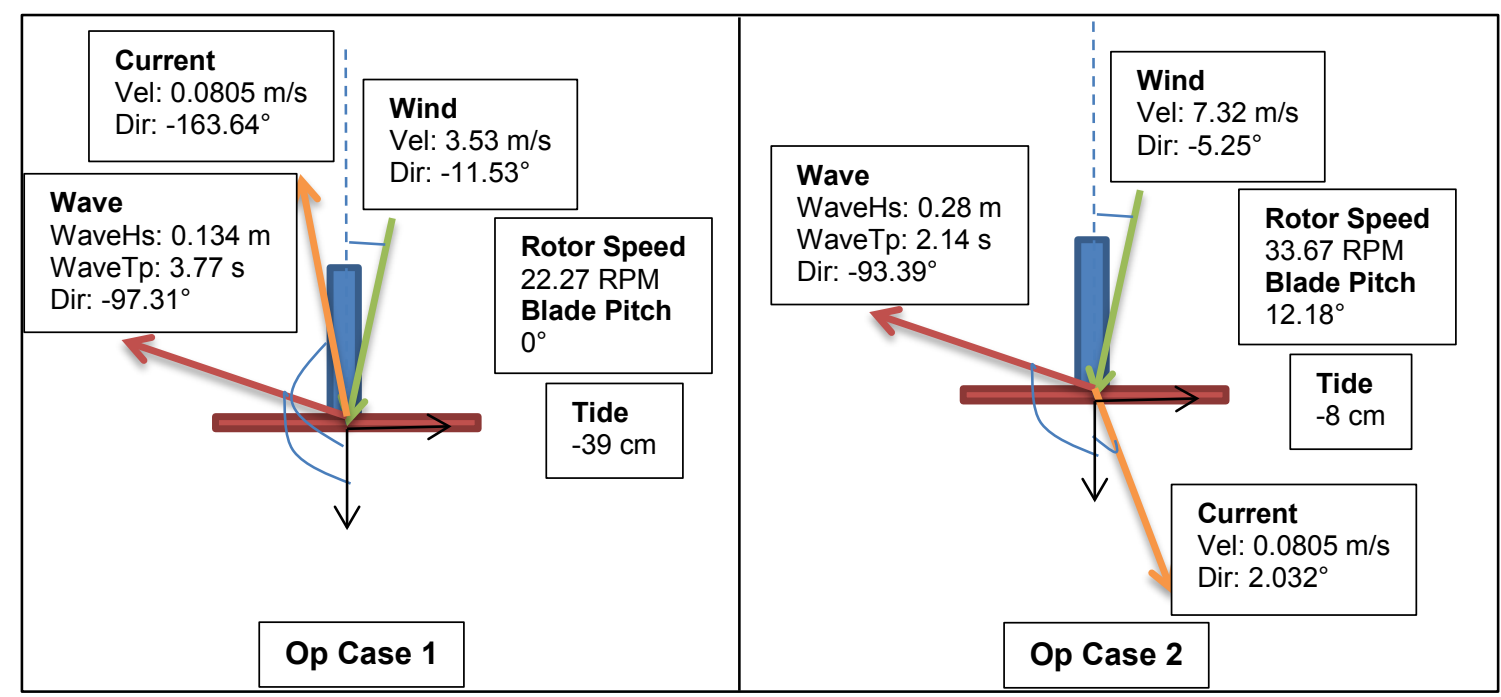

Figure 31. Summary of operational test cases

\subsubsection{Simulation Procedure}

The system was first set at an equilibrium position calculated from a simulation of the static equilibrium. For the region II test case, the FAST simulation was conducted for a simulation time of $600 \mathrm{~s}$ (10 minutes), and the first 5 minutes of the simulation were discarded. For the region III test case, the simulation was conducted for a simulation time of 1,200 s (20 minutes), and the first 10 minutes of the simulation were discarded. This is to remove any initial transient behavior. 


\subsubsection{Wind}

As with the nonoperating cases, the wind inflow file used by AeroDyn was generated using TurbSim with the settings shown in Table 19. These settings were based on measurements obtained from the ultrasonic anemometer attached to the boom. The usable analysis time was set at $600 \mathrm{~s}$ for the region II test case and 1,200 s for the region III test case. The turbulence model was assumed to follow the IEC Kaimal spectral normal turbulence model, and the turbulence intensity and reference wind speed were derived from sonic anemometer readings of wind speed at $12.5 \mathrm{~m}$.

Table 19. TurbSim Wind Inflow Properties for Operating Cases

\begin{tabular}{l|l|l}
\hline & Op Case 1 & Op Case 2 \\
\hline Vertical grid-point matrix dimension & 51 & \\
Horizontal grid-point matrix dimension & 61 & \\
Hub height [m] & 13.133 & \\
Grid height [m] & 20.000 & $12.087 \%$ \\
Grid width [m] & 25.000 & 7.325 \\
Turbulence model & IEC Kaimal spectral normal turbulence model \\
\cline { 2 - 3 } Turbulence intensity & $15.311 \%$ & \\
\cline { 2 - 3 } Reference wind speed [m/s] & 3.527 & \\
\cline { 2 - 3 } Reference height of anemometer [m] & 12.500 & \\
Wind profile type & IEC, Power law on rotor disk, logarithmic elsewhere \\
Power law exponent & 0.140 & \\
Surface roughness length [m] & 0.030 & \\
\hline
\end{tabular}

As with the nonoperating cases, the mean and standard deviation of the wind inflow velocity for the experiment shows good comparison with the wind inflow generated by TurbSim, with a slightly larger mean for the experimental data. Summaries of the measured and simulated wind properties for both test cases is shown in Table 20 and Table 21, and Figure 32 and Figure 33 show the time domain comparison for the wind inflow velocity for downwind and crosswind directions for both FAST and experimental data.

Table 20. Comparison of Wind Properties for Op Case 1

\begin{tabular}{l|llll}
\hline & Mean (Exp) & Mean (FAST) & Std. Dev.(Exp) & Std. Dev. (FAST) \\
\hline$U(\mathrm{~m} / \mathrm{s})$ & 3.5071 & 3.5814 & 0.5240 & 0.3929 \\
$V(\mathrm{~m} / \mathrm{s})$ & -0.6216 & -0.7900 & 0.5082 & 0.3965 \\
\hline
\end{tabular}


Table 21. Comparison of Wind Properties for Op Case 2

\begin{tabular}{l|llll}
\hline & Mean (Exp) & Mean (FAST) & Std. Dev.(Exp) & Std. Dev. (FAST) \\
\hline$U(\mathrm{~m} / \mathrm{s})$ & 7.1336 & 7.3681 & 0.8922 & 0.8525 \\
$V(\mathrm{~m} / \mathrm{s})$ & -0.7231 & -0.5817 & 0.6683 & 0.6344 \\
\hline
\end{tabular}
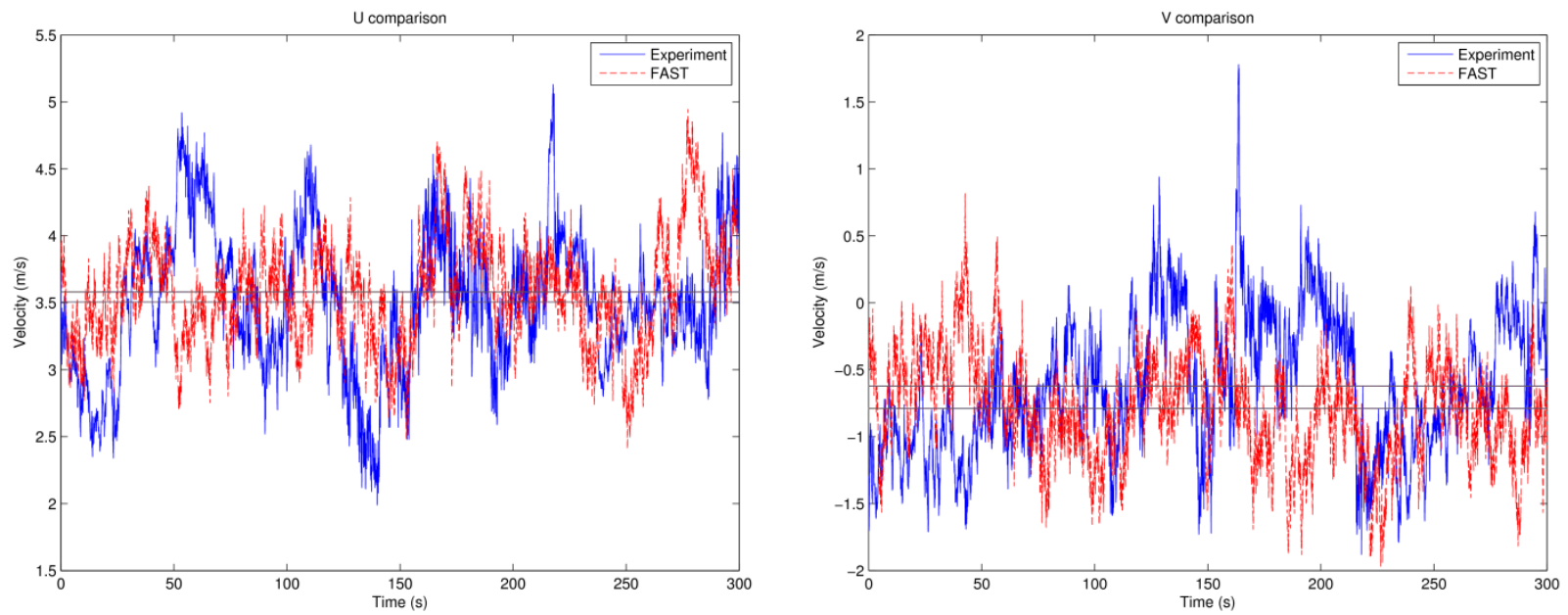

Figure 32. Velocity inflow comparison (Op Case 1)
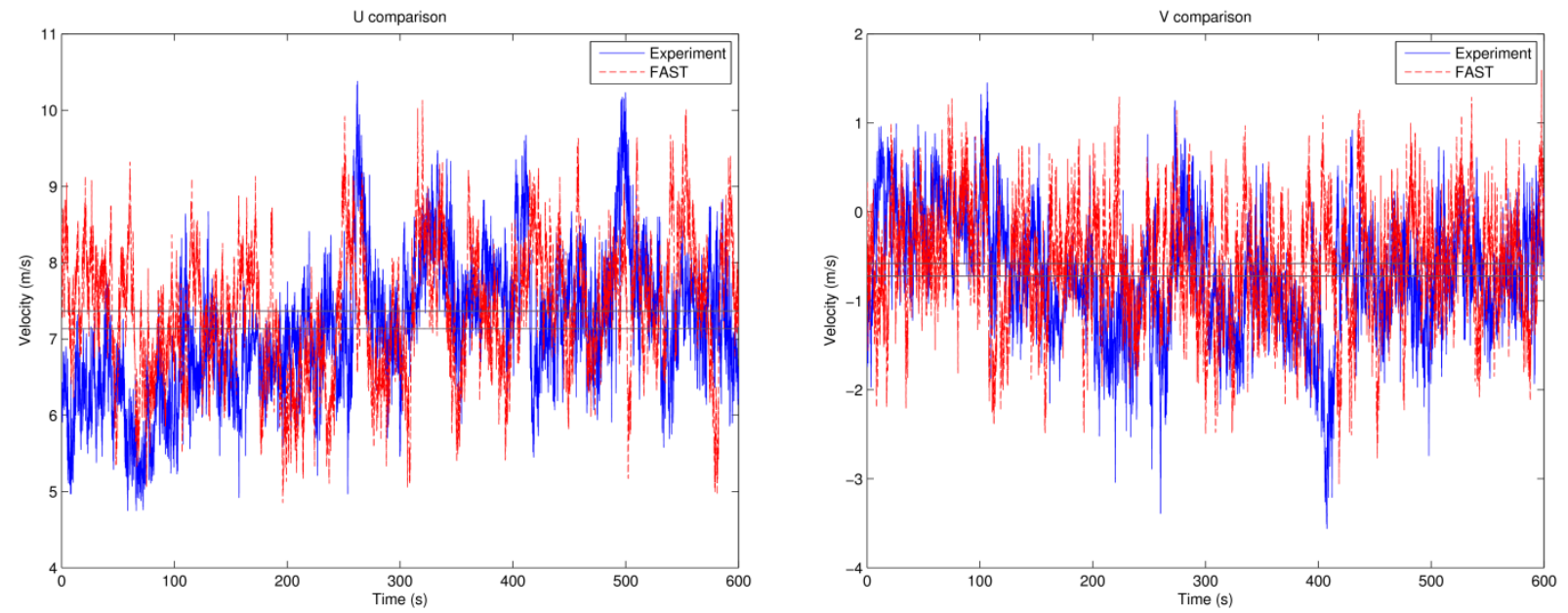

Figure 33. Velocity inflow comparison (Op Case 2)

\subsubsection{Waves}

For each simulation case, a user-defined wave spectrum was inputted into FAST from 5-min wave height data for Op Case 1 and 10-min wave height data for Op Case 2, which were obtained from the tower wave height sensor. The mean wave direction was obtained from the 1$\mathrm{hr}$ averaged data observed by the AWAC. This process was done for both cases; the time- and frequency-domain comparisons of the waves generated in FAST and the experimental data are shown in Figure 34 and Figure 35. 

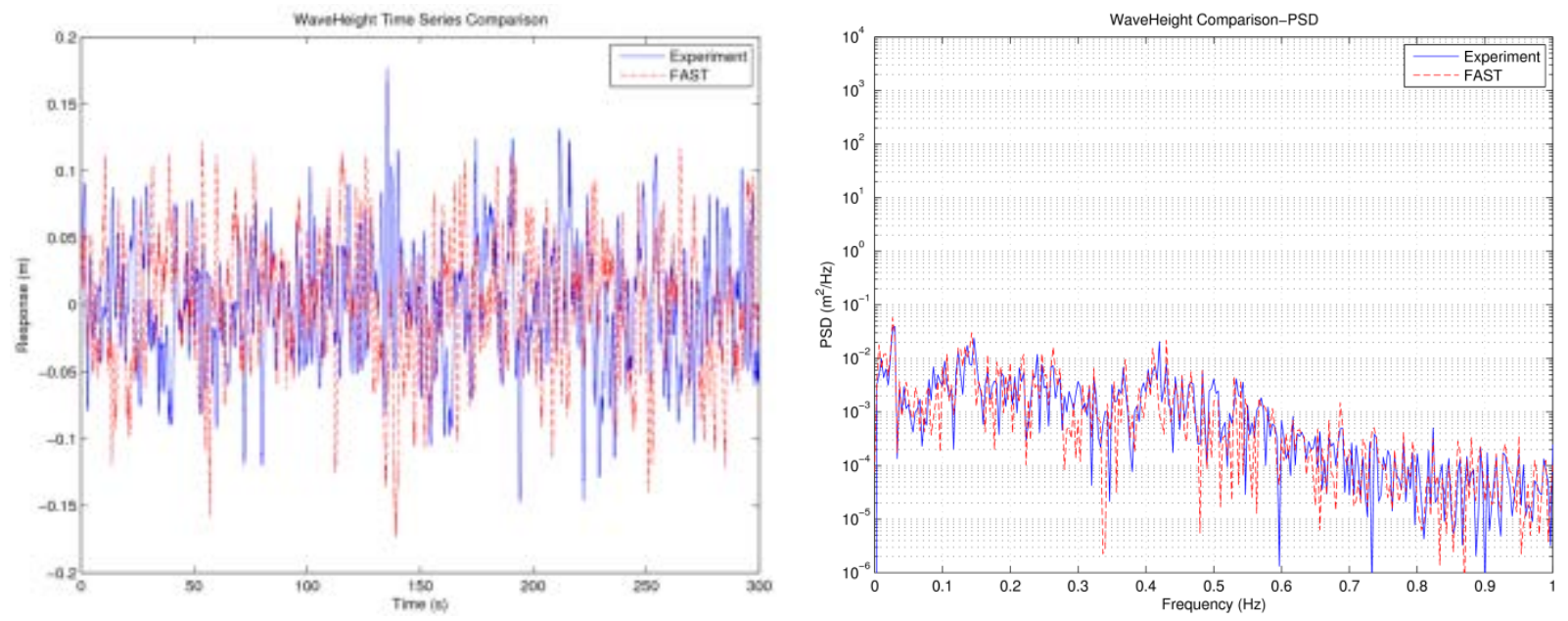

Figure 34. Wave height comparison (Op Case 1)
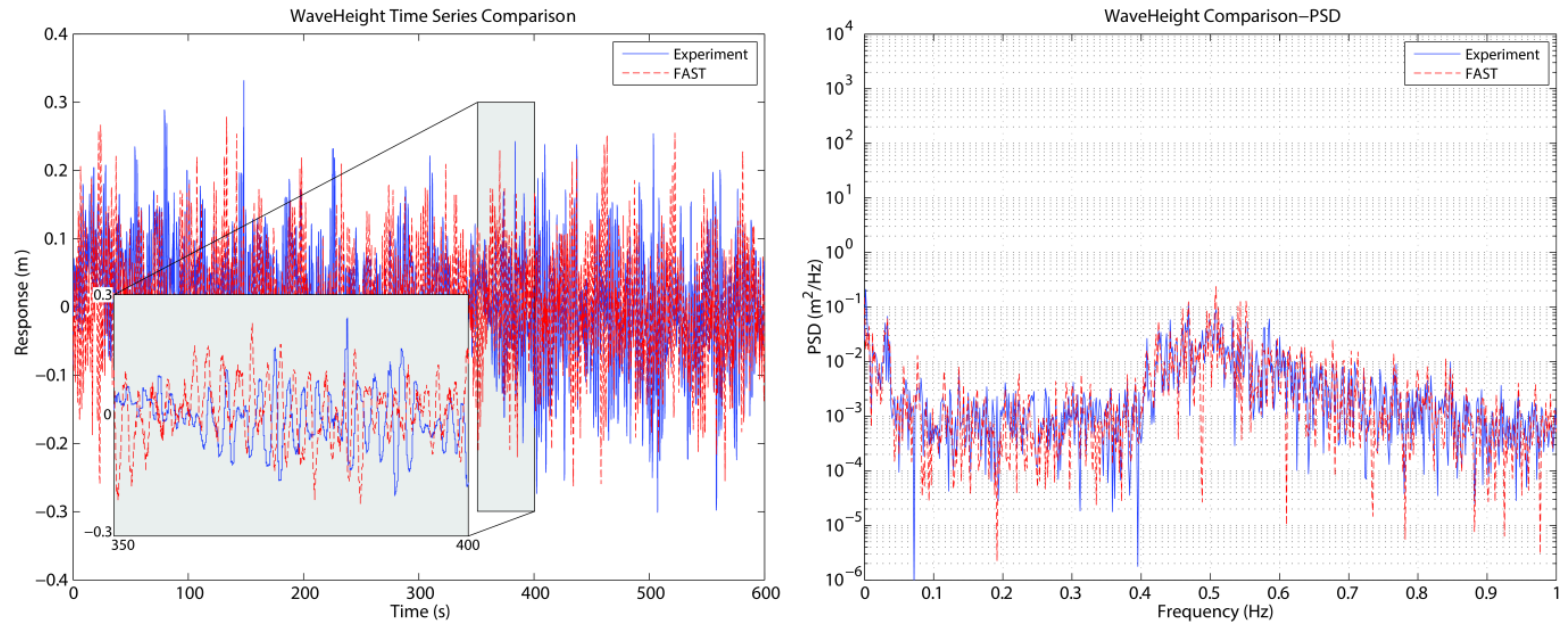

Figure 35. Wave height comparison (Op Case 2)

\subsubsection{Simulation Assumptions}

In addition to the issues discussed in Section 7.1.5 in the nonoperating cases, it was assumed for the FAST simulations that the rotor speed operates at a constant rotor speed and blade pitch angle for both cases. Constant values were used because control algorithms for the blade pitch and generator speed were unavailable. The lack of control will result in significant differences between the simulation and experiment.

\subsubsection{Results}

Table 22 and Table 23 show the mean and standard deviation values for the pitch, surge, roll, and sway motions of the wind turbine over the 5-min period for Op Case 1 and the 10-min period for Op Case 2. The corresponding PSD plots are shown in Figure 36 and Figure 37. 
Table 22. Mean and Standard Deviation for DOFs for the Op Case 1

\begin{tabular}{l|lll}
\hline DOFs & Experiment & $\begin{array}{l}\text { FAST (with } \\
\text { Tower Load) }\end{array}$ & $\begin{array}{l}\text { FAST (w/o } \\
\text { Tower Load) }\end{array}$ \\
\hline Pitch (Mean) & $11.33967^{\circ}$ & $7.87317^{\circ}$ & $7.32953^{\circ}$ \\
Pitch (Std) & $1.35566^{\circ}$ & $1.033019^{\circ}$ & $0.93576^{\circ}$ \\
Surge (Mean) & $1.13291 \mathrm{~m}$ & $2.47827 \mathrm{~m}$ & $2.31766 \mathrm{~m}$ \\
Surge (Std) & $0.42099 \mathrm{~m}$ & $0.27074 \mathrm{~m}$ & $0.23966 \mathrm{~m}$ \\
Roll (Mean) & $0.84450^{\circ}$ & $-2.89152^{\circ}$ & $-2.77953^{\circ}$ \\
Roll (Std) & $0.53510^{\circ}$ & $0.88706^{\circ}$ & $0.85878^{\circ}$ \\
Sway (Mean) & $-3.86009 \mathrm{~m}$ & $-0.12162 \mathrm{~m}$ & $-0.08808 \mathrm{~m}$ \\
Sway (Std) & $0.16942 \mathrm{~m}$ & $0.29393 \mathrm{~m}$ & $0.288766 \mathrm{~m}$ \\
\hline
\end{tabular}

Table 23. Mean and Standard Deviation for DOFs for the Op Case 2

\begin{tabular}{l|lll}
\hline DOFs & Experiment & $\begin{array}{l}\text { FAST (with } \\
\text { Tower Load) }\end{array}$ & $\begin{array}{l}\text { FAST (w/o } \\
\text { Tower Load) }\end{array}$ \\
\hline Pitch (Mean) & $12.90595^{\circ}$ & $13.95103^{\circ}$ & $12.69992^{\circ}$ \\
Pitch (Std) & $1.05561^{\circ}$ & $2.63459^{\circ}$ & $2.54336^{\circ}$ \\
Surge (Mean) & $6.76051 \mathrm{~m}$ & $4.03822 \mathrm{~m}$ & $3.69268 \mathrm{~m}$ \\
Surge (Std) & $0.34020 \mathrm{~m}$ & $0.72369 \mathrm{~m}$ & $0.71435 \mathrm{~m}$ \\
Roll (Mean) & $1.63395^{\circ}$ & $-1.43630^{\circ}$ & $-1.30943^{\circ}$ \\
Roll (Std) & $0.66471^{\circ}$ & $0.98300^{\circ}$ & $1.03791^{\circ}$ \\
Sway (Mean) & $0.31973 \mathrm{~m}$ & $-0.32309 \mathrm{~m}$ & $-0.29564 \mathrm{~m}$ \\
Sway (Std) & $0.19840 \mathrm{~m}$ & $0.18473 \mathrm{~m}$ & $0.19001 \mathrm{~m}$ \\
\hline
\end{tabular}



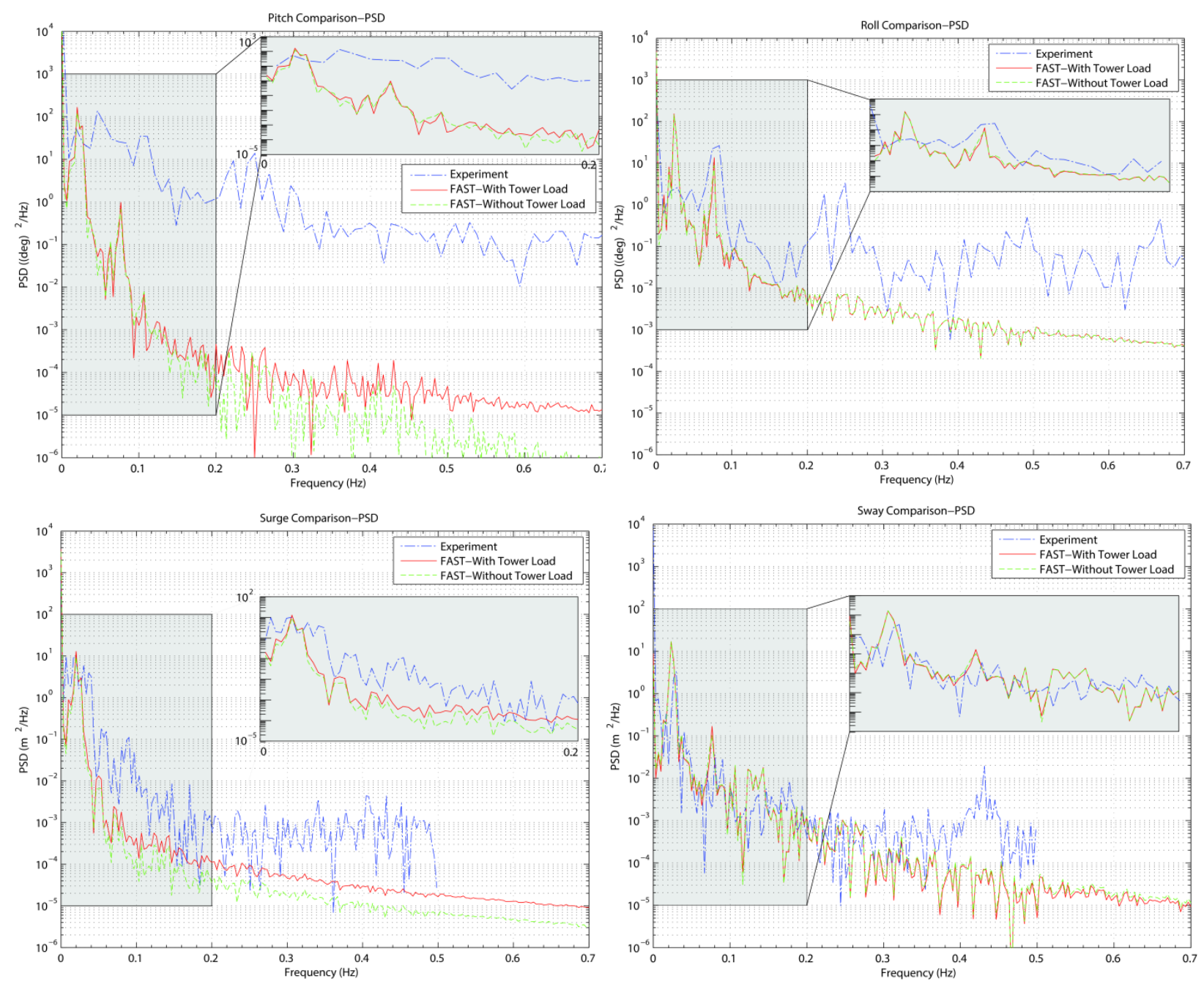

Figure 36. Summary of results for Op Case 1

This report is available at no cost from the National Renewable Energy Laboratory (NREL) at www.nrel.gov/publications. 

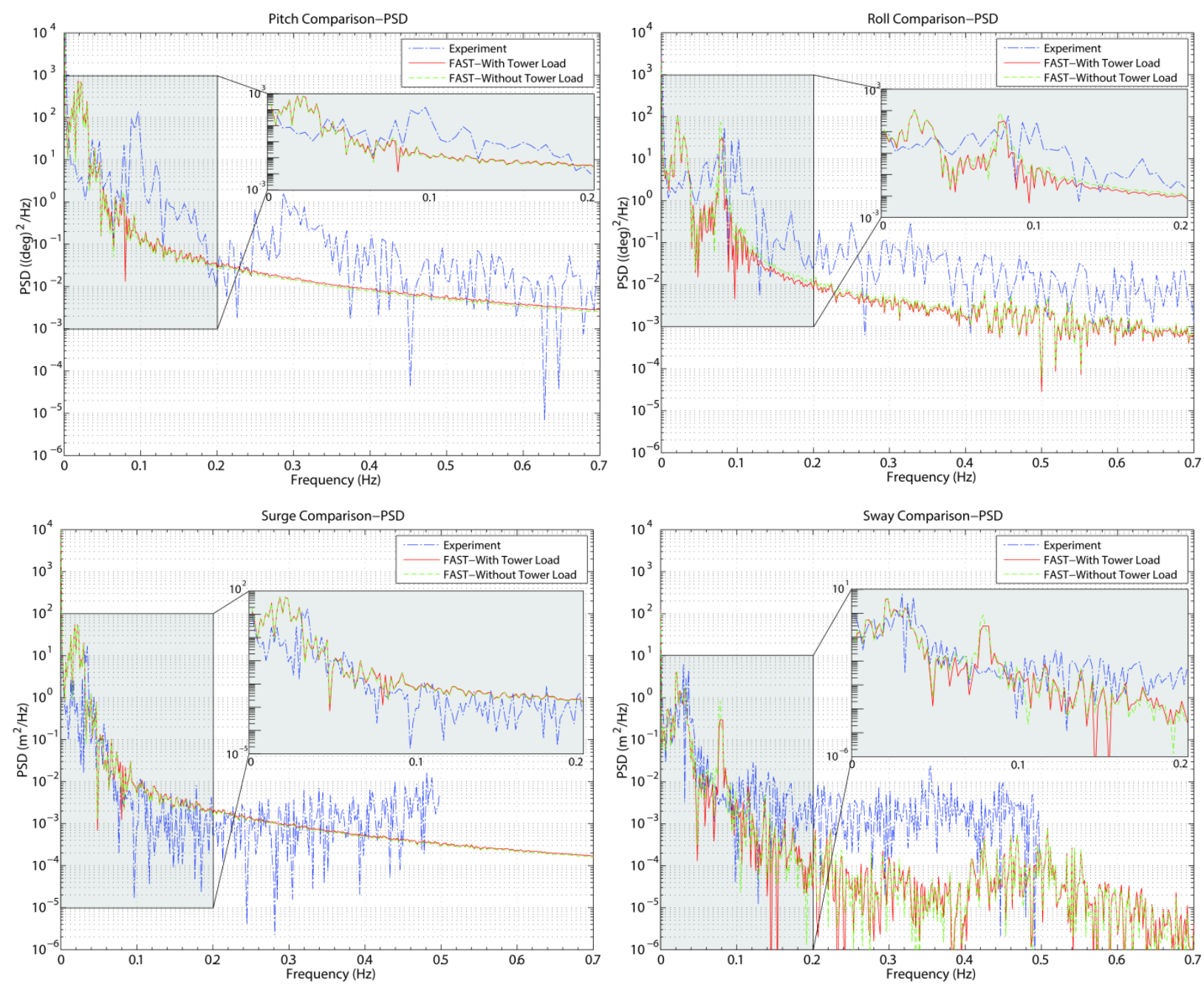

Figure 37. Summary of results for Op Case 2

\subsubsection{Global Dynamics Observations}

\subsubsection{Tower Loading vs. No Tower Loading}

For Case 1 in Table 22, it can be observed that mean pitch increased from $7.33^{\circ}$ without tower loading to $7.87^{\circ}$ with tower loading, and the mean surge increased from $2.32 \mathrm{~m}$ to $2.48 \mathrm{~m}$. The standard deviation of pitch and surge increased from $0.61^{\circ}$ to $86^{\circ}$ and from $0.19 \mathrm{~m}$ to $026 \mathrm{~m}$ respectively. Similarly for Op Case 2 in Table 23 , the mean pitch increased from $12.70^{\circ}$ to $13.95^{\circ}$ and the mean surge increased from 3.69 to $4.04 \mathrm{~m}$ upon introducing wind loading to the tower. This increase is less significant than it was in the Nonop cases, as the dominant loading of the wind turbine system occurs on the wind turbine blades.

Similar to the nonoperating cases, the wind is more dominant in the surge/pitch direction of the system and there are minor crosswind effects on the system. This is reflected in the small increases in the mean and standard deviation values of the roll and sway values shown in Tables 22 and 23. The inclusion of the wind loading on the tower does not affect the PSD plots significantly in Figure 36 and Figure 37. 


\subsubsection{Experiment versus Simulation}

When comparing the simulated data with experimental data, it can be observed from Table 22 and Table 23 that simulating the wind loading on the tower increased the accuracy of the results for the surge and pitch component for the operational cases. The improvement of accuracy is less evident in the results in the nonoperational cases. Also, for the Op Case 2 in Table 23, the standard deviations for pitch and surge were less for the experiment than they were for the simulation. This is probably because the control system in the experiment reduces the variations of the thrust loads on the rotor, which again reduces the tower motions. This is confirmed by the better comparison of results from Op Case 1 in Table 22, which was in control region II.

For both cases, Table 22 and Table 23 show that the roll and sway simulation data significantly deviate from the experimental observations. The reason for these deviations are similar to those for the nonoperating case, in which no current conditions were set for the simulation and wave directions for the different wave modes were not represented well. In addition, from the experimental data for Op Case 1, a larger mean value was observed for sway $(-3.86 \mathrm{~m})$ than roll $\left(0.84^{\circ}\right)$, and a smaller mean value was observed for surge $(1.13 \mathrm{~m})$ than pitch $\left(11.34^{\circ}\right)$. This leads the authors to suspect that the surge and sway data that are derived from the GPS measurements may contain GPS drift errors.

In the frequency domain for the Op Case 1, the simulated data show significant frequency peaks at $0.023 \mathrm{~Hz}$ and $0.077 \mathrm{~Hz}$ (see Figure 36). The $0.023-\mathrm{Hz}$ frequency peak is influenced by the natural frequency of the system and the wave conditions, where the wave spectrum in Figure 26 showed a corresponding peak at $0.03 \mathrm{~Hz}$. The $0.077-\mathrm{Hz}$ frequency peak is due to the second natural frequency of the entire system in roll and pitch DOFs, as discussed in Section 6.2. For the experimental data, a peak occurred at about $0.02 \mathrm{~Hz}$ for all DOFs in the PSD plots that was due to wave conditions. An additional peak occurred for the roll and pitch DOFs at $0.250 \mathrm{~Hz}$ and for the surge and sway DOFs at $0.431 \mathrm{~Hz}$. These additional peaks were not observed in the simulation; they are also likely caused by the wave conditions. The second natural frequency of the system shifted to about $0.09 \mathrm{~Hz}$.

For the Op Case 2, the simulated data for all DOFs shows a significant frequency peak around $0.022 \mathrm{~Hz}$, which corresponds to the wave spectrum in Figure 27 with a peak at $0.033 \mathrm{~Hz}$. In the simulated data, another peak was more evident for the roll and sway DOFs around $0.08 \mathrm{~Hz}$. For the experimental data, a peak occurred at about $0.35 \mathrm{~Hz}$ for all DOFs that was due to wave conditions. Additional peak for roll and pitch DOFs at about $0.085 \mathrm{~Hz}$ was due to the natural frequency of the system. The wave frequency peak at about $0.5 \mathrm{~Hz}$ in Figure 27 influenced the sway and surge DOFs plots, but the observation is limited by the range of frequencies due to the sampling rate of the sensor.

\subsubsection{Blade Load Observations}

The loading on the blades was analyzed in the frequency domain using a FFT. Figure 38 to Figure 41 show the FFT analysis and comparison of the flapwise and edgewise loading on Blade 2. 
Table 24 and Table 25 list the blade frequencies observed in the analysis.

In the flapwise direction, 1P, 2P, and 3P frequencies were detected in the FFT plots in both experiment and simulation results. The first and second flapwise modal frequencies calibrated and analyzed in Section 6.3 were also observed.

For the edgewise loading, the 1P frequency and the first edgewise modal frequency analyzed in Section 6.3 were detected in the FFT analysis.

Although the frequencies showed fairly good correlation between experiment and simulation, the magnitude of the PSD was quite different. The assumption is that either the units of the blade loads were incorrect or the sensor connection was poor.
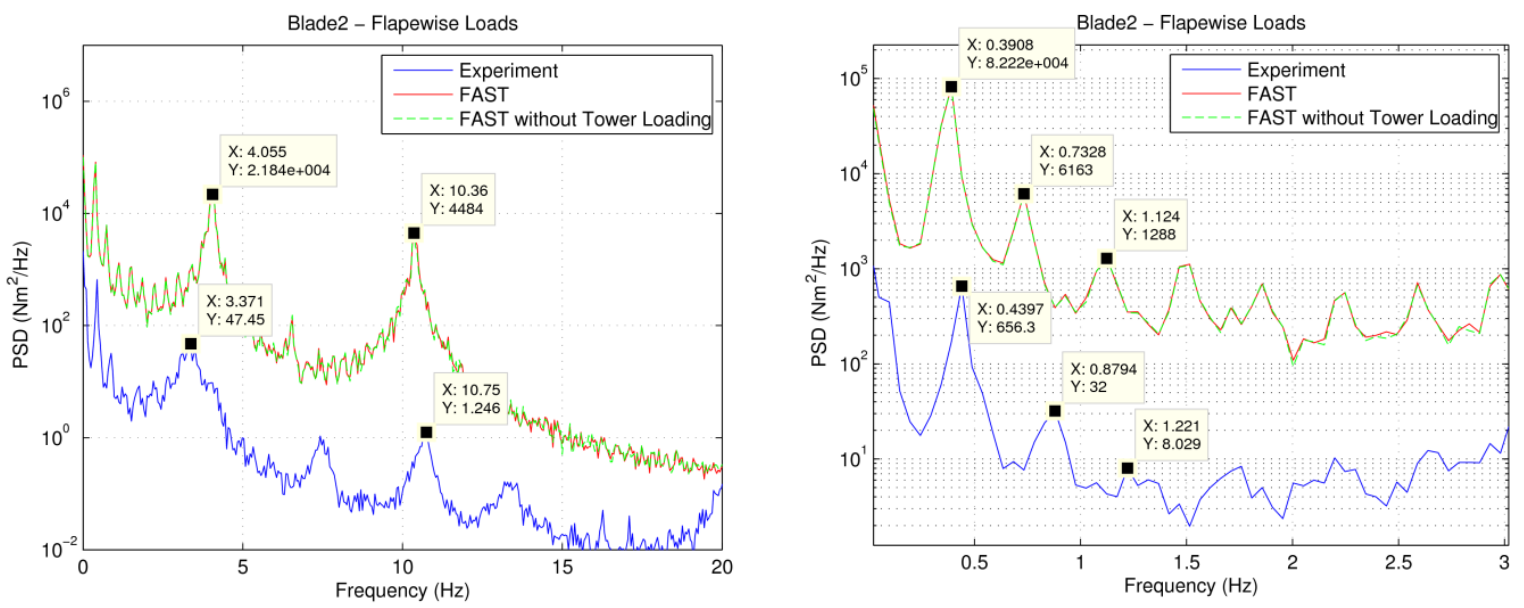

Figure 38. FFT analysis of the flapwise loading on Blade 2 for Op Case 1

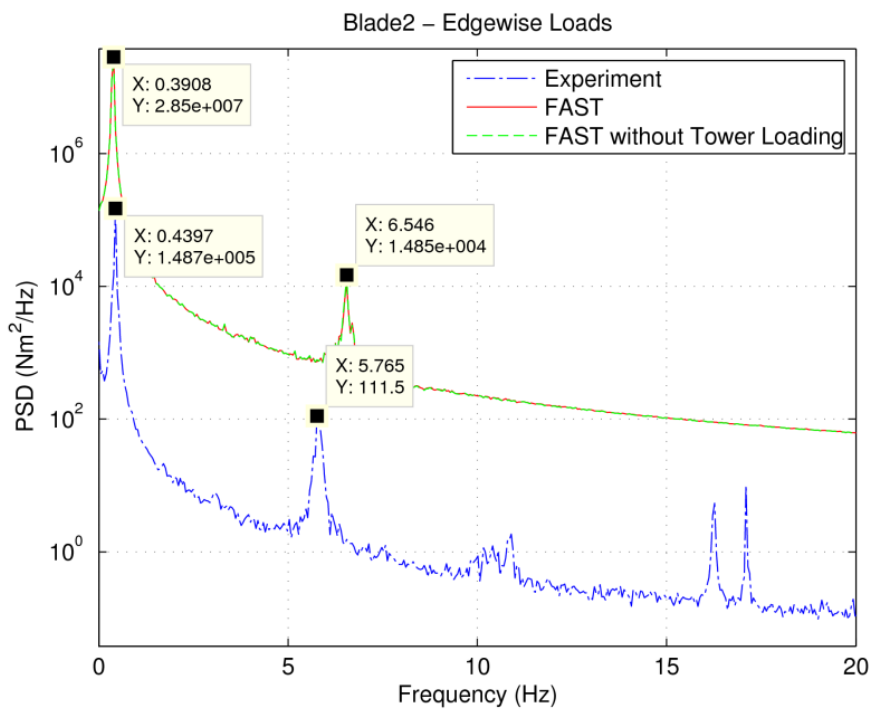

Figure 39. FFT analysis of the edgewise loading on Blade 2 for Op Case 1 
Table 24. Blade Frequencies $(\mathrm{Hz})$ Observed in Experiment and Simulation for Op Case 1

\begin{tabular}{l|llllll}
\hline & 1P & 2P & 3P & $\begin{array}{l}\text { Flapwise } \\
\mathbf{1}^{\text {st }} \text { Mode }\end{array}$ & $\begin{array}{l}\text { Flapwise } \\
\mathbf{2}^{\text {nd }} \text { Mode }\end{array}$ & $\begin{array}{l}\text { Edgewise } \\
\mathbf{1}^{\text {st }} \text { Mode }\end{array}$ \\
\hline FAST & 0.3908 & 0.7328 & 1.124 & 4.055 & 10.36 & 6.546 \\
Experiment & 0.4397 & 0.8794 & 1.221 & 3.371 & 10.75 & 5.765 \\
\hline
\end{tabular}
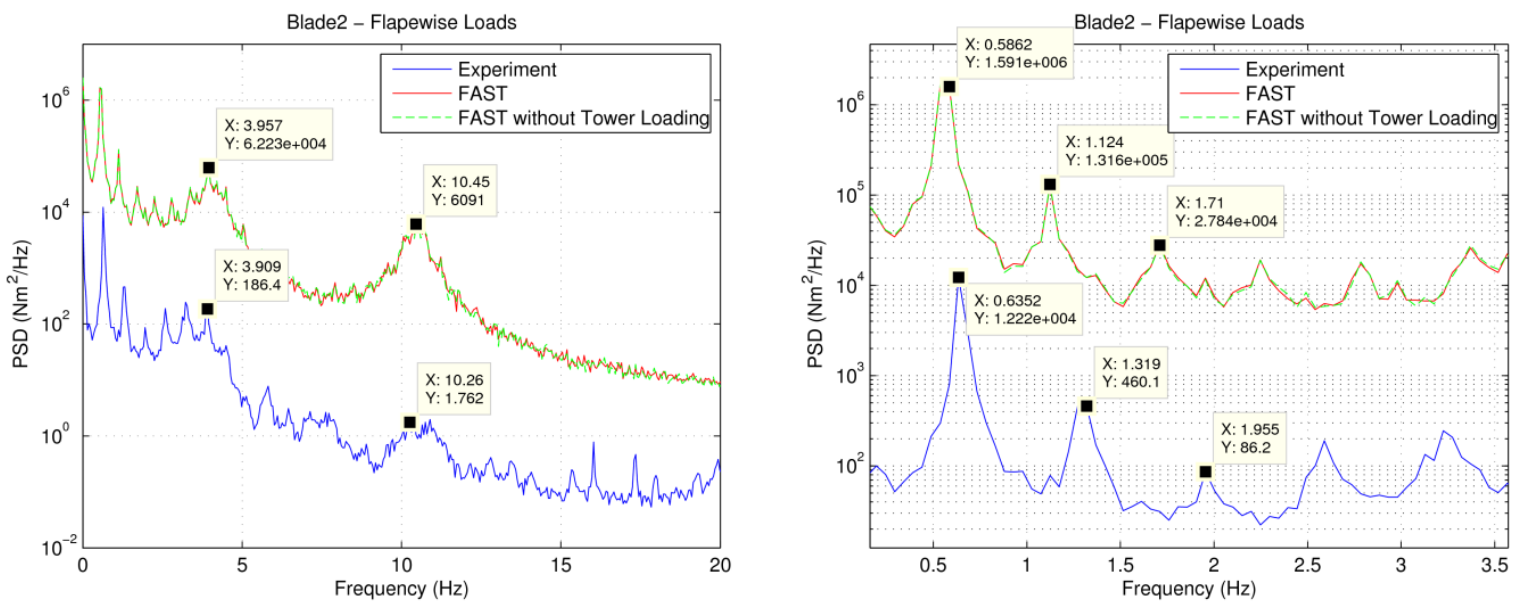

Figure 40. FFT analysis of the flapwise loading on Blade 2 for Op Case 2

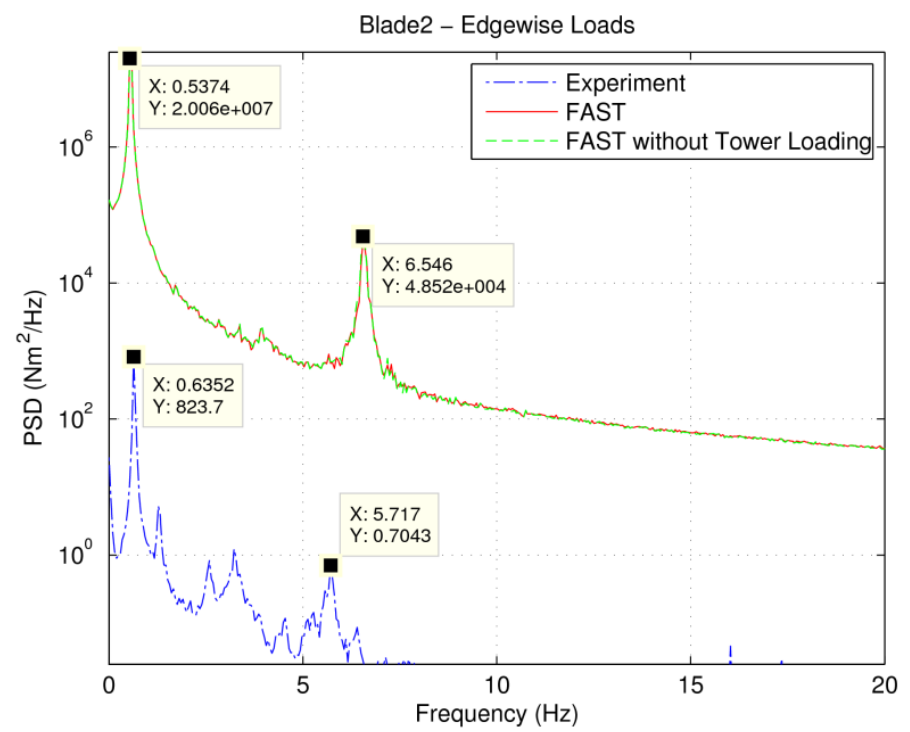

Figure 41. FFT analysis of the edgewise loading on Blade 2 for Op Case 2

Table 25. Blade Frequencies $(\mathrm{Hz})$ Observed in Experiment and Simulation for Op Case 2

\begin{tabular}{l|llllll}
\hline & 1P & 2P & 3P & $\begin{array}{l}\text { Flapwise } \\
\mathbf{1}^{\text {st }} \text { Mode }\end{array}$ & $\begin{array}{l}\text { Flapwise } \\
\mathbf{2}^{\text {nd }} \text { Mode }\end{array}$ & $\begin{array}{l}\text { Edgewise } \\
\mathbf{1}^{\text {st }} \text { Mode }\end{array}$ \\
\hline FAST & 0.5862 & 1.124 & 1.710 & 3.957 & 10.45 & 6.546 \\
Experiment & 0.6352 & 1.319 & 1.955 & 3.909 & 10.26 & 5.717 \\
\hline
\end{tabular}




\section{Conclusions}

In this study, a FAST model of the spar-type $1 / 6.5^{\text {th }}$-scale prototype SWAY system was built with design descriptions made available by SWAY AS. Different modeling strategies and assumptions were used to enable the model to work without major changes to the FAST tool.

The FAST model was calibrated to account for the design changes made to the prototype blades and the incomplete design parameters that resulted in uncertainties in the mass distribution of the floating system. A static equilibrium test was conducted to calibrate the offsets of the system. One roll free-decay test and one pitch free-decay test were used to calibrate the mass moment of inertia and platform damping matrix. After calibration, the comparison of the FAST simulations and experiment results matched with minor discrepancies because of the simplifying assumptions made in modeling the turbine. The inability to model frictional damping in the universal joints of the system and the inability to simulate the disturbed fluid field around the platform also contributed to discrepancies between measured and simulated results. The flapwise modal frequencies of the blades were tuned by analyzing the blade loading during nonoperational mode at a mean wind speed of $4.35 \mathrm{~m} / \mathrm{s}$. The blade flapwise modal stiffness for the first and second mode was tuned using factors of 1.15 and 0.6 .

During the initial runs of the simulation cases, it was noted that wind loading on the tower may be important in the analysis of floating turbines - particularly for the SWAY prototype that has a large tower relative to the size of the rotor-especially in conditions where the turbine blades are not operating. Changes were made to the FAST code to account for the wind loading on each tower element for each simulation time step. Although the improvements are focused on tubular tower designs, code users have the option to manually input the drag coefficient of the tower or to use the in-built $\mathrm{Re}-\mathrm{C}_{\mathrm{D} \text {,tower }}$ table applicable for a circular smooth tower.

To validate the model, two nonoperating test cases with a significant wave height of $0.31 \mathrm{~m}$ and $0.65 \mathrm{~m}$ (with corresponding mean wind speeds of $5.05 \mathrm{~m} / \mathrm{s}$ and $13.97 \mathrm{~m} / \mathrm{s}$ ) and two operating test cases (one in control region II and one in control region III) with turbine rotating at mean rotational speed of 22.67 RPM and 33.67 RPM were selected from the available data sets. From the results, it is shown that wind loading on the tower does have a significant effect on the dynamics of the wind turbine system when it is not operating in high wind speeds and a less significant effect when the system is operating, as the dominant wind loading occurs on the turbine blades. Including the wind loading on the tower increased the accuracy of the simulation results in comparison with the experimental results, particularly in the wind-loading direction.

Although there is some good correlation of the simulation results and the experiment, there are many differences. First, the mean values of the surge and sway offset are very different, especially for the nonoperating condition where wave loads are the dominating force. This can be a result of the inability (in this version [v7] of FAST) to model slow drift forces on the structure and also possible drift errors in the GPS measurements. The low-frequency peaks of the system motion are fairly similar between simulation and experiment, meaning that the FAST model is able to capture the dominant wave frequencies and system natural frequencies. The higher frequencies of the pitch and roll response, however, show large differences between experiment and simulation. The difference is larger for the nonoperational cases, which indicates to the issue being related to wave excitation or else turbulence in the wind load on the tower. 
For the blade loads, the flapwise and edgewise bending structural frequencies as well as the 1P, $2 \mathrm{P}$, and 3P frequencies are similar for both the experiment and simulation results; however, there are significant differences in the magnitude of the loads. It is assumed that either the units of the blade loads were inaccurate or the connection of the blade load sensors was not good.

There are at least four key reasons for the errors between the results of the simulation and experiment. First, the FAST model is unable to model the wave conditions accurately, due to both the limited wave data available and limitations of FAST in representing the multidirectional nature of the waves. The near-shore location of the turbine creates very complicated wave forms due to reflection of the waves from the shore. Second, tidal variations were excluded in the model due to the inability of FAST to simulate them easily without major changes to the input files. Third, current conditions were excluded due to the reduced confidence of the AWAC readings that resulted from its location and data-averaging frequency. Fourth, no control system was included for the operational case. Other uncertainties/assumptions in the modeling and issues with setting up the instrumentation on the prototype may have also contributed to the errors observed.

Although mixed results were observed in comparing the system behavior in the experiment and FAST simulations, this study was useful in building competencies, learning and understanding the key issues and challenges in an open-sea validation study, and identifying some limitations in the modeling approach. Unlike laboratory testing, the complex nature of the environment and the inability to fully characterize its influence on the system is one of the key challenges in validating a model using open-sea data. In addition, the lack of a control system model significantly limited the ability to accurately represent the turbine behavior.

Future work may look at quantifying the assumptions and estimating the resulting errors. A simple control system may be considered, and the model fidelity may be increased to reduce assumptions. Some changes to the FAST tool might include altering the mooring-line model to better represent the tension-rod system, addressing the ability to model different tide levels, including flexibility, and including the capability in HydroDyn to model multi-directional waves. However, the complexity of the present location of the SWAY system may preclude the ability to model the wave conditions accurately even with multi-directional waves, due to the inability to measure the conditions. Since this work was done, a new version of FAST has become available that addresses the issues related to wind loading on the tower, variability of the tidal level, and wave spreading.

Finally, although this report has largely focused on the validation work that was performed, some of the significant benefits of this project were related to the instrumentation work performed. Significant hands-on experience was gained in installing instrumentation in an offshore environment, and interfacing with other instrumentation and DAS systems. 


\section{References}

[1] Jonkman, Jason M., and Marshall L. Buhl Jr. 2005. FAST User's Guide. Golden, Colorado: National Renewable Energy Laboratory. NREL/EL-500-38230.

[2] Jonkman, J. M. 2007. "Dynamics Modeling and Loads Analysis of an Offshore Floating Wind Turbine." Ph.D. diss, University of Colorado.

[3] Browning, J.R., J. Jonkman, A. Robertson, and A. J. Goupee. 2012. "Calibration and Validation of a Spar-Type Floating Offshore Wind Turbine Model using the FAST Dynamic Simulation Tool: Preprint." Paper presented at the Science of Making Torque from Wind (TORQUE), Oldenburg, Germany, October 9-11, 2012.Golden, CO: National Renewable Energy Laboratory. NREL/CP-5000-56138.

[4] Stewart, G., M. Lackner, A. Robertson, J. Jonkman, and A. Goupee. 2012. "Calibration and Validation of a FAST Floating Wind Turbine Model of the DeepCwind Scaled Tension-Leg Platform: Preprint." Paper presented at the 22nd International Offshore and Polar Engineering Conference, Rhodes, Greece, June 17-22, 2012.Golden, CO: National Renewable Energy Laboratory. NREL/CP-5000-54822.

[5] Prowell, I., G. M. Stewart, and A. J. Goupee. 2013 "Numerical Prediction of Experimentally Observed Behavior of a Scale Model of an Offshore Wind Turbine Supported by a Tension-Leg Platform: Preprint." Paper in 2013 Offshore Technology Conference, Houston, Texas, May 6-9, 2013, pp. 3246-3276.

[6] Coulling, Alexander J, Andrew J. Goupee, Amy N. Robertson, Jason M. Jonkman, and Habib J. Dagher. 2013. "Validation of a FAST Semi-Submersible Floating Wind Turbine Numerical Model with DeepCwind Test Data." Journal of Renewable and Sustainable Energy 5: 023116-023116.

[7] Bir, Gunjit S. 2007. User's Guide to BModes (Software for Computing Rotating Beam Coupled Modes). Golden, CO: National Renewable Energy Laboratory. https://nwtc.nrel.gov/ system/files/BModes.pdf.

[8] Jonkman, J. (forthcoming. FAST Theory Manual. Golden, CO: National Renewable Energy Laboratory. NREL/TP-500-32449.

[9] Viterna, Larry A., and David C. Janetzke. 1982. Theoretical and Experimental Power from Large Horizontal-Axis Wind Turbines. Washington, D.C.: National Aeronautics and Space Administration, United States, Rep. 82944.

[10] Du, Zhaohui, and Michael Selig. 1998. "A 3-D Stall-Delay Model for Horizontal Axis Wind Turbine Performance Prediction." Paper in 36th AIAA Aerospace Sciences Meeting and Exhibit, Reno, Nevada.

[11] Eggers, A. J., and R. V. Digumarthi. 1992. "Approximate Scaling of Rotational Effects on Mean Aerodynamic Moments and Power Generated by CER Blades Operating in DeepStalled Flow." Paper in 11th ASME Wind Energy Symposium, Houston, Texas. 
[12] Bak, C., H. Aagaard Madsen, and J. Johansen. 2001. "Influence from Blade-Tower Interaction on Fatigue Loads and Dynamics." Poster presented in European Wind Energy Conference and Exhibition 2001, Copenhagen, Denmark, 2001, pp. 394-397.

[13] Powles, S. J. R. 1983. "The Effects of Tower Shadow on the Dynamics of a HorizontalAxis with Turbine." Wind Engineering. 7(1): 26-42.

[14] Laino, David J., and A. Craig Hansen. 2002. "User's Guide to the Wind Turbine Aerodynamics Computer Software." Salt Lake City, UT: Windward Engineering. Prepared for the National Renewable Energy Laboratory.

[15] Moriarty, P.J., and A.C. Hansen. 2005. AeroDyn Theory Manual. Golden, CO: National Renewable Energy Laboratory. NREL/TP-500-36881

[16] Jonkman, Jason M. 2009. "Dynamics of Offshore Floating Wind Turbines: Model Development and Verification," Wind Energy 2009(12): 459-492.

[17] "WAMIT User Manual Version 7.1," Dept. of Ocean Engineering, Massachusetts Institute of Technology, 2015.

[18] Jonkman B.J., and M.L. Buhl, Jr., 2012. TurbSim User's Guide: Revised February 1, 2007 for Version 1.21. Golden, CO: National Renewable Energy Laboratory. NREL/TP-50041136.

[19] International Organization for Standardization. 2009. "ISO 4354:2009 Wind Actions on Structures."

[20] Holmes, John D. 2007. Wind Loading of Structures, 2nd ed. London: Taylor \& Francis.

[21] Scruton, C. An Introduction to Wind Effects on Structures. 1981. London: Oxford University Press for the Design Council, the British Standards Institution and the Council of Engineering Institution.

[22] International Electrotechnical Commission 2009. "IEC 61400-3 Wind Turbines_Part 3: Design Requirements for Offshore Wind Turbines."

[23] Roshko, Anatol. 1961. "Experiments on the Flow Past a Circular Cylinder at Very High Reynolds Number." Journal of Fluid Mechanics 10(3): 345-356.

[24] Wieselsberger, C. 1921. "Neuere Feststellungen über die Gesetze des Flüssigkeits- und Luftwiderstandes," Phys. Z 22: 321-328.

[25] Scruton, C., E. W. E. Rogers, J. B. Menzies, and R. S. Scorer. 1971. "Steady and Unsteady Wind Loading of Buildings and Structures [and Discussion]," Philosophical Transactions of the Royal Society of London. Series A, Mathematical and Physical Sciences 269(1199): 353-383. 1971-05-13 00:00:00. 
[26] Engineering Sciences Data Unit. 1986. ESDU 80025 Mean Forces, Pressures and Flow Field Velocities for Circular Cylindrical Structures: Single Cylinder with Two-Dimensional Flow, ed: Engineering Sciences Data Unit.

[27] European Committee for Standardization. 2005. EN 1991-1-4:2005 Eurocode 1. Actions on Structures. General Actions. Wind Actions."

[28] Nichols, J. 2011. SWAY 1:6 Scale Tower Wind Turbine Controller Pitch System Interface to Turbine Controller. Glasgow, Scotland: Garrad Hassan \& Partners Ltd.

[29] Holmas, T. 2010. Design of SWAY Alu Tower. Sandsli, Norway: Virtual Prototyping AS.

[30] T. Holmas, 2010. "SWAY Tower Dimensions," Virtual Prototyping AS, Rådal, Norway.

[31] Koh, J.H., A. N. Robertson, J. M. Jonkman, F. Driscoll, and E. Y. K. Ng. 2013. "Building and Calibration of a FAST Model of the SWAY Prototype Floating Wind Turbine: Preprint," presented at the International Conference on Renewable Energy Research and Applications (ICRERA), October 20-23, 2013, Madrid, Spain. Golden, CO: National Renewable Energy Laboratory. NREL/CP-5000-60096. 